Opportune Landing Site Program

\title{
GIS-based OLS Suitability Assessment
}

Charles C. Ryerson, Forrest R. Scott, and Brian T. Tracy

April 2008

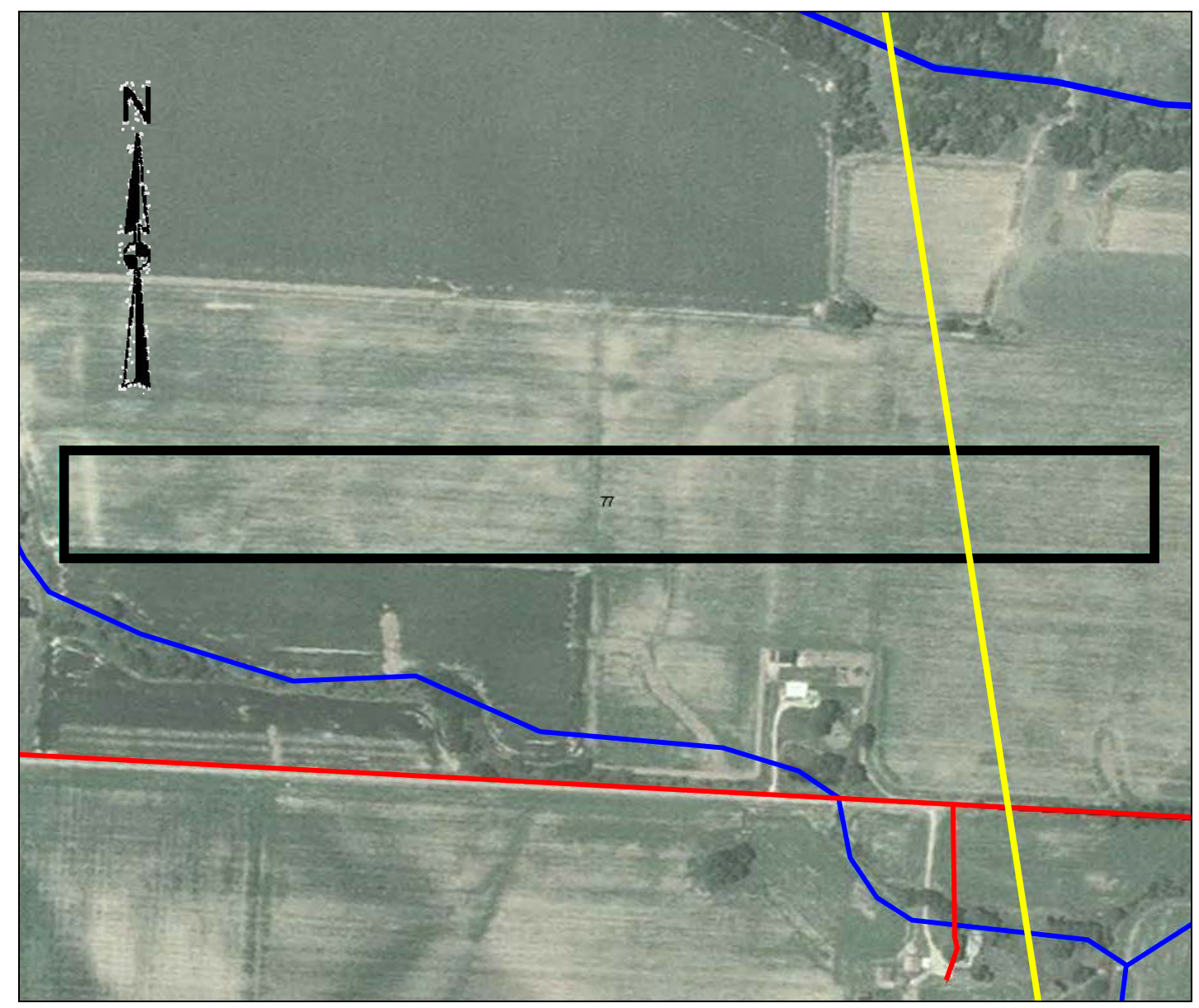




\title{
GIS-based OLS Suitability Assessment
}

\author{
Charles C. Ryerson and Brian T. Tracy \\ Cold Regions Research and Engineering Laboratory \\ U.S. Army Engineer Research and Development Center \\ 72 Lyme Road \\ Hanover, NH 03755-1290 \\ Forrest R. Scott \\ Sensor Concepts and Applications, Inc. \\ Phoenix, MD
}

Approved for public release; distribution is unlimited.

\author{
Prepared for U.S. Air Force Mobility Command \\ and \\ U.S. Air Force Research Laboratory Air Vehicles Directorate
}




\begin{abstract}
A goal of the Air Force Research Laboratory Opportune Landing Site (OLS) program was to locate large, smooth, flat, obstructionfree areas safe for aircraft operations. The ERDC was tasked to evaluate the quality of OLSs as located by OLS Multi-Spectral (OLS-MS) software that was developed by the Boeing Company and uses Landsat multispectral imagery. ERDC conducted extensive field work evaluating OLSs in Indiana, New Mexico, and California. However, while seeking these OLS-MS-selected field sites, many other software-selected potential OLSs were casually observed not to satisfy requirements with regard to obstructions. Our objective was to evaluate a statistically valid sample of OLSs for freedom from obstructions. We utilized OLSs located by the final version of the OLS-MS software, plotted them over orthophotoquads, and assessed their intersections with obstructions within geographic information system (GIS) datasets containing natural and cultural features. A sample of OLSs was also visually evaluated to assess the accuracy of the GIS analysis process. Features in the GIS datasets often did not correspond exactly with features on the ground, a source of analysis error that may be due to digitizing uncertainty and differences in the creation dates of the images and datasets. The success of the OLS software in avoiding obstructions is presented in the results.
\end{abstract}




\section{Contents}

Preface ...vi

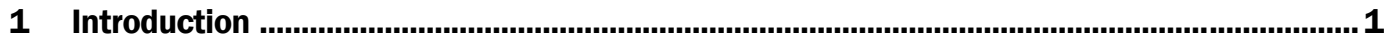

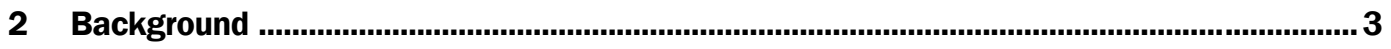

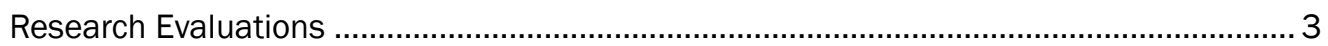

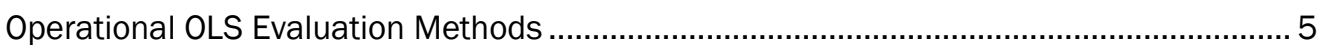

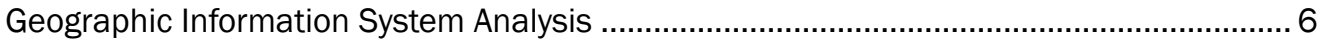

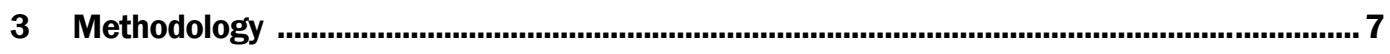

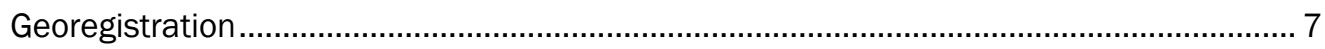

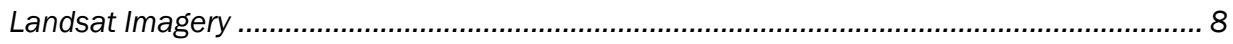

Digital OrthophotographicQuadrangles ......................................................................... 10

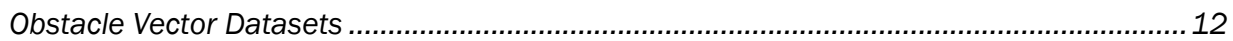

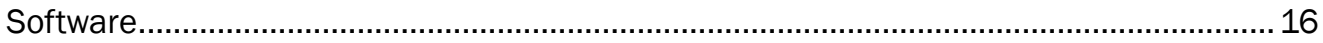

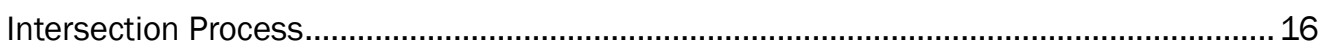

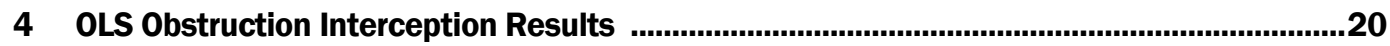

OLS

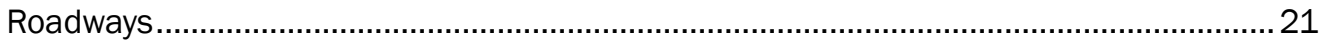

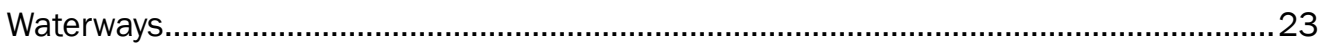

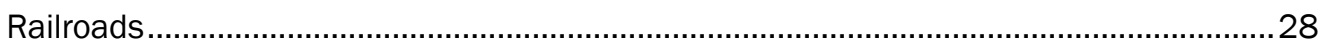

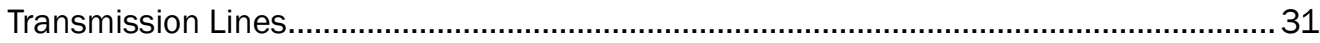

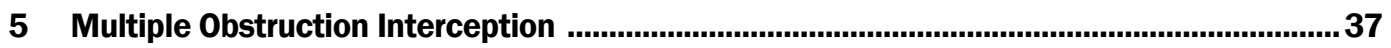

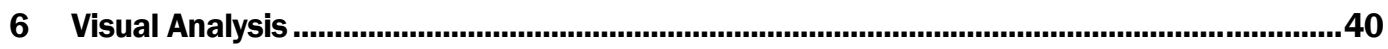

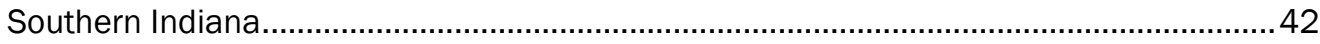

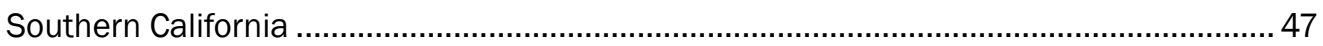

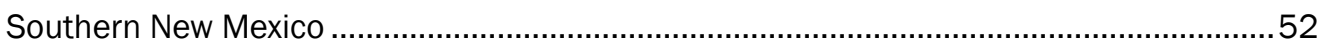

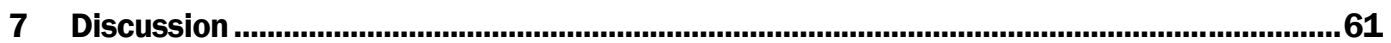

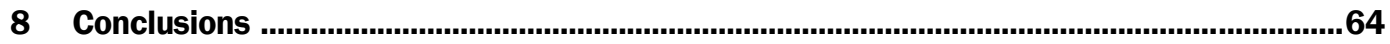

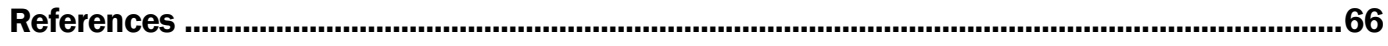

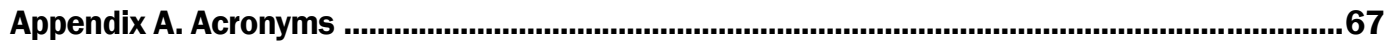

Appendix B. Landsat Image Characteristics for Products Used ...............................................69

Report Documentation Page ................................................................................................... 


\section{Figures and Tables}

\section{Figures}

Figure 1. Predicted OLSs mapped against orthophotoquadrangles for field checking in southern Indiana, 17 March 2005

Figure 2. Reconnaissance of an OLS on Ford Farm in southeastern Indiana .................................. 4

Figure 3. OLS at Ft. Bliss partially walked and found to be unacceptable due to mesquite dunes

Figure 4. Landsat image of southeastern California used for this study, Row 39/Path 37,

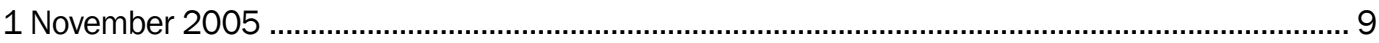

Figure 5. Typical DOQ header ............................................................................................ 11

Figure 6. Tele Atlas primary and secondary road vectors overlying a DOQ and USGS DLG

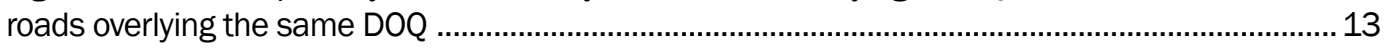

Figure 7. OLS with various headings outlined by black vectors ................................................... 18

Figure 8. Example in southern California of the intersection of roads with OLSs .............................22

Figure 9. Intersection of roads with OLSs in southern California .................................................... 22

Figure 10. Intersection of a road with an OLS in southern Indiana ...............................................2

Figure 11. Intersection of waterways with OLSs in California .......................................................... 25

Figure 12. OLS intersection of a drainage ditch or straightened stream in southern

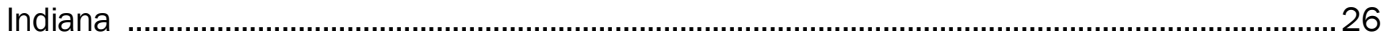

Figure 13. OLSs avoiding a meandering stream in southern Indiana ...........................................26

Figure 14. OLS located in a reservoir .................................................................................. 27

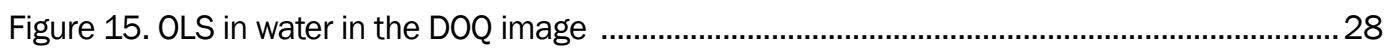

Figure 16. Railroad and OLS intersections in southern California ..............................................30

Figure 17. OLSs in southern Indiana successfully avoiding trees, a highway, a railroad, and

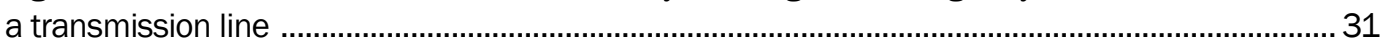

Figure 18. Area of southern California showing both undigitized transmission lines and transmission lines digitized with no ground visual verification 33

Figure 19. Interception of OLS with digitized transmission line and undigitized transmission line within in subset of Figure 18

Figure 20. Intersection of transmission lines with OLS runway polygons in southern California 35

Figure 21. Intersection of transmission line with OLSs in southern California

Figure 22. USGS and GE transmission lines together, which extend the transmission line to intersect eight additional OLSs in southern California, illustrating the effect of incomplete databases on analyses 36

Figure 23. Multiple OLSs intercepting a stream and a road in southern California ........................38

Figure 24. OLS crossing a road and a stream in southern New Mexico .........................................39

Figure 25. OLS in Indiana crossed by an undigitized agricultural road ............................................ 43

Figure 26. Seven OLSs in southern Indiana ............................................................................... 44 
Figure 27. Apparent north-south-oriented shelterbelt crossing a northeast-southwestoriented OLS

Figure 28. Possible relict surface drainage feature at the north end of an OLS ............................46

Figure 29. Chevron-shaped apparent subsurface drainage features crossing OLSs ...................... 47

Figure 30. OLS crossed by an unpaved road near its southern end ...............................................48

Figure 31. OLS avoiding a multiple lane highway but crossed by an unconfirmed transmission line

Figure 32. OLS crossing a dune field that could have sufficient soft sand and relief to hamper aircraft ground operations 50

Figure 33. OLS crossed by a road and drainage features

Figure 34. OLS, outlined in black, avoiding streams to the west and a lava field to the northeast, as do the surrounding light green OLSs. The OLSs are $930 \mathrm{~m}$ long and $90 \mathrm{~m}$ wide.

Figure 35. Northwest-southeast-oriented OLS avoiding road to the northwest but

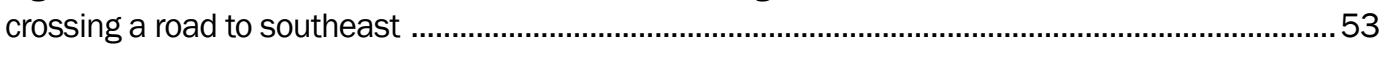

Figure 36. OLS located alongside and avoiding a road and a stream .........................................54

Figure 37. OLS crossing drainage features ........................................................................... 55

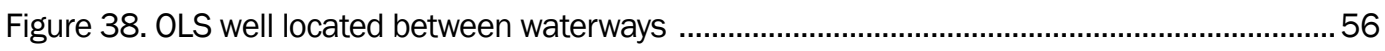

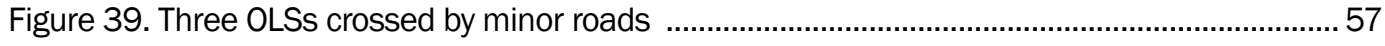

Figure 40. OLS crossing prominent waterways ...........................................................................58

Figure 41. Two OLSs crossing examples of possibly poorly digitized roads and streams ................58

Figure 42. OLS crossing into a golf course at its northern end ......................................................59

Figure 43. OLSs crossing the Carrizozo Malpais Lava Flow ........................................................6 60

Figure 44. Surface of the Carrizozo Malpais Lava Flow, which is unsuitable for aircraft

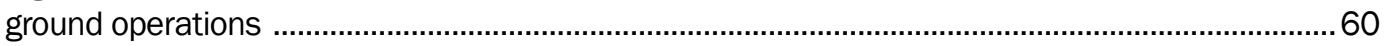

Figure 45. OLSs in southern Indiana crossed by a transmission line and stream represented by GIS databases with a DOQ background, and the same features against the Landsat image processed to map the OLSs

\section{Tables}

Table 1. Characteristics of selected vector geographic data sets ................................................... 14

Table 2. Roadway intersections by OLS location and heading ..........................................................2

Table 3. Waterway intersections by OLS location and heading ..................................................... 24

Table 4. Railroad intersections by OLS location and heading ........................................................ 29

Table 5. Transmission line intersections by OLS location and heading ............................................32

Table 6. Multiple OLS and obstruction theme interceptions by location .......................................... 37

Table 7. Visual feature verification ............................................................................................. 42 


\section{Preface}

This report is a deliverable product in support of Customer Order No. GWRVA00472412, "Opportune Landing System," conducted in collaboration with Boeing, the Air Force Research Laboratory (AFRL), and Syngenics Corporation. Dr. Charles C. Ryerson, Terrestrial and Cryospheric Sciences Branch (TCSB), Cold Regions Research and Engineering Laboratory (CRREL), U.S. Army Engineer Research and Development Center (ERDC), Hanover, NH, was the Program Manager at ERDC/CRREL, and J ames McDowell, Air Vehicles Directorate, Air Force Research Laboratory, Wright-Patterson Air Force Base, and Kenneth Eizenga, General Dynamics Advanced Information Systems, Dayton, Ohio, were consecutive overall Program Managers.

Funding for this work was provided by the U.S. Transportation Command (TRANSCOM) through the Air Force Mobility Command (AMC) and the Air Force Research Laboratory Air Vehicles Directorate (AFRL/RB) at Wright Patterson Air Force Base.

This report was prepared by Dr. Ryerson of ERDC-CRREL-TCSB; Forrest R. Scott, Sensor Concepts and Applications, Inc., Phoenix, Maryland under contract number W913E5-04-C-0003; and Brian T. Tracy of the ERDC Remote Sensing/ Geographic Information Center (RS/ GIS), ERDCCRREL, Hanover, NH, under the general supervision of J anet P. Hardy, Chief, TCSB; Dr. J ustin B. Berman, Chief, Research and Engineering Division; and Dr. Robert E. Davis, Director, CRREL.

The authors thank the following individuals for assistance: D. MacDonald, T. Baldwin, S. Daly, A. Stender, and E. Ochs of the ERDC RS/ GIS; J . Danielson of the USGS; S. Sutton of I-Cubed; C. Hines, B. Penn, and R. Almassy of The Boeing Company; and J . Alford-Teaster of the Dartmouth College Geography Department. The authors also thank Dr. J oyce A. Nagle and Elke Ochs of ERDC-CRREL for their thorough and thoughtful reviews of this report.

The Commander and Executive Director of ERDC is COL Richard B. J enkins. The Director is Dr. James R. Houston. 


\section{Introduction}

Verification of the quality of Opportune Landing Sites (OLSs) is a key process for assessing their safety prior to use. Verification examines the quality of information used in, and conclusions drawn from, imagery and map analysis processes. Separate checks on modeling inferences and predictions using sources of information independent of the OLS prediction models provide a measure of confidence regarding the quality of OLS predictions.

Operationally, Air Force Special Operations Command routinely checks the quality of proposed OLSs located using remotely sensed and traditional mapped information. Teams are then placed on the ground to reassess site geometry such as flatness, smoothness, and freedom from obstructions and to measure soil strength, since it is not obtainable from imagery. These operations are time-consuming and can place personnel at risk.

A role of the U.S. Army Engineer Research and Development Center (ERDC) in the OLS Demonstration Program was to verify the capability of the Boeing OLS-MS software for locating large, smooth, flat, obstructionfree areas (Ryerson and McDowell 2007). In that regard, ERDC evaluated the quality of four field sites at three locations: southern Indiana, Ft. Bliss, TX, and the El Centro Naval Air Facility (NAF), El Centro, CA. Four sites were chosen by the OLS Demonstration Program to add to four other sites used by Boeing for independent evaluation of the OLS software using Internal Research and Development funds prior to the start of the OLS demonstration program (Vincent and J ennings 2004). Four or eight sites, however, do not make statistically significant samples, being too small to develop broad conclusions regarding software capability. In addition to the small sample size, gathering information in the field is labor intensive, slow, and expensive. Creating a statistically significant sample using manual methods would not be possible because of the need to obtain landowner permission to access the land. The only other alternative currently considered would be the use of low-flying aircraft to inspect OLSs.

The goal of this report is to assess a GIS-based approach for evaluating the quality of OLSs. GISs are analysis tools, allowing the integration of spatial 
information in a variety of formats to answer a variety of spatial questions. In this case, we present and demonstrate a methodology for using the GIS to assess the intersection of OLSs with obstructions. 


\section{Background}

\section{Research Evaluations}

ERDC formally evaluated OLS quality by selecting four field sites for intensive field work. Field sites were selected by conducting reconnaissance trips in southern Indiana, Ft. Bliss, and El Centro NAF. Potential field sites were located in each area by using the OLS software to predict all prospective OLSs with a specified length, width, and suite of headings (Fig. 1) (Affleck et al. 2008a, 2008b, Barna et al. 2008). A field team then visited the areas and viewed as many OLSs as reasonably possible by drive-by inspection (Fig. 2).

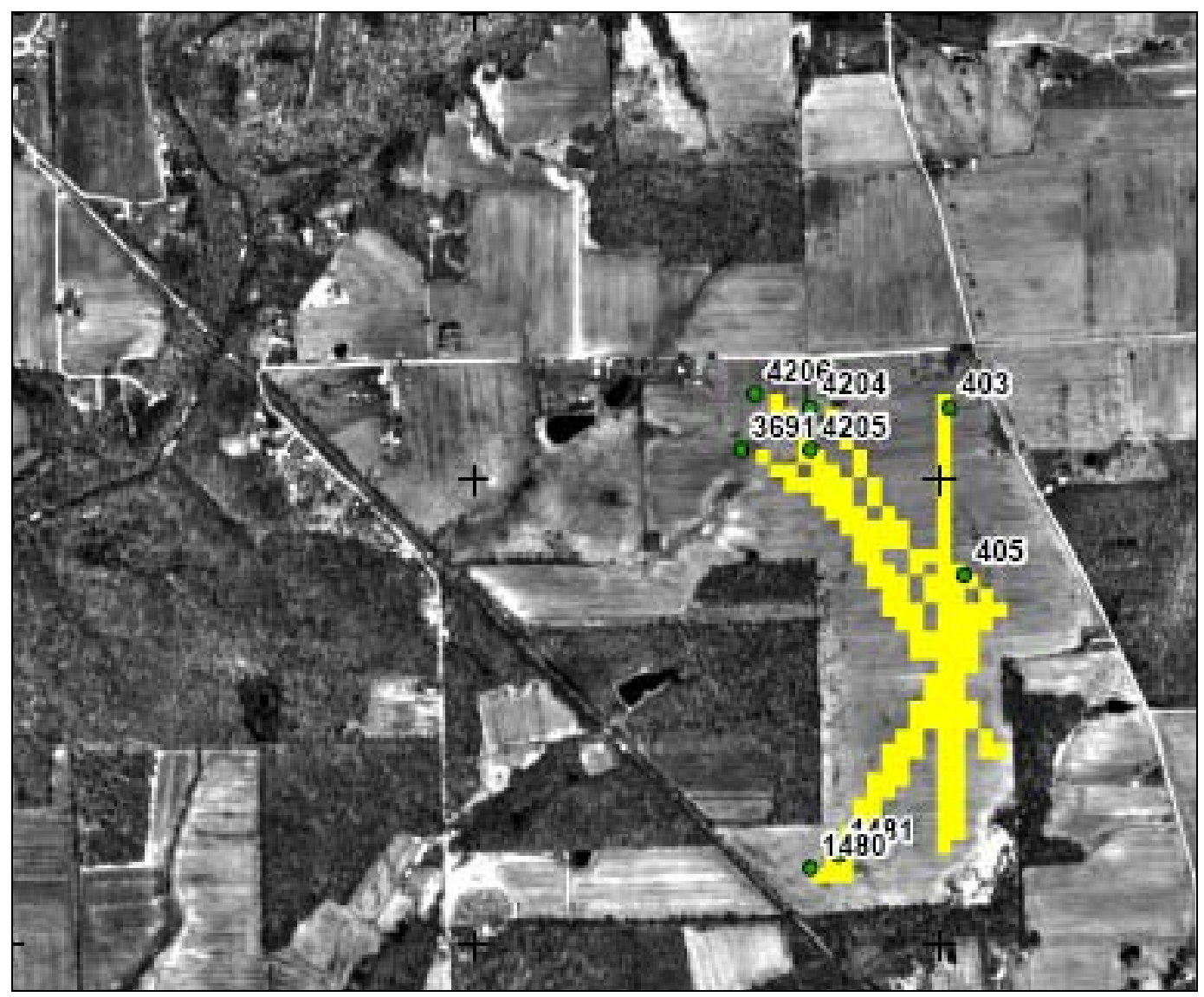

Figure 1. Predicted OLSs mapped against orthophotoquadrangles for field checking in southern Indiana, 17 March 2005. Yellow pixels denote OLS locations, green dots indicate the ends of OLSs, and numbers identify each OLS. Overlapping numbers are artifacts of the OLS software. Each pixel in an OLS is $30 \mathrm{~m}$ square on the Earth's surface. 


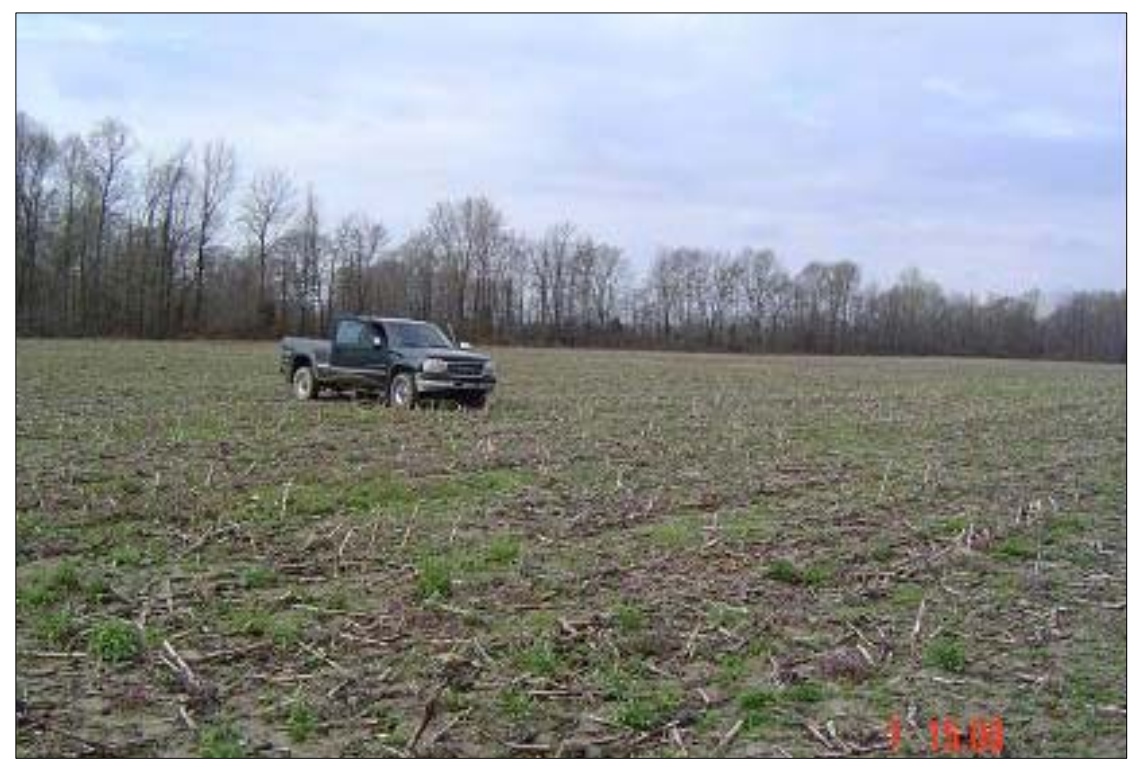

Figure 2. Reconnaissance of an OLS on Ford Farm in southeastern Indiana.

In this manner, it was possible to generally inspect each OLS, or clusters of OLSs, by eye from a distance. At locations allowing it, such as on Ft. Bliss, it was occasionally possible to walk OLSs to assess their quality. However, it was possible to walk the full length of only a few OLSs because of time constraints (Fig. 3). For those OLS that could not be walked, it was not possible to accurately or reliably assess the full range of obstructions that may occur on a 915-m long by 61-m wide OLS when it is viewed only from one end. As a result, ditches, swales, and other features may have been missed, though electric lines and fences could often be seen from a distance. In addition, the exact location of the OLS was often unclear

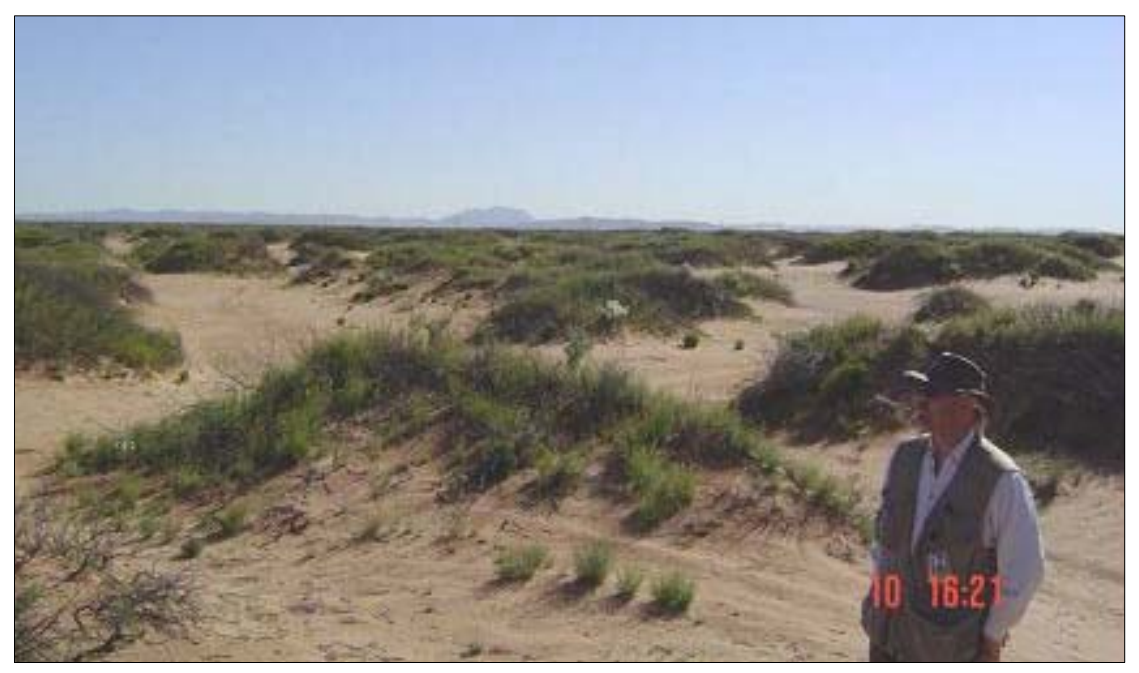

Figure 3. OLS at Ft. Bliss partially walked and found to be unacceptable due to mesquite dunes. 
without walking the site with GPS equipment. Though desired, the driveby approach did not provide a viable method of rigorously evaluating the software capability statistically.

\section{Operational OLS Evaluation Methods}

Operationally, OLSs are generally located by the U.S. Air Force Special Tactics Teams (STT), Combat Control Teams (CCT), Global Airfield Assessment Teams (GAAT), Contingency Response Groups (CRG), or Rapid Engineer Deployable Heavy Operational Repair Squadron Engineers (RED HORSE) teams. Candidate OLSs are located using imagery analysis techniques followed by field inspections. The Air Force teams generally follow steps, described below, to identify candidate OLS locations. The focus of the process is to eliminate areas that are not acceptable for landing aircraft.

The general steps used to identify OLS locations are:

1. Locate an area based on the aircraft runway length and width required, glide slope, taxiway, and proximity to needed aviation requirements.

2. Map the slope using image processing software such as ERDAS Imagine* or Digital Terrain Elevation Data (DTED) to eliminate areas with slopes that are too steep. The highest-resolution DTED available is always used. Three-dimensional DTED models can also be created by ERDAS Imagine or other programs.

3. Create raster image files of areas under consideration to determine the vegetation cover using ERDAS Imagine and FalconViewt.

4. Check candidate runway and taxiway locations for obstructions to airground operations, though telephone poles and other obstructions can be demolished. Higher-quality images are used to identify discontinuities (ditches, small obstacles, etc.).

5. Conduct virtual fly-throughs with the highest-resolution imagery and DTED using ERDAS Imagine or Virtual Geographic Information System ${ }^{\ddagger}$ (VGIS) over 3-D terrain to see where the ground texture and terrain undulations may intrude on a usable runway surface.

6. Select the highest-quality candidate sites and send a field team to the sites.

\footnotetext{
* http://gi.leica-geosystems.com/LGISub1x33x0.aspx

† http://www.falconview.org/

‡ http://www.dvg.uncc.edu/research/vgis.html
} 
7. Measure and report glide slope and missed approach information, boundaries, and the strength and depth of the weight bearing surface as measured by a dynamic cone penetrometer (DCP) in California bearing ratio (CBR) units. The area is then rated for the number of possible passes for the aircraft intending to use the field.

Field equipment can include a GPS, clinometers, compasses, a DCP, measuring wheels or range finders, and Total Station survey systems.

\section{Geographic Information System Analysis}

Operationally, current methods of seeking OLSs, and evaluating their quality, are labor intensive, slow, and potentially dangerous to personnel if operating in hostile areas. In addition, obtaining statistically significant samples in a research environment is generally not feasible because access to land owned privately is often necessary, and the process of inspecting by walking the length of OLSs is slow.

GISs provide tools capable of satisfying shortcomings of current procedures. This study quantifies the capability of the Boeing software to avoid obstructions by using the GIS as an OLS analysis tool.

The GIS has the potential to more efficiently assess the selection of OLS locations and evaluate the quality of OLSs in research and operational environments. Some areas where the GIS can provide this capability include mapping the flatness (deviation from a plane) and levelness (deviation from slope) of an OLS; evaluating approach and departure corridors using DTED; evaluating the variability of soil type; appraising soil moisture, soil strength, and vegetation cover pixel by pixel along the length of an OLS; assessing the seasonal quality of an OLS chosen by the software; examining the quality of an OLS chosen in different geographic areas that may be different, for example, with regard to climate; and detecting obstructions that may not be detected by the OLS software.

This study investigated the last topic-the use of the GIS to detect OLS obstructions. The study is a proof of concept of the approach. It also provides quantitative information regarding the accuracy of the OLS-MS software with regard to locating obstruction-free OLSs and, for OLSs that are not obstruction free, indicating the nature of the obstructions. 


\section{Methodology}

The goal of this study was to use a GIS and its tools for assessing whether potential obstructions are found on OLSs chosen by the Boeing OLS-MS software. The work was accomplished in the following sequence, with details to follow:

1. Georegister image, map, and digitized vector data sources.

2. Execute OLS-MS software, acquire OLS coordinates, and generate OLS outline polygons.

3. Select obstacle vector datasets for roads, water bodies, railroads, and electrical transmission lines that intersect OLSs.

4. Intersect the OLS and obstacle vectors and compute statistics for the number of intersections with OLSs.

5. Visually verify the accuracy of the intersection process using digital orthophoto quadrangles (DOQ).

\section{Georegistration}

Projects relying on multiple representations for the Earth's surface features, such as survey data, GPS coordinates, computer-model-generated ground point coordinates, paper or digital maps, aerial photographs, or remote sensor images require an understanding and quantification of their relationship to the Earth and to each other. Accurate comparison of different representations of the Earth's surface with one another requires consistency with regard to coordinate reference systems such as projections, reference datums, and positional accuracies involving georeferencing, georectification, and/ or orthorectification.

This project required a common coordinate reference system for all data sources used for expressing the location of Earth features. Many coordinate systems are currently in use, but three of the most common global coordinate systems are latitude and longitude, Universal Transverse Mercator (UTM), and the Military Grid Reference System (MGRS). The UTM coordinate system was selected for this work.

Geodetic datums define the size and shape of the Earth and the origin and orientation of coordinate systems used to map the Earth. A datum is a set of reference points to which coordinate systems are tied. We used the 
World Geodetic System (WGS), now called WGS 84 from its latest revision in the 1980s. It is the reference system used by GPSs and is geocentric and globally consistent within $\pm 1 \mathrm{~m}$. It has good fidelity for Earth features in our Indiana, New Mexico, and California study areas and is a datum to which virtually all other datums can be converted.

Georeferencing assigns geographical coordinates to image pixels or vector elements. Standard image products, such as those from the U.S. Geological Survey (USGS) (for example, Landsat images), typically have coordinates applied prior to release. Georectification is the process of reassigning georeferenced location values by shifting the coordinates relative to the pixels so as to better align them within a higher-accuracy reference system (different projection, datum, accuracy, etc.). This is accomplished by aligning ground control points (GCP) (visually well-defined geographical features) on the lower-accuracy product with ground control points on the higher-accuracy product. A mathematical algorithm is then created within most GIS software packages to translate all coordinate values within the candidate image product to those of the baseline product with some degree of expressed error. This is referred to as triangulation adjustments, rubber-sheeting, or warping the image to fit to the standard and can be a time-consuming process, depending on the number of points required to produce satisfactory fidelity. Baseline products must be chosen with sufficient resolution, precision, and accuracy to meet the needs of the project prior to geo-rectifying, as all other products are fit to this standard.

This project primarily used three forms of spatial information to produce products. These were Landsat images used to locate OLSs with the Boeing OLS-MS software, DOQ, and vector data for a variety of features, i.e., roads and hydrography.

\section{Landsat Imagery}

Landsat images are digital raster formatted files derived from multispectral measurements of the Earth taken by a series of NASA-deployed, USGS-managed, satellite-borne sensor package called Thematic Mapper (Fig. 4). The sensors record signals for various bands of the visual and infrared spectrum of electromagnetic energy reflected or emitted from Earth.

Over the 35-year period of the Landsat project, many variations have existed in the output products due to the differences in onboard sensors, 


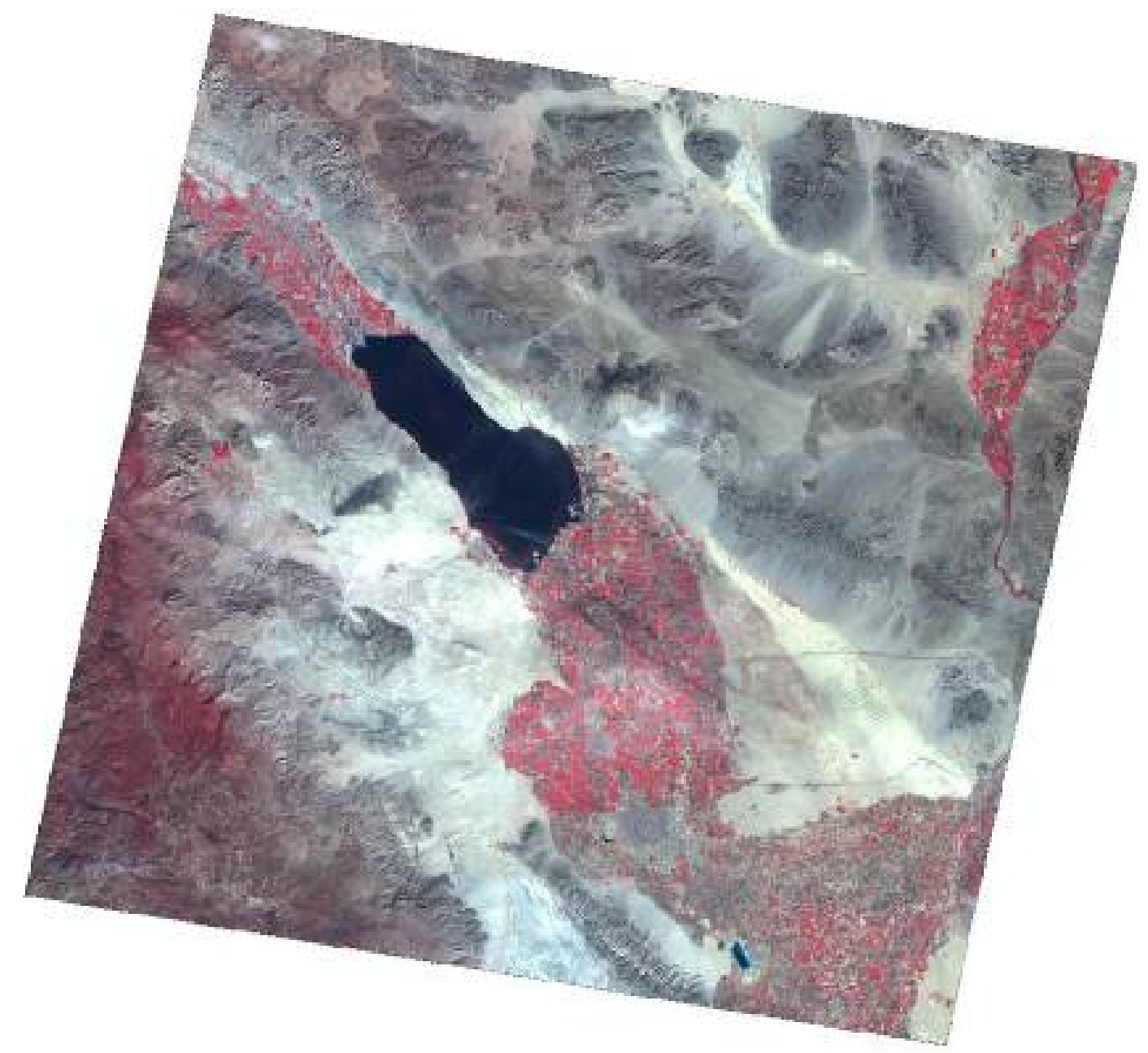

Figure 4. Landsat image of southeastern California used for this study, Row 39/Path 37, 1 November 2005. The approximate image size is $170 \mathrm{~km}$ from top to bottom (north to south) and $183 \mathrm{~km}$ from left to right (west to east) (106 mi by $114 \mathrm{mi})$.

satellite deployment configurations, and signal processing techniques. There are products containing reformatted raw data with no radiometric correction or map projection coordinates, as well as products with radiometric correction and different degrees of georegistration. The image files for these various products also differ in pixel size, content, formats, and accompanying metadata or explanatory materials.

Currently the geodetic horizontal accuracy is provided in three versions by the USGS for the Landsat system. The coarsest precision is the systematic product. The systematic product's correction process does not employ ground control or relief models to attain absolute geodetic accuracy but uses only the satellite ephemeris for positioning. Residual error in the systematic product is approximately $250 \mathrm{~m}$ in flat areas. The precision 
product, the next higher level of accuracy above systematic, employs GCPs to reduce geodetic error to approximately $30 \mathrm{~m}$. This accuracy is attained in areas where relief is moderate. Terrain correction, the highest level of standard processing, employs both GCPs and DEMs to reduce the geodetic error of the output product to less than $30 \mathrm{~m}$ in areas where terrain relief is substantial. The distribution of Landsat precision and terrain corrected image data is restricted to the U.S. Government and its affiliated users. Higher-level products can be ordered, or a value-added service organization with such geocorrection capabilities can be employed to attain higher precision. In the systematic, precision, and terrain correction processes, the WGS84 ellipsoid is employed as the Earth model for coordinate transformation. Appendix B provides the technical characteristics of the three Landsat images used for this project in southern Indiana, southwestern Ohio and northern Kentucky; southeastern New Mexico and western Texas; and southeastern California and northern Mexico. The appendix also includes copies of the three Landsat images with OLSs plotted in yellow. The pixel size in each of the images is $30 \mathrm{~m}$.

\section{Digital Orthophotographic Quadrangles (DOQ)}

The USGS DOQs are georeferenced images created from photographs or remotely sensed images where GCPs have been position-corrected due to sensor orientation or perspective (Fig. 1). A DOQ is a raster product produced from multiple images by the National Aerial Photography Program (NAPP). DOQs were used in this study to visually verify the quality of the vector features, to assess the capability of the GIS-based evaluation technique, and to determine whether other features in addition to those selected from the vector datasets were OLS obstacles.

A DOQ area coverage is typically a 7.5-minute topographic map quadrangle. Additionally there are 3.75-minute quarter-quadrangles referred to as digital orthophotographic quarter-quadrangles (DOQQs). DOQQs have a ground pixel spacing distance of $1 \mathrm{~m}$, while a DOQ may have either a 1- or 2-m ground pixel spacing, depending on the photographic source scale. The horizontal placement accuracy of DOQs and DOQQs meets the USGS National Map Accuracy Standards (NMAS) for 1:24,000- and 1:12,000scale map products, respectively. Therefore, for the 1:24,000-scale (7.5minute) products, $90 \%$ of the well-defined points must fall within $12.2 \mathrm{~m}$ when compared to values determined from aerotriangulation or by an independent survey of higher accuracy. For 1:12,000-scale DOQQ products, $90 \%$ of the well-defined points must fall within $10.2 \mathrm{~m}$ when com- 
pared to values determined from aerotriangulation or by an independent survey of higher accuracy.

The DOQs used in this study ranged in date from J une 1996 through September 2004 and were referenced to the UTM coordinate system and to the NAD83 datum, which has a small offset from the WGS84 datum used for the Landsat images in this study. The NAD83 and WGS84 datums are nearly identical and, as stated by Schwarz and Wade (1990), though "differences as large as several meters are found occasionally, the expected value of these differences is zero." An example for the normal header that is contained within a standard DOQ file can be found in Figure 5. DOQ image specifications and ordering information can be found at http:// nationalmap.gov/ digitalbackyard/ doqbkyd.html\#6."

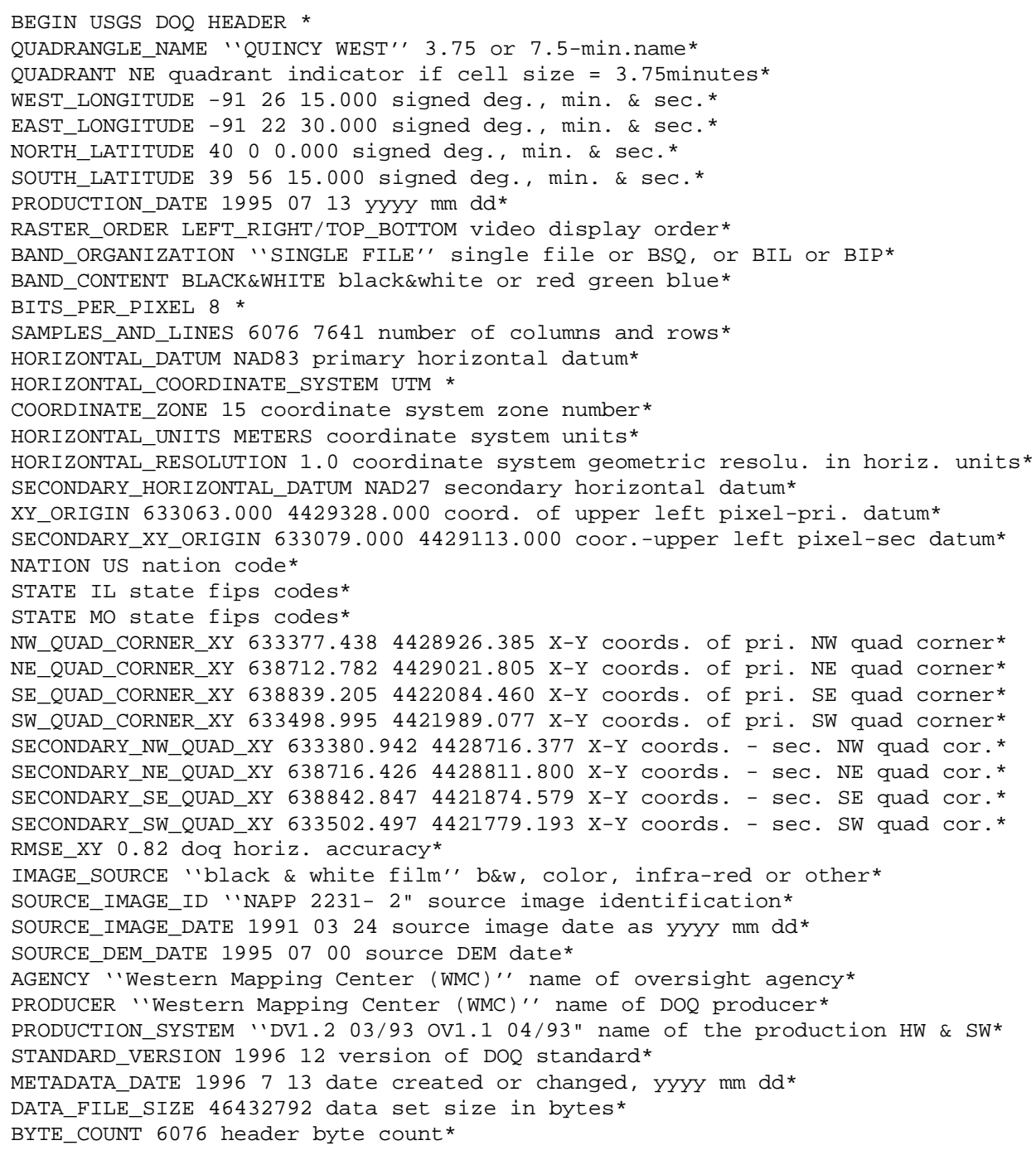

Figure 5. Typical DOQ header. 


\section{Obstacle Vector Datasets}

OLS obstructions were assessed by intersecting predicted OLSs with obstacle vector datasets. An obstacle vector feature is a vector map layer for a category of feature types such as transportation (highways, roads, streets, etc.) or utilities (electrical transmission towers, lines, substations, pipelines, etc.). A common source of government-created vector data is the USGS Digital Line Graph (DLG) derived from maps and imagery. Vector datasets are also available from commercial sources. We used datasets from government and commercial sources.

Since creators of these digital data representations of Earth features create the data for their own purposes, themes and standards differ by source. Even if themes share a common name (i.e. "transportation"), the features portrayed may not be identical for each source. That is, there are no unifying standardized definitions for themes or attribute information. One producer may have digitized transmission line towers as well as the electrical power lines, while another may have only digitized the lines. Also, duplication of ground features may exist for different thematic layers when multiple segments of the same roadways, for example, are included within each layer.

Coverage for common features (i.e., railroads) may also differ from source to source due to resolutions of input products, date of survey information, ground accuracy requirements, and digitization criteria. For example, for some sources, multiple rail tracks within a railroad yard may be of little or no importance, while others may find it meaningful to give each track a representation in the data set.

Due to the inconsistencies in vector information, and since the description of digitized features is often incomplete, we conducted multiple visual verifications of vector-layer ground features for placement and continuity of coverage. DOQs were typically used as ground truth, and cross checks were made in several representative areas within the study area such as urban, suburban, and rural areas. Using these visual checks, we compared each vendor's databases for scale accuracy and database completeness. Files were not acceptable when digitization errors were larger than $30 \mathrm{~m}$ or when files did not represent a large percentage of the features sought. For example, files created by a vendor of roadways in Indiana showed primary and secondary roads (Fig. 6), whereas files by another vendor of the same area provided only primary roads. Secondary roads were 

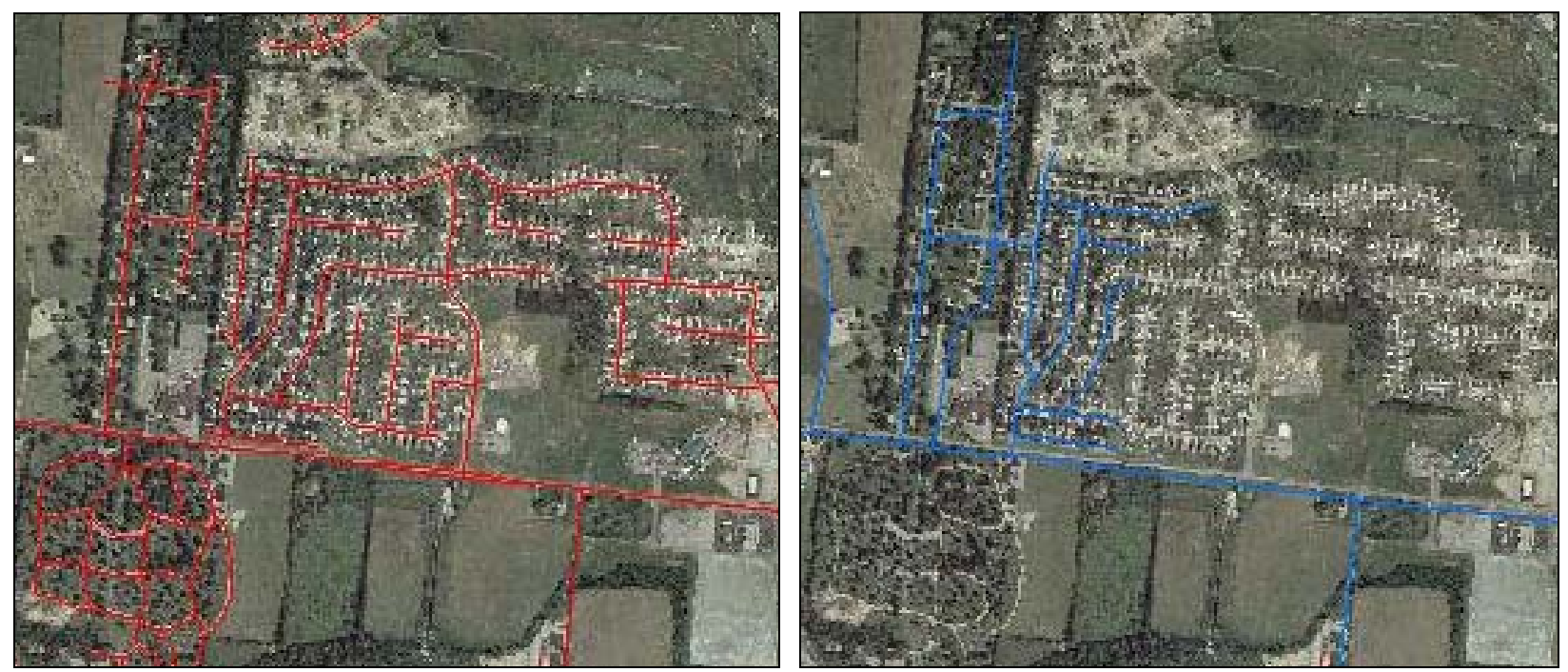

Figure 6. Tele Atlas primary and secondary road vectors, in red, overlying a DOQ (left) and USGS DLG roads, in blue, overlying the same DOQ (right). Secondary roads are not as completely represented on the USGS product.

important to our study because most OLSs will be located in rural areas where buildings are few and where large agricultural fields are available.

In another example, a transmission line vector attribute file from Global Energy (2007) was used in Indiana, where it was verified as accurate when compared by eye with DOQs, but was questionable in California because the positional accuracy of features and feature representation was difficult to verify by eye. In some cases, digitized transmission lines were significantly offset from their location in the DOQ. In other cases, transmission lines that existed were not digitized, and occasionally transmission lines were digitized that did not exist on the DOQ. Some of these problems could have been caused because database and DOQ dates did not match well. More discussion occurs later in this report about this problem.

Vector attribute files must conform to the same positional standards as image and map products, especially since they are generally overlaid onto other products to create maps of features or, as we did, to find intersections between vector source themes. Table 1 shows characteristics of vector-based geographic data products examined from USGS DLG, Environmental Research Institute* (ESRI) databases, Tele Atlas ${ }^{\dagger}$ databases, and Global Energy data.

\footnotetext{
* http://www.esri.com/

† http://www.tele atlas.com/index.htm
} 
Table 1. Characteristics of selected vector geographic data sets.

\begin{tabular}{|c|c|c|c|c|}
\hline $\begin{array}{l}\text { Producer } \\
\text { name }\end{array}$ & USGS DLG & ESRI & Tele Atlas & $\begin{array}{l}\text { Homeland Security } \\
\text { Infrastructure Program, } \\
\text { Global Energy } \\
\text { Decisions }\end{array}$ \\
\hline $\begin{array}{l}\text { Data } \\
\text { resources } \\
\text { used }\end{array}$ & $\begin{array}{l}\text { 1:24,000 USGS topo } \\
\text { maps } \\
\text { - USGS orthoquad } \\
\text { verification }\end{array}$ & $\begin{array}{l}\text { - 1:5M NIMA Digital } \\
\text { Chart of the World } \\
\text { - 1:3M NIMA Digital } \\
\text { Chart of the World } \\
\text { - 1:1.5M NIMA Digital } \\
\text { Chart of the World } \\
\text { 1:250,000 USGS } \\
\text { topo maps } \\
\text { 1:100,000 USGS topo } \\
\text { maps } \\
\text { - USGS DLG data } \\
\text { - Additional sources } \\
\text { specific to vector layer: } \\
\text { roads from Geog. Data } \\
\text { Technology (now Tele } \\
\text { Atlas), and U.S. } \\
\text { Census TIGER data; } \\
\text { rivers from Rand } \\
\text { McNally New } \\
\text { International Atlas, } \\
\text { The Times Atlas of the } \\
\text { World; and NIMA } \\
\text { Digital Chart of the } \\
\text { World }\end{array}$ & $\begin{array}{l}\text { 1:100,000 USGS } \\
\text { topo maps } \\
\text { - USGS DLG data } \\
\text { - USGS Orthoquad } \\
\text { verification } \\
\text { - Ground truth } \\
\text { verification } \\
\text { - Previous work by } \\
\text { Geographic Data } \\
\text { Technology (now Tele } \\
\text { Atlas) and U.S. } \\
\text { Census TIGER data } \\
\end{array}$ & $\begin{array}{l}\text { Theme keywords: } \\
\text { electric transmission } \\
\text { lines, energy }\end{array}$ \\
\hline $\begin{array}{l}\text { Version } \\
\text { date }\end{array}$ & $\begin{array}{l}\text { 1996, some revisions } \\
\text { in } 2001\end{array}$ & 2003 & 2005 & \begin{tabular}{|l|} 
9/9/2005; Metadata \\
updated 2/8/2007
\end{tabular} \\
\hline $\begin{array}{l}\text { Information } \\
\text { sources }\end{array}$ & $\begin{array}{l}\text { - USGS document, } \\
\text { Standards for Digital } \\
\text { Line Graphs Part } 1 \\
\text { and 2, National } \\
\text { Mapping Program, } \\
\text { Technical Instructions } \\
\text { - http://rockyweb.cr. } \\
\text { usgs.gov/nmpstds/ } \\
\text { dlgstds.html }\end{array}$ & $\begin{array}{l}\text { - ESRI metatdata } \\
\text { information } \\
\text { http://www.esri.com/ } \\
\text { metadata/ } \\
\text { - FGDC Content } \\
\text { Standards for Digital } \\
\text { Geospatial Metadata } \\
\text { FGDC-STD-001-1998 } \\
\text { http://www.fgdc.gov/ } \\
\text { metadata/fgdc-std- } \\
\text { 001-1998.dtd/view }\end{array}$ & $\begin{array}{l}\text { - Tele Atlas User } \\
\text { Manual For ArcSDE } \\
\text { Loadable Solution for } \\
\text { USACE 2007. } \\
\text { - FGDC Content } \\
\text { Standards for Digital } \\
\text { Geospatial Metadata } \\
\text { FGDC-STD-001-1998 } \\
\text { http://www.fgdc.gov/ } \\
\text { metadata/fgdc-std- } \\
\text { 001-1998.dtd/view }\end{array}$ & $\begin{array}{l}\text { - HSIP_GOLD.ElectricTr } \\
\text { ansmissionLines } \\
\text { - Metadata Standard } \\
\text { Name: } \\
\text { FGDC Content } \\
\text { Standards for Digital } \\
\text { Geospatial Metadata }\end{array}$ \\
\hline $\begin{array}{l}\text { Available } \\
\text { formats }\end{array}$ & $\begin{array}{l}\text { - Standard (abandoned } \\
\text { by USGS in July 1996) } \\
\text { - Optional (currently } \\
\text { only DLG format } \\
\text { available) } \\
\text { - Graphic (abandoned } \\
\text { by USGS in July 1996) } \\
\text { - Shapefiles by WebGIS } \\
\text { http://www.webgis. } \\
\text { com/index.html }\end{array}$ & $\begin{array}{l}\text { - ESRI shapefile } \\
\text { - ERSI coverage }\end{array}$ & - ESRI shapefile & - GED shapefile \\
\hline
\end{tabular}


Table 1 (cont.). Characteristics of selected vector geographic data sets.

\begin{tabular}{|c|c|c|c|c|}
\hline $\begin{array}{l}\text { Available } \\
\text { projections }\end{array}$ & $\begin{array}{l}\text { - Standard UTM or } \\
\text { Albers Conical Equal } \\
\text { Area } \\
\text { - Optional UTM or } \\
\text { Albers Conical Equal } \\
\text { Area } \\
\text { - Graphic geographic } \\
\text { (lat/lon) } \\
\text { - Shapefiles by WebGIS } \\
\text { UTM and Geographic }\end{array}$ & $\begin{array}{l}\text { - Geographic (lat/lon) } \\
\text { decimal degree }\end{array}$ & $\begin{array}{l}\text { - Geographic (lat/lon) } \\
\text { decimal degree }\end{array}$ & $\begin{array}{l}\text { - Geographic (lat/lon) } \\
\text { decimal degree }\end{array}$ \\
\hline $\begin{array}{l}\text { Positional } \\
\text { accuracy }\end{array}$ & $\begin{array}{l}\text { If DLG map scale is } \\
<1: 20,000 \text {, positional } \\
\text { accuracy is } 30 \mathrm{ft} \text {. If } \\
\text { DLG map scale is } \\
>1: 20,000 \text {, positional } \\
\text { accuracy is } \geq 56 \mathrm{ft} \text {. }\end{array}$ & $\begin{array}{l}\text { Positional accuracy } \\
\text { varies with vector layer. } \\
\text { Some layers meet } \\
\text { National Map } \\
\text { Accuracies standards; } \\
\text { others are unknown. } \\
\end{array}$ & $\begin{array}{l}\text { Positional accuracy } \\
\text { varies with vector layer. } \\
\text { Some layers meet } \\
\text { National Map } \\
\text { Accuracies standards; } \\
\text { others are unknown. } \\
\end{array}$ & $\begin{array}{l}\text { Metadata Standard } \\
\text { Version } \\
\text { FGDC-STD-001-1998 }\end{array}$ \\
\hline Resolution & $\begin{array}{l}\text { - Standard }<1: 100,000 \\
\text { has resolution of } \\
<2.54 \mathrm{~m} \\
\text { - Optional 1:100,000 } \\
\text { has resolution of } 2.54 \\
\mathrm{~m} \\
\text { - Graphic 1:2,000,000 } \\
\text { has resolution of } \\
50.80 \mathrm{~m}\end{array}$ & $\begin{array}{l}\text { - Standard }<1: 100,000 \\
\text { has resolution of } \\
<2.54 \mathrm{~m} \\
\text { - Optional 1:100,000 } \\
\text { has resolution of } 2.54 \\
\mathrm{~m} \\
\text { - Graphic } 1: 2,000,000 \\
\text { has resolution of } \\
50.80 \mathrm{~m}\end{array}$ & $\begin{array}{l}\text { - Microdegrees of } \\
\text { geographical } \\
\text { coordinates }\end{array}$ & \\
\hline Layers & $\begin{array}{l}\text { Hydrography, } \\
\text { transportation, builtup, } \\
\text { hypsography, } \\
\text { nonvegetative surface } \\
\text { cover, vegetative } \\
\text { surface cover, and } \\
\text { named landforms }\end{array}$ & $\begin{array}{l}\text { Hydrography, } \\
\text { transportation, cultural } \\
\text { points, and land } \\
\text { features }\end{array}$ & $\begin{array}{l}\text { Hydrography, } \\
\text { transportation, cultural } \\
\text { locations, and physical } \\
\text { features }\end{array}$ & $\begin{array}{l}\text { Electric Transmission } \\
\text { Lines Intelligent Map } \\
\text { layer consists of market- } \\
\text { significant transmission } \\
\text { lines in North America. } \\
\text { Depicted lines generally } \\
\text { greater than } 115 \mathrm{kV} \\
\text { and tie major power } \\
\text { plants to the electrical } \\
\text { grid. Default thematic } \\
\text { has been placed on the } \\
\text { Numeric_Voltages } \\
\text { column of Electric } \\
\text { Transmission Lines. } \\
\text { Thematic created using } \\
\text { Voltage Class kV. }\end{array}$ \\
\hline
\end{tabular}

Tele Atlas North America (TANA) ArcSDE, provided under contract to the U.S. Army Corps of Engineers, was the source for all attribute vector information used in this project, except for electrical transmission lines. TANA ArcSDE is based upon the Tele Atlas Dynamap product (Tele Atlas 2007). Positional information for each of the vector files includes a datum and a coordinate system. For each file the GIS converted file geographic coordinates to UTM coordinates to conform to the Landsat and DOQ image coor- 
dinates that were used. The datum was set to WGS84 when the coordinate system was converted from geographic to UTM. The base horizontal accuracy of Dynamap digitized products is $12 \mathrm{~m}$ (Tele Atlas 2005). This is similar to National Map Accuracy standards for positional accuracy on 1:24,000-scale topographic maps, where $90 \%$ of well-defined features must have 12.2-m accuracy (USGS 1999). The USGS also allows an additional $1.8 \mathrm{~m}$ of error at 1:24,000 scale for digitizing errors (USGS 1999).

\section{Software}

ESRI ArcMap GIS was used to organize, visualize, manipulate, and analyze data layers and their attributes. Environment for Visualizing Images* (ENVI) software was utilized to convert the multi-spectral data products, such as Landsat imagery, to a format (i.e., TIFF) that was compatible with the ArcMap software.

\section{Intersection Process}

For each study area-Indiana, New Mexico, and California-ArcMap used OLSs created from OLS-MS software Version 10 (release date 12 March 2007) to intersect feature layers representative of water, railway and roadway, and power transmission line obstructions. The single in-hand precision georeferenced Landsat image that generated the greatest number of predicted OLSs was chosen for analysis at each location.

The overlay process occurred in the following steps:

1. Create Landsat image. Landsat spectral bands 1 (blue), 2 (green), and 3 (red) were combined for the single Landsat image used at each of the three locations to provide a natural visual backdrop for evaluating/ assessing the GIS data layer fidelity. All Landsat imagery provided a 30-m ground sampling resolution with horizontal ground feature placement accuracies in the order of $30 \mathrm{~m}$. The footprint of the Landsat image was used to define boundaries of all other GIS data layers (Fig. 4).

2. Register Landsat and DOQ. USGS DOQ images with 1-m pixel resolution were overlaid with the Landsat imagery to check for registration between the Landsat and DOQ imagery. Visual comparisons were made at nine locations over the entire Landsat image. No additional georectification was attempted if the identified horizontal displacement discrepancies were less

* http://www.ittvis.com/envi/ 
than $30 \mathrm{~m}$. Due to the higher resolution (finer detail) of the DOQ, they were also used to evaluate the ground placement fidelity of the GIS obstacle layers in lieu of using the Landsat imagery. If necessary, images were regeoreferenced as occurred in New Mexico.

3. Register OLS. Version 10 of the OLS-MS software was executed for each Landsat image using the following user-selectable settings as recommended by Boeing (Almassy and Blake 2007):

- Vegetation threshold: 1.8

- Gradient threshold: 0.02

- OLS headings: $0.0,30.0,60.0,90.0,120.0,150.0$ degrees

- Minimum runway width: $200 \mathrm{ft}(61 \mathrm{~m})$

- Minimum runway length: $3000 \mathrm{ft}(915 \mathrm{~m})$

- Threshold type: filt

- Gradient base: vector

- Gradient type: value

- Trona threshold: 99.9000

- Find runways: yes

- Find clouds: yes

The OLS-MS software requests runway width and length in feet from users. Since the Landsat images used in this study have 30-m-square pixels, the OLS-MS software adjusts OLS width and length to the next larger multiple of pixels. This is an appropriate response because a larger OLS area is safer than a smaller one and because the software can only process entire pixels and not fractions of pixels. Therefore, our 200-ft- (2.03-pixel-) wide by 3000-ft- (30.49-pixel) long OLSs are actually processed on Landsat images as 3 pixels wide by 31 pixels long. Therefore, the requested 200-ft-wide by 3000-ft-long OLSs are displayed in the images of this report as $90 \mathrm{~m}(295 \mathrm{ft})$ wide by $930 \mathrm{~m}$ (3050 ft) long.

The six individual runway headings at $30^{\circ}$ intervals, as indicated above, were created as individual output layers. The six heading layers were then overlaid using ArcMap to display all runway headings together.

Another output product of the OLS-MS software that contains OLS center-point coordinates and runway heading values was used in an offline routine to generate UTM coordinates that outlined each runway 
with vectors. This was accomplished by calculating polygon vertices for each OLS heading based on the OLS center coordinates. This process defined the outline of the OLS for each of the six headings with vectors, since each heading had a different shape as a result of crossing the Landsat image pixel array. The OLS shape for each heading is identical to all others of the same heading because the Landsat image is a Cartesian coordinate-based grid and is everywhere at the same scale. Figure 7 shows four OLSs at three headings outlined with vectors (stepped lines for headings that are not north-south or east-west in orientation). These coordinates were incorporated into runway polygon files, which were converted by the ArcMap software to generate six vector layers, one for each runway heading.

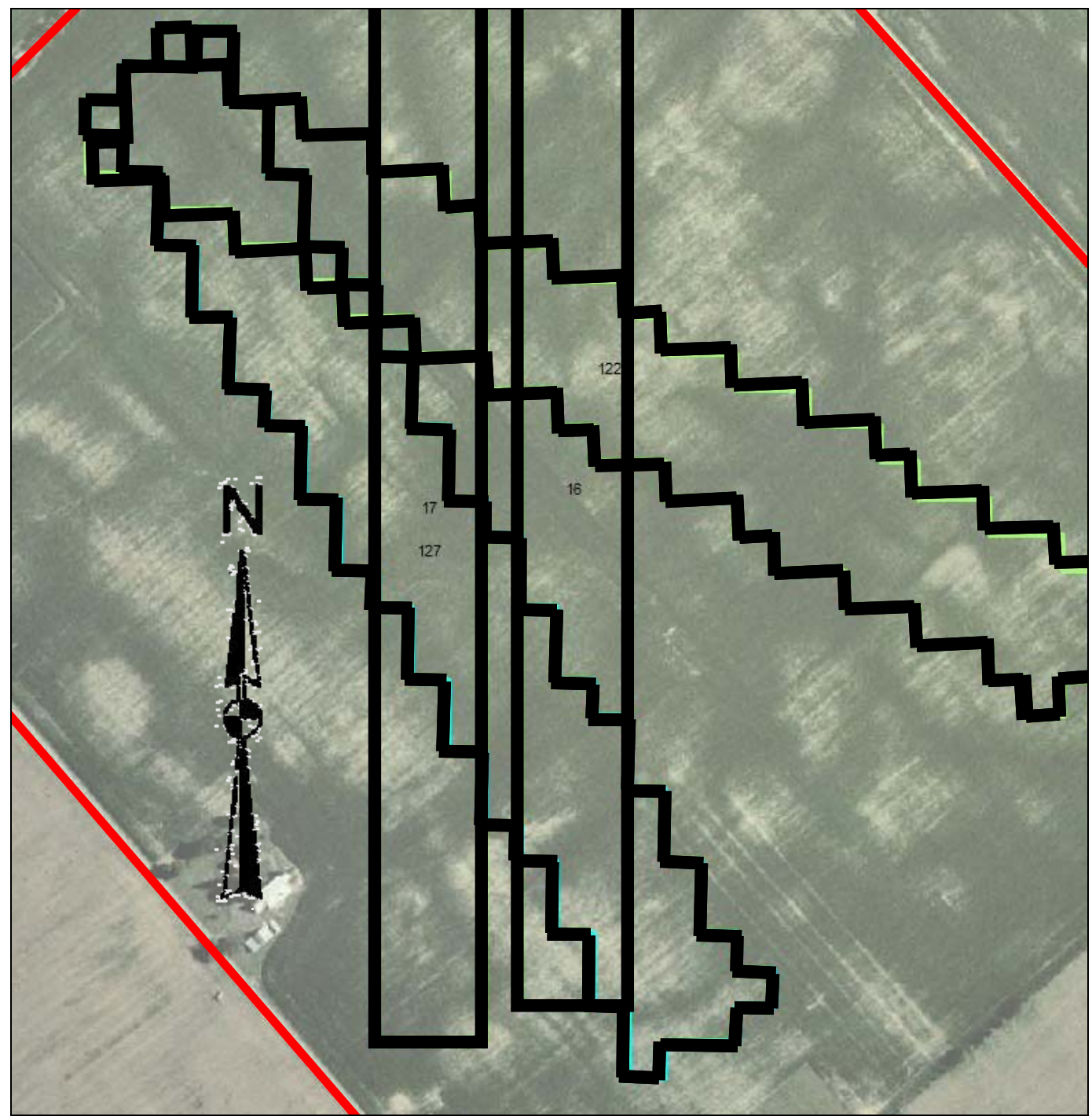

Figure 7. OLS with various headings outlined by black vectors. The OLSs are $930 \mathrm{~m}$ long and $90 \mathrm{~m}$ wide. 
4. Find intersections. Information from each of the four database suppliers investigated as sources of commencial off-the-shelf (COTS) digital vector coverage varied in projection, content, and format. Each product was converted to the UTM coordinate system and loaded into the GIS for evaluation. A visual inspection was conducted at locations within the Landsat image area, in both rural and urban environments, for ground placement fidelity of vectors within each layer versus that depicted in the DOQ and Landsat images. Another assessment compared the products for the detail or extent of network represented, such as roads, waterways, or railroads.

Using the ArcMap "Select by Location" tool, vectors for each attribute theme, for example roadways, and all the intersected OLS-MS predicted runways, were identified. This process produced six listings, one for each runway heading, highlighting each runway being intersected by an obstacle type as well as the total number of OLSs (of each heading) intersected. A summation of counts by runway heading and locale (CA, NM, or IN) was then tabulated. A sample of approximately 140200 OLSs was then selected from each Landsat image area for visual verification of intersection accuracy and identification of obstructions not in the databases using all six OLS headings. 


\section{OLS Obstruction Interception Results}

Intersections of OLS outline vectors and vectors of potential OLS obstructions were sought for four obstruction themes. These were roads; waterways such as rivers and streams, and water areas such as ponds and lakes; railroads; and transmission lines. There were sufficient differences in each theme that each merits separate discussion.

\section{OLSs}

OLSs that were mapped from Landsat images using OLS-MS Version 10 software in each area-Indiana, New Mexico, and California-with the number of OLSs tabulated by direction (Table 2, Fig. 7). Landsat images were available for each season in each study area. To provide the largest

Table 2. Roadway intersections by OLS location and heading.

\begin{tabular}{|c|c|c|c|}
\hline $\begin{array}{l}\text { Study area/ } \\
\text { Landsat image }\end{array}$ & $\begin{array}{c}\text { Runway } \\
\text { heading } \\
\text { (degrees) }\end{array}$ & $\begin{array}{l}\text { Runways predicted by } \\
\text { OLS-MS software } \\
\text { (number and percent) }\end{array}$ & $\begin{array}{c}\text { Runways intersected by } \\
\text { roadways } \\
\text { (number and percent) }\end{array}$ \\
\hline \multirow{7}{*}{$\begin{array}{l}\text { Southern Indiana } \\
\text { Landsat } 5 \\
\text { Path 20, Row } 33 \\
12 \text { November } 2005\end{array}$} & 0 & $36(26 \%)$ & $2(1 \%)$ \\
\hline & 30 & $17(12 \%)$ & $3(2 \%)$ \\
\hline & 60 & $2014 \%)$ & $1(1 \%)$ \\
\hline & 90 & $45(32 \%)$ & $5(4 \%)$ \\
\hline & 120 & $9(6 \%)$ & $1(1 \%)$ \\
\hline & 150 & $12(9 \%)$ & $0(0 \%)$ \\
\hline & Total & $139(100 \%)$ & $12(9 \%)$ \\
\hline \multirow{7}{*}{$\begin{array}{l}\text { Southern California } \\
\text { Landsat } 5 \\
\text { Path 39, Row } 37 \\
1 \text { November } 2005\end{array}$} & 0 & $3,807(20 \%)$ & $493(3 \%)$ \\
\hline & 30 & $2,751(15 \%)$ & $367(2 \%)$ \\
\hline & 60 & $2,781(15 \%)$ & $324(2 \%)$ \\
\hline & 90 & $4,282(23 \%)$ & $424(2 \%)$ \\
\hline & 120 & $2,566(14 \%)$ & $309(2 \%)$ \\
\hline & 150 & $2,423(13 \%)$ & $334(2 \%)$ \\
\hline & Total & $18,610(100 \%)$ & $2,251(13 \%)$ \\
\hline \multirow{7}{*}{$\begin{array}{l}\text { Southern New Mexico } \\
\text { Landsat } 5 \\
\text { Path 33, Row } 37 \\
22 \text { October } 2005\end{array}$} & 0 & 208 (21\%) & $45(5 \%)$ \\
\hline & 30 & 114 (12\%) & 32 (3\%) \\
\hline & 60 & $136(14 \%)$ & $34(3 \%)$ \\
\hline & 90 & $251(25 \%)$ & $54(5 \%)$ \\
\hline & 120 & $137(14 \%)$ & $36(4 \%)$ \\
\hline & 150 & $139(14 \%)$ & $44(4 \%)$ \\
\hline & Total & 985 (100\%) & $245(25 \%)$ \\
\hline
\end{tabular}


sample, the Landsat image used to locate OLSs was from the season that generated the largest number of OLSs: November in Indiana and California and October in New Mexico.

The arid sites produced the largest number of OLSs, with New Mexico producing seven times the number of OLSs as Indiana, and California producing over 133 times the number of OLSs as Indiana's 139 (Table 2). In general, there is an OLS-MS software preference in each geographic area for predicted OLSs to be oriented north-south and east-west. Approximately 1.5 to 2 times more OLSs are found in the north-south and east-west orientations than in the other headings for all three images analyzed.

\section{Roadways}

The ESRI, USGS, and Tele Atlas data were investigated as sources of COTS digital roadway vector coverage. ESRI organized roadway coverage into groups for roads, U.S. routes, major roads, interstates, and highways, each often duplicating the same roadways. The USGS roadway coverage was provided in one file named roads, which contained different attributes for the various roadway classes. The Tele Atlas roadway coverage was broken into two files named streets and highways, where the highways were derived from street vectors. The roadway vector product chosen was the Tele Atlas streets database because it utilizes older ESRI and USGS products augmented with updated digitization from more recent air photos and GPS-generated ground data collection methods.

An example in the California study area with numerous OLSs and road intersections is illustrated in Figure 8 for north- south-oriented OLSs. Though some OLSs are clearly intersected by roads, others are only intersected at their ends and may be a result of minor errors in georegistration.

Figure 9 also shows a group of OLSs with seven road intersections. Two intersections, however, occur with the road barely intersecting the southern end of the OLS. The small overlap may be due to georegistration errors in the Landsat or vector information.

Figure 10 illustrates an OLS in southern Indiana with a road intersection nearly in its center. Though there are misalignments between the vector roads and the roads visible in the DOQ, the OLS- road intersection is still significant. 


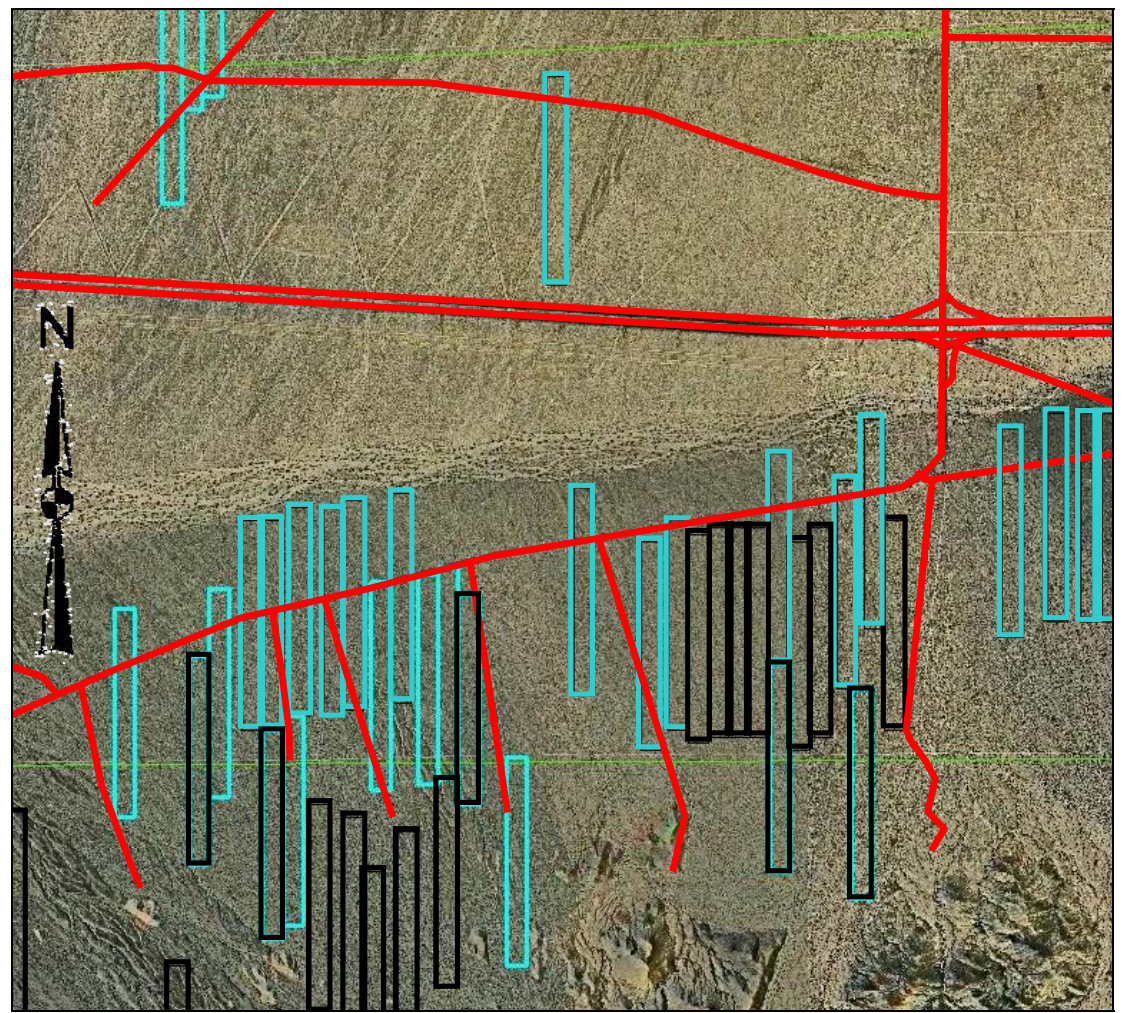

Figure 8. Example in southern California of the intersection of roads (red lines) with OLSs (blue rectangles). OLSs not intersected by roads are outlined in black. The OLSs are $930 \mathrm{~m}$ long and $90 \mathrm{~m}$ wide.

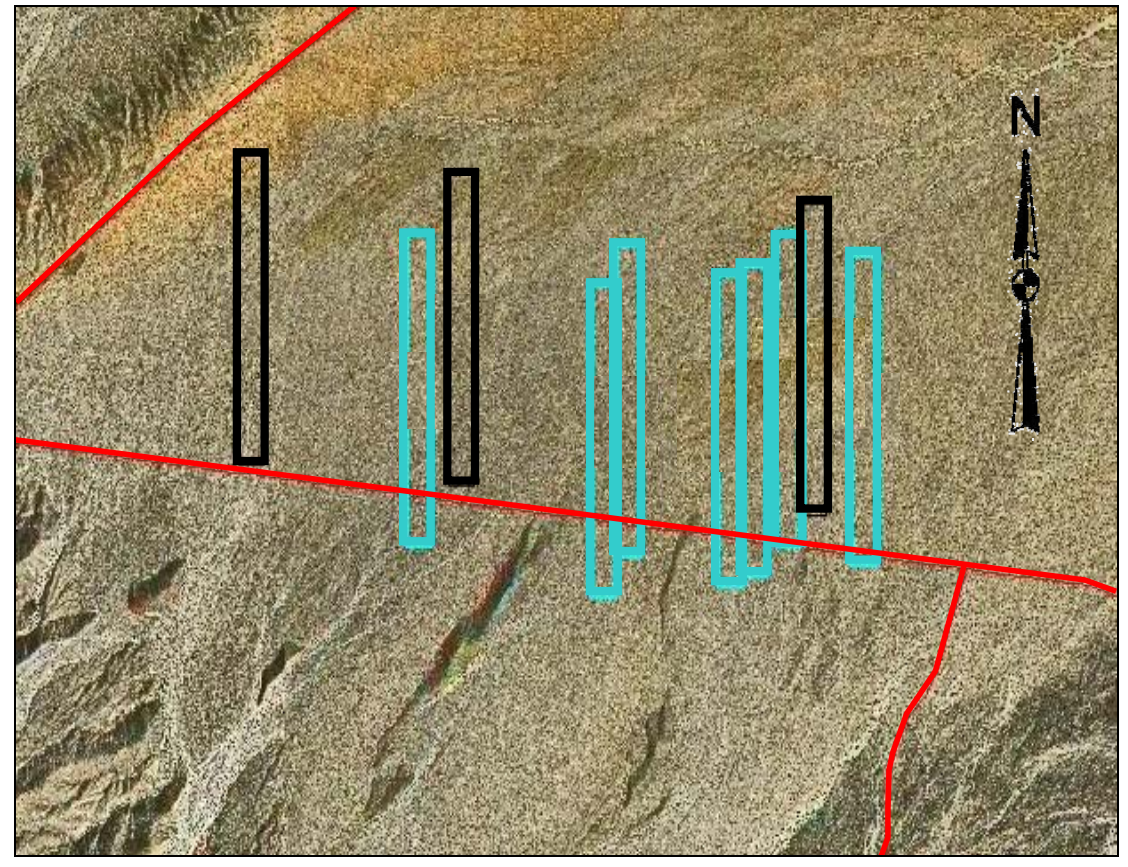

Figure 9. Intersection of roads (red lines) with OLSs (blue rectangles) in southern California. OLSs not intersected by roads are outlined in black. The OLSs are $930 \mathrm{~m}$ long and $90 \mathrm{~m}$ wide. 


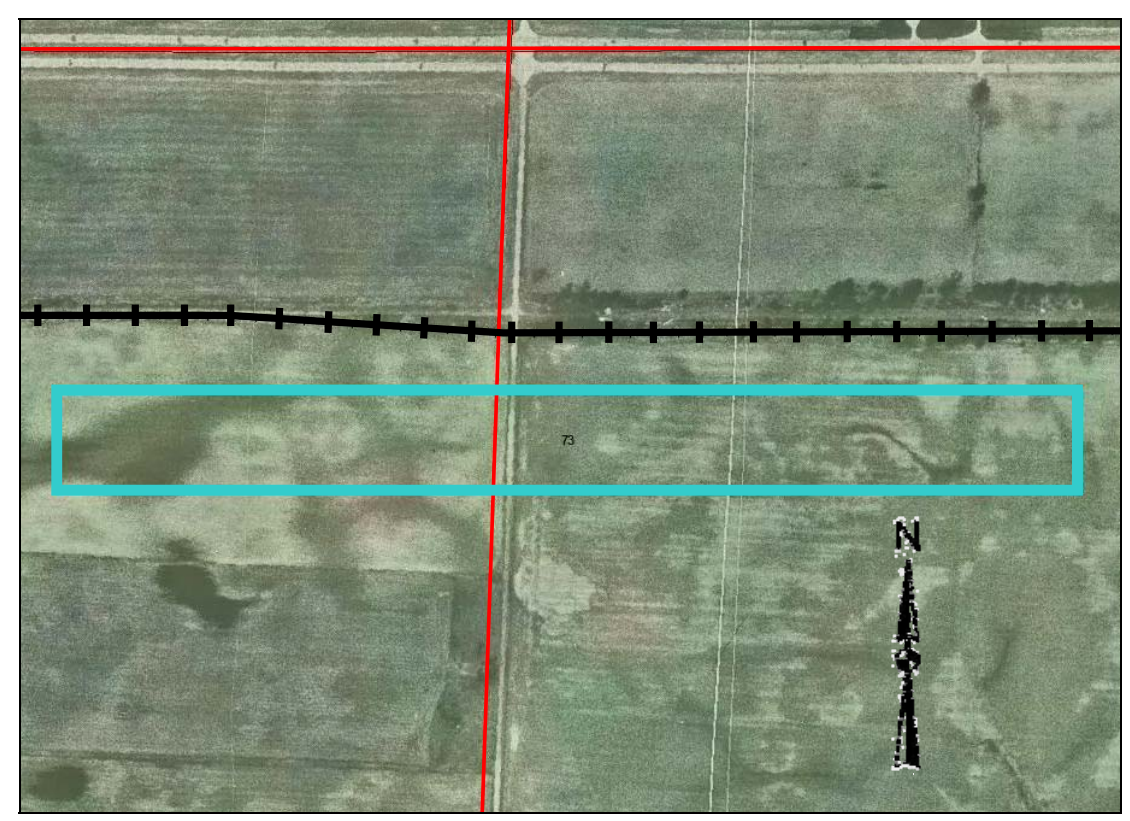

Figure 10. Intersection of a road (red lines) with an OLS (light blue rectangle) in southern Indiana. The hatched black line is a railroad. The OLS is $930 \mathrm{~m}$ long and $90 \mathrm{~m}$ wide.

\section{Waterways}

The same suppliers were investigated as sources of COTS digital waterway vectors as for roadways. ESRI waterways were broken into file groups for rivers, major water, and lakes, with rivers and lakes often included in the major water file. USGS waterways were provided in one file named water that contained different attributes for the various waterway classes. Tele Atlas waterways came in three files named water, water_polygon, and mwater, with the latter a subset of the water_polygon listing. To provide a representative waterway coverage, two waterway vector products were selected: the Tele Atlas water and water_polygon files. As with roadways, the Tele Atlas waterways appeared to have more frequent updates and more precise ground registration than products from other sources. OLSs and waterways were intersected using the same process as OLS and roadway intersections. Table 3 shows the number of runway and waterway intersections by location and OLS heading, and the percent of OLSs intersected at each heading. 
Table 3. Waterway intersections by OLS location and heading.

\begin{tabular}{|c|c|c|c|}
\hline $\begin{array}{l}\text { Study area/ } \\
\text { Landsat image }\end{array}$ & $\begin{array}{c}\text { Runway } \\
\text { heading } \\
\text { (degrees) }\end{array}$ & $\begin{array}{l}\text { Runways predicted by } \\
\text { OLS-MS software } \\
\text { (number and percent) }\end{array}$ & $\begin{array}{l}\text { Runways intersected by } \\
\text { waterways } \\
\text { (number and percent) }\end{array}$ \\
\hline \multirow{7}{*}{$\begin{array}{l}\text { Southern Indiana } \\
\text { Landsat } 5 \\
\text { Path 20, Row } 22 \\
12 \text { November } 2005\end{array}$} & 0 & $36(26 \%)$ & $1(1 \%)$ \\
\hline & 30 & $17(12 \%)$ & $0(0 \%)$ \\
\hline & 60 & $2014 \%)$ & $1(1 \%)$ \\
\hline & 90 & 45 (32\%) & $4(3 \%)$ \\
\hline & 120 & $9(6 \%)$ & $1(1 \%)$ \\
\hline & 150 & $12(9 \%)$ & $1(1 \%)$ \\
\hline & Total & $139(100 \%)$ & $8(6 \%)$ \\
\hline \multirow{7}{*}{$\begin{array}{l}\text { Southern California } \\
\text { Landsat } 5 \\
\text { Path 39, Row } 37 \\
1 \text { November } 2005\end{array}$} & 0 & $3,807(20 \%)$ & $558(3 \%)$ \\
\hline & 30 & $2,751(15 \%)$ & $340(2 \%)$ \\
\hline & 60 & $2,781(15 \%)$ & $417(2 \%)$ \\
\hline & 90 & $4,282(23 \%)$ & $673(4 \%)$ \\
\hline & 120 & $2,566(14 \%)$ & $437(2 \%)$ \\
\hline & 150 & $2,423(13 \%)$ & $425(2 \%)$ \\
\hline & Total & $18,610(100 \%)$ & $2,850(15 \%)$ \\
\hline \multirow{7}{*}{$\begin{array}{l}\text { Southern New Mexico } \\
\text { Landsat } 5 \\
\text { Path 33, Row } 37 \\
22 \text { October } 2005\end{array}$} & 0 & $208(21 \%)$ & $62(6 \%)$ \\
\hline & 30 & $114(12 \%)$ & $36(4 \%)$ \\
\hline & 60 & $136(14 \%)$ & $40(4 \%)$ \\
\hline & 90 & 251 (25\%) & $64(6 \%)$ \\
\hline & 120 & $137(14 \%)$ & $32(3 \%)$ \\
\hline & 150 & $139(14 \%)$ & $38(4 \%)$ \\
\hline & Total & 985 (100\%) & $272(28 \%)$ \\
\hline
\end{tabular}

The percentage of OLSs intersected by waterways by heading closely resembles the percentage of roadways intersected by heading. Figure 11 shows a cluster of OLSs in southern California that have been intercepted by waterways in the southern portion of the image, with several OLS clusters in the northern portion of the image that do not intersect waterways. Though a few OLSs intersect streams only at their ends, the majority of interceptions are through a middle portion of the OLS. 


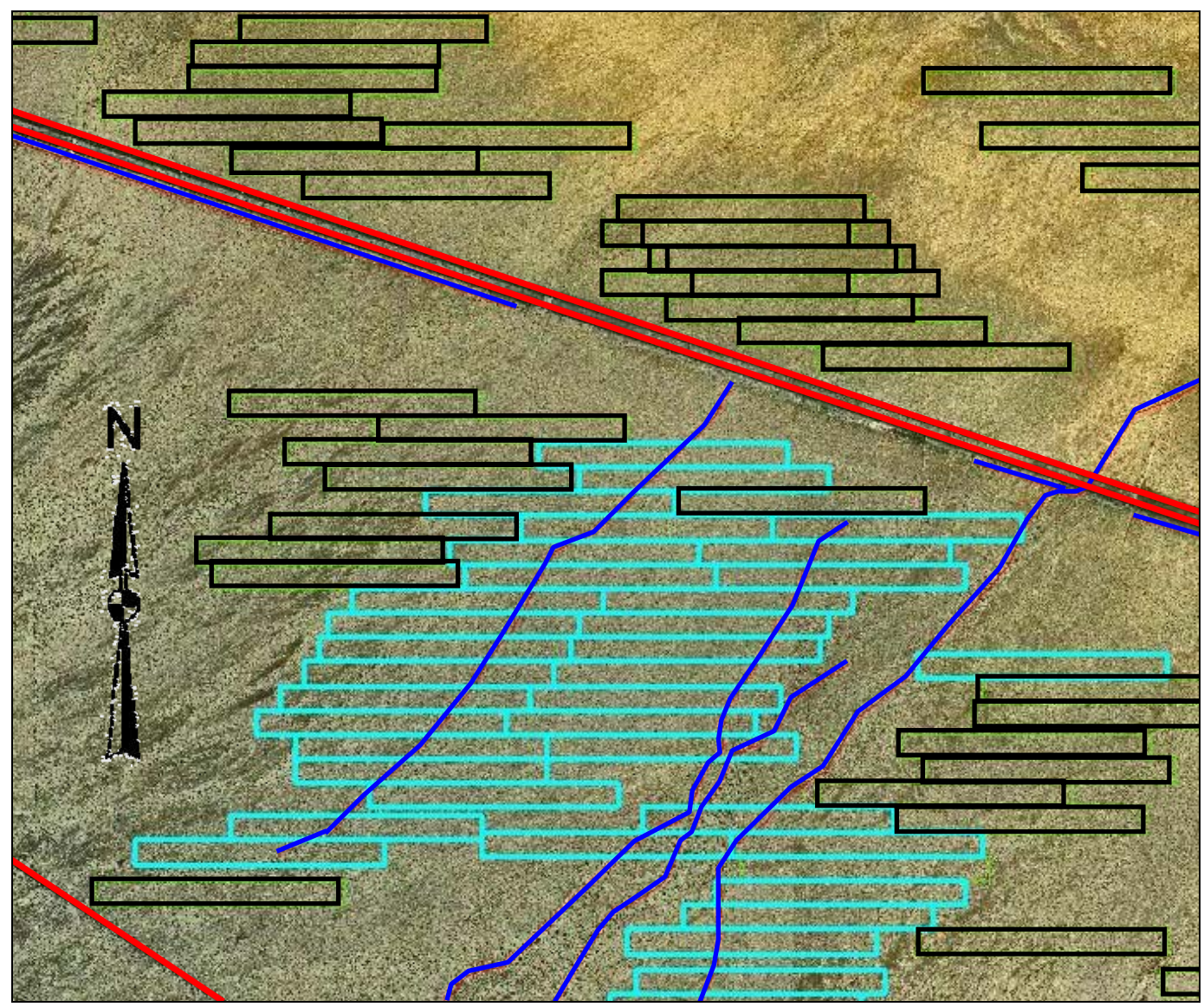

Figure 11. Intersection of waterways (dark blue) with OLSs (light blue rectangles) in California. OLSs not intersected are outlined in black, and roads are red. The OLSs are $930 \mathrm{~m}$ long and $90 \mathrm{~m}$ wide.

Figure 12 illustrates an OLS in southern Indiana being crossed by a stream or a drainage ditch. The ditch may be sufficiently small that its signature on the Landsat image is undetectable. Also, the dates of the stream digitizing and the DOQ could be different and may explain some of the differences. The stream database was current as of 2005. The DOQ dates are between March 1998 and September 2004.

The OLS-MS software also can avoid water obstructions. Figure 13 provides an example of an OLS cluster that avoids a meandering stream. Note the differences between stream position on the DOQ and the digitized stream. This may be due to digitizing errors or to differences in dates of the stream database (2005) and the DOQ (March 1998 through September 2004). 


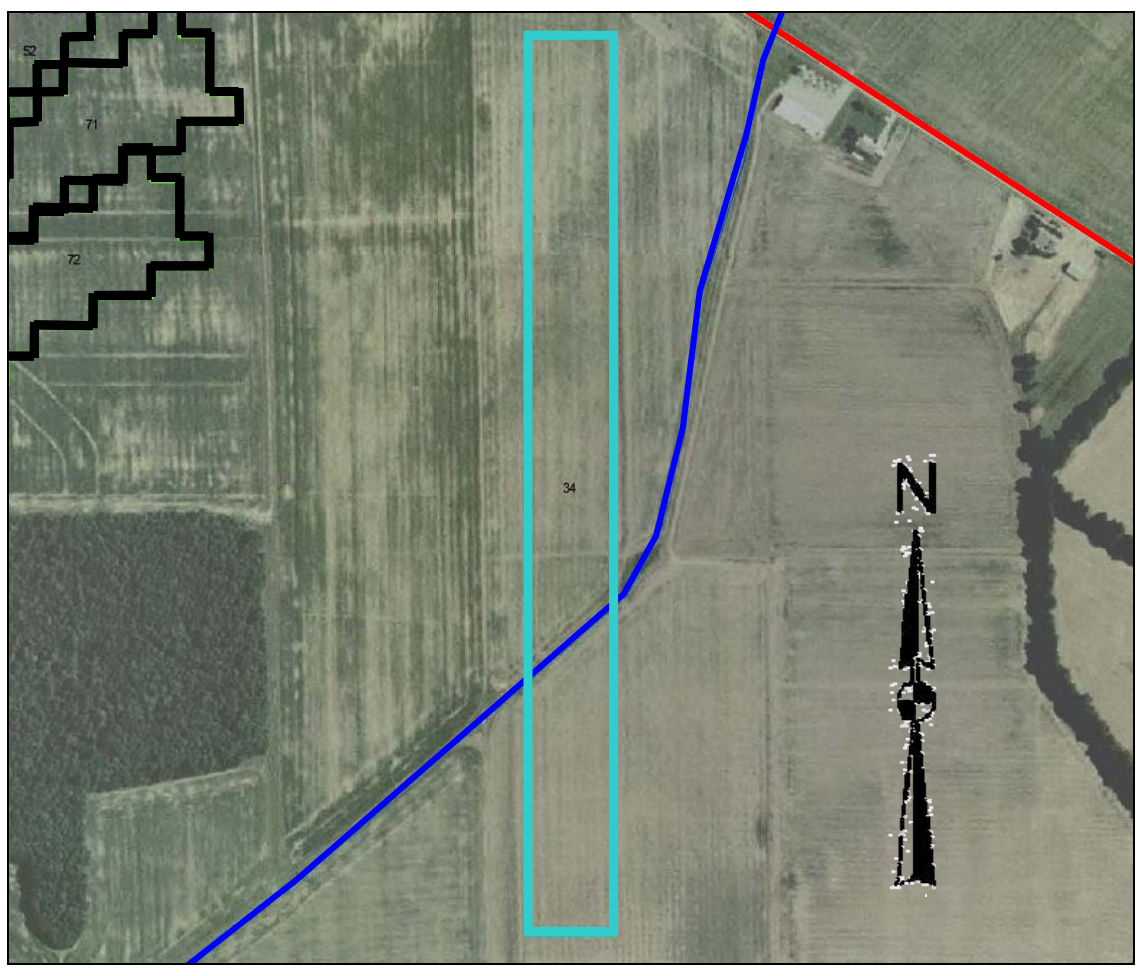

Figure 12. OLS (light blue rectangle) intersection of a drainage ditch or straightened stream (dark blue line) in southern Indiana. The OLS is $930 \mathrm{~m}$ long and $90 \mathrm{~m}$ wide.

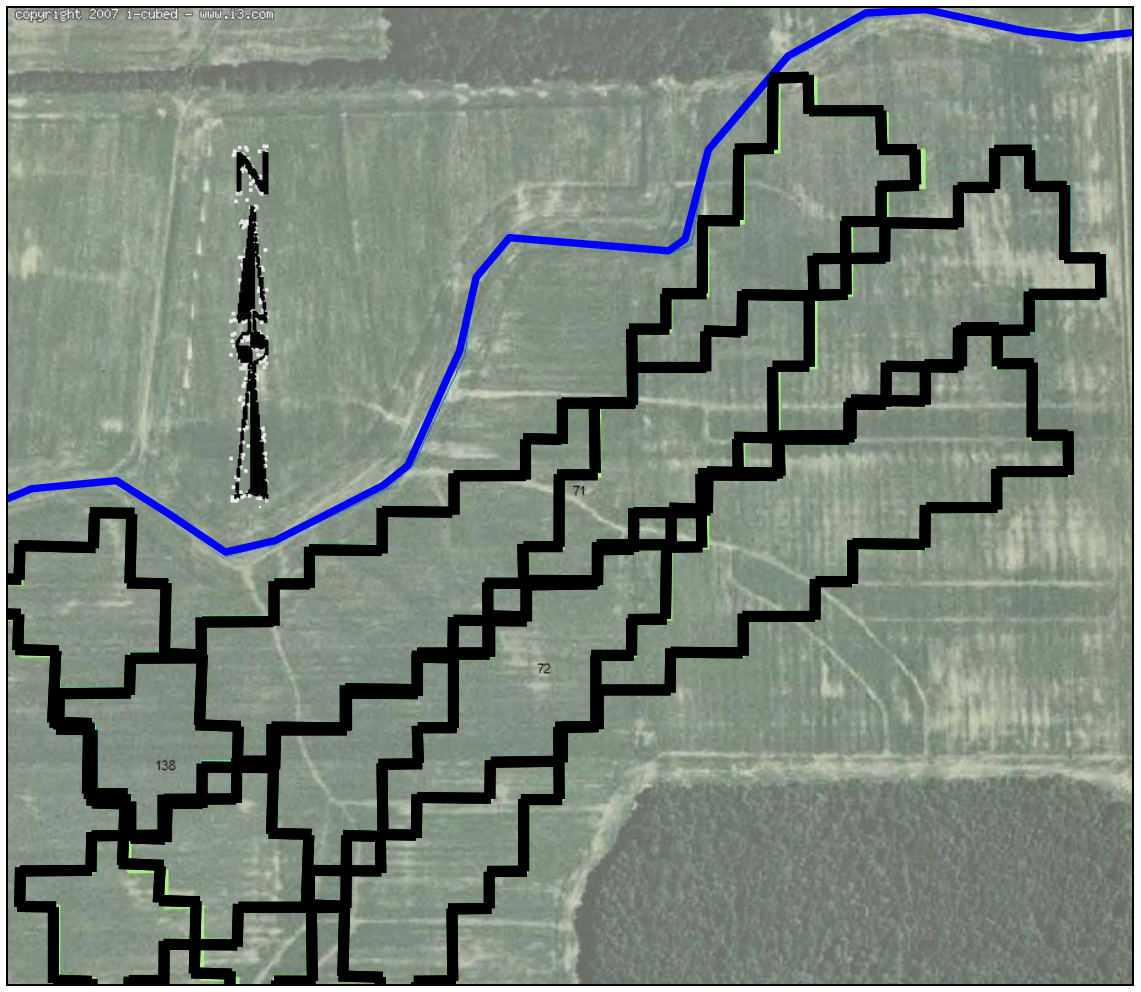

Figure 13. OLSs, outlined in black, avoiding a meandering stream (dark blue line) in southern Indiana. The OLSs are $930 \mathrm{~m}$ long and $90 \mathrm{~m}$ wide. 
The effects of image date and environment dynamics on the location of OLSs determined by the OLS-MS software are illustrated in Figures 14 and 15. This is the only example in the three study areas where an OLS was intersected by a water area, in this case a reservoir. Figure 14 indicates the OLS to be located in the reservoir. Figure 15 shows that the reservoir was higher in the DOQ but had been drawn down when the Landsat image was scanned. As a result, the OLS-MS software interpreted the site as dry land and placed the OLS in the reservoir. This situation indicates that the timing of image acquisition and conditions on the ground can significantly impact OLS quality.

Note that the reservoir analysis illustrated in Figure 14 occurred on a Landsat image that was precision georeferenced by the USGS but only met our 30-m registration standard along the north-south centerline of the image. The error increased well beyond our standards east and west of the centerline. The "OLS in the reservoir" example appeared in the initial georeferenced image, and the reservoir was located in an area that was georeferenced to precision accuracy. However, because pixel signatures change as images are rubber-sheeted in the georectification process, this OLS did not reappear when the OLS-MS software was again run with the ERDC-georectified Landsat image.

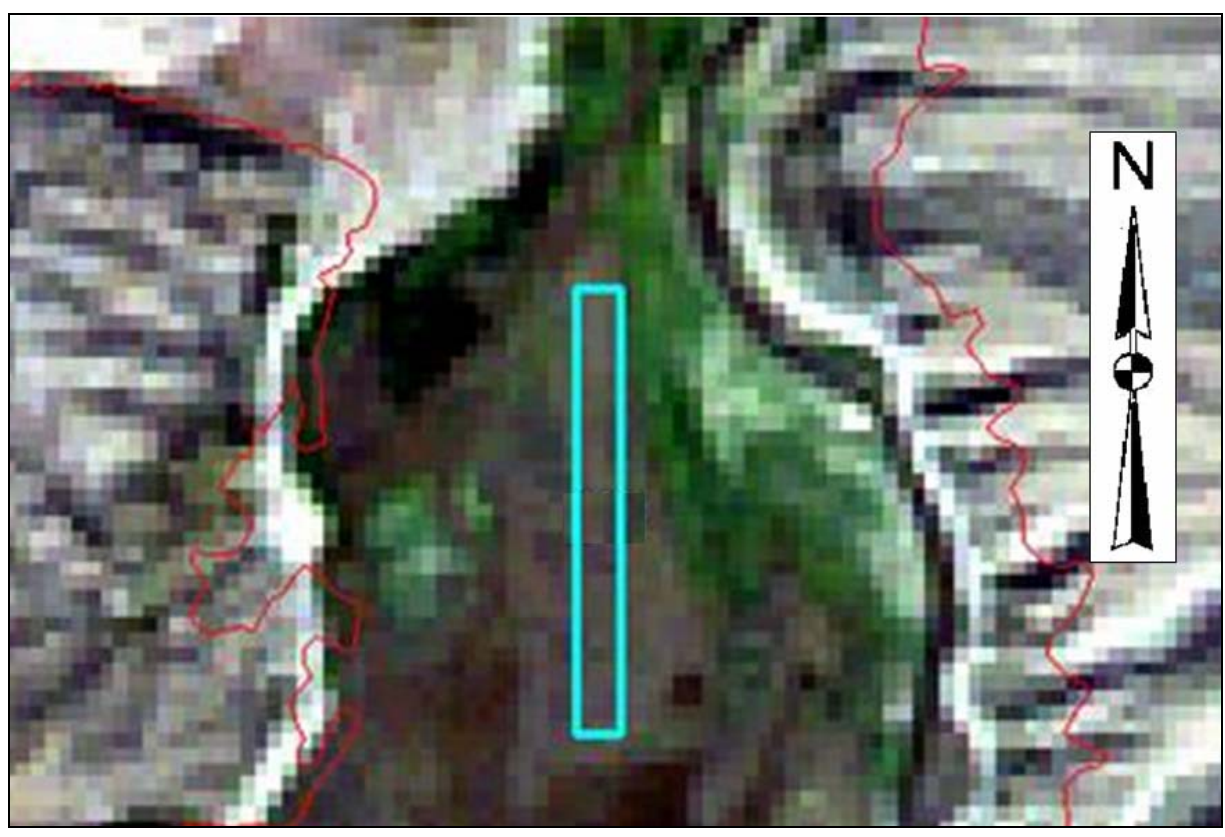

Figure 14. OLS, outlined in light blue, located in a reservoir. The reservoir is drawn down and the OLS may be located on the emerged reservoir floor. The OLS is 930 $\mathrm{m}$ long and $90 \mathrm{~m}$ wide. During the reservoir draw-down the spectral signature for water may have been below the threshold that the OLS-MS software could detect. 


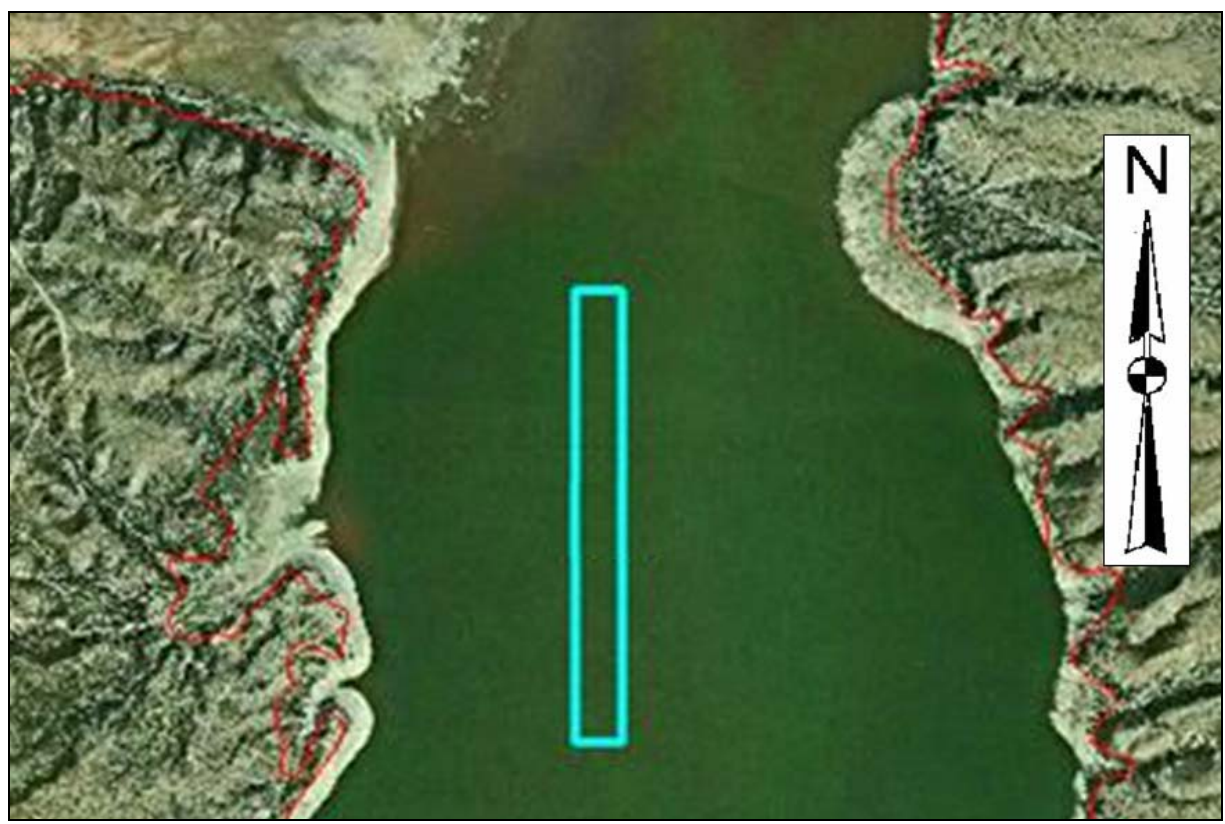

Figure 15. OLS in water in the DOQ image.

\section{Railroads}

Visual assessment of the railroad vector files from the three vendors indicated, as with the roads and waterways, that the Tele Atlas railroads file records were complete and accurate. Railroad OLS intersections were searched in the same manner as for roads and linear water features. Though railroads occurred in each of the three Landsat images analyzed, intersections occurred with OLSs only in the southern California area (Table 4).

Figure 16 provides an example of the intersection of railroads with OLSs in southern California, where 2 of the 2,566 predicted OLSs in the $120^{\circ}$ heading were intersected. The intersection of the OLS in the northern portion of the image appears as a true intersection, but the intersection in the southern portion of the image is suspect. Either the railroad is inaccurately digitized and would not have been highlighted as intersecting if the railroad had been accurately digitized, or a single digitized line is representing parallel railroad tracks at that location providing the appearance that the digitized railroad is inaccurately positioned. 
Table 4. Railroad intersections by OLS location and heading.

\begin{tabular}{|c|c|c|c|}
\hline $\begin{array}{l}\text { Study area/ } \\
\text { Landsat image }\end{array}$ & $\begin{array}{c}\text { Runway } \\
\text { heading } \\
\text { (degrees) }\end{array}$ & $\begin{array}{l}\text { Runways predicted by } \\
\text { OLS-MS software } \\
\text { (number and percent) }\end{array}$ & $\begin{array}{c}\text { Runways intersected by } \\
\text { railways } \\
\text { (number and percent) }\end{array}$ \\
\hline \multirow{7}{*}{$\begin{array}{l}\text { Southern Indiana } \\
\text { Landsat } 5 \\
\text { Path } 20, \text { Row } 22 \\
12 \text { November } 2005\end{array}$} & 0 & $36(26 \%)$ & $0(0 \%)$ \\
\hline & 30 & $17(12 \%)$ & $0(0 \%)$ \\
\hline & 60 & $20(14 \%)$ & $0(0 \%)$ \\
\hline & 90 & 45 (32\%) & $0(0 \%)$ \\
\hline & 120 & $9(6 \%)$ & $0(0 \%)$ \\
\hline & 150 & $12(9 \%)$ & $0(0 \%)$ \\
\hline & Total & 139 (100\%) & $0(0 \%)$ \\
\hline \multirow{7}{*}{$\begin{array}{l}\text { Southern California } \\
\text { Landsat } 5 \\
\text { Path } 39, \text { Row } 37 \\
1 \text { November } 2005\end{array}$} & 0 & 3,807 (20\%) & $0(0 \%)$ \\
\hline & 30 & $2,751(15 \%)$ & $1(<1 \%)$ \\
\hline & 60 & $2,781(15 \%)$ & $0(0 \%)$ \\
\hline & 90 & $4,282(23 \%)$ & $1(<1 \%)$ \\
\hline & 120 & $2,566(14 \%)$ & $2(<1 \%)$ \\
\hline & 150 & $2,423(13 \%)$ & $2(<1 \%)$ \\
\hline & Total & $18,610(100 \%)$ & $6(<1 \%)$ \\
\hline \multirow{7}{*}{$\begin{array}{l}\text { Southern New Mexico } \\
\text { Landsat } 5 \\
\text { Path 33, Row } 37 \\
22 \text { October } 2005\end{array}$} & 0 & 208 (21\%) & $0(0 \%)$ \\
\hline & 30 & $114(12 \%)$ & $0(0 \%)$ \\
\hline & 60 & $136(14 \%)$ & $0(0 \%)$ \\
\hline & 90 & 251 (25\%) & $0(0 \%)$ \\
\hline & 120 & $137(14 \%)$ & $0(0 \%)$ \\
\hline & 150 & 139 (14\%) & $0(0 \%)$ \\
\hline & Total & 985 (100\%) & $0(0 \%)$ \\
\hline
\end{tabular}




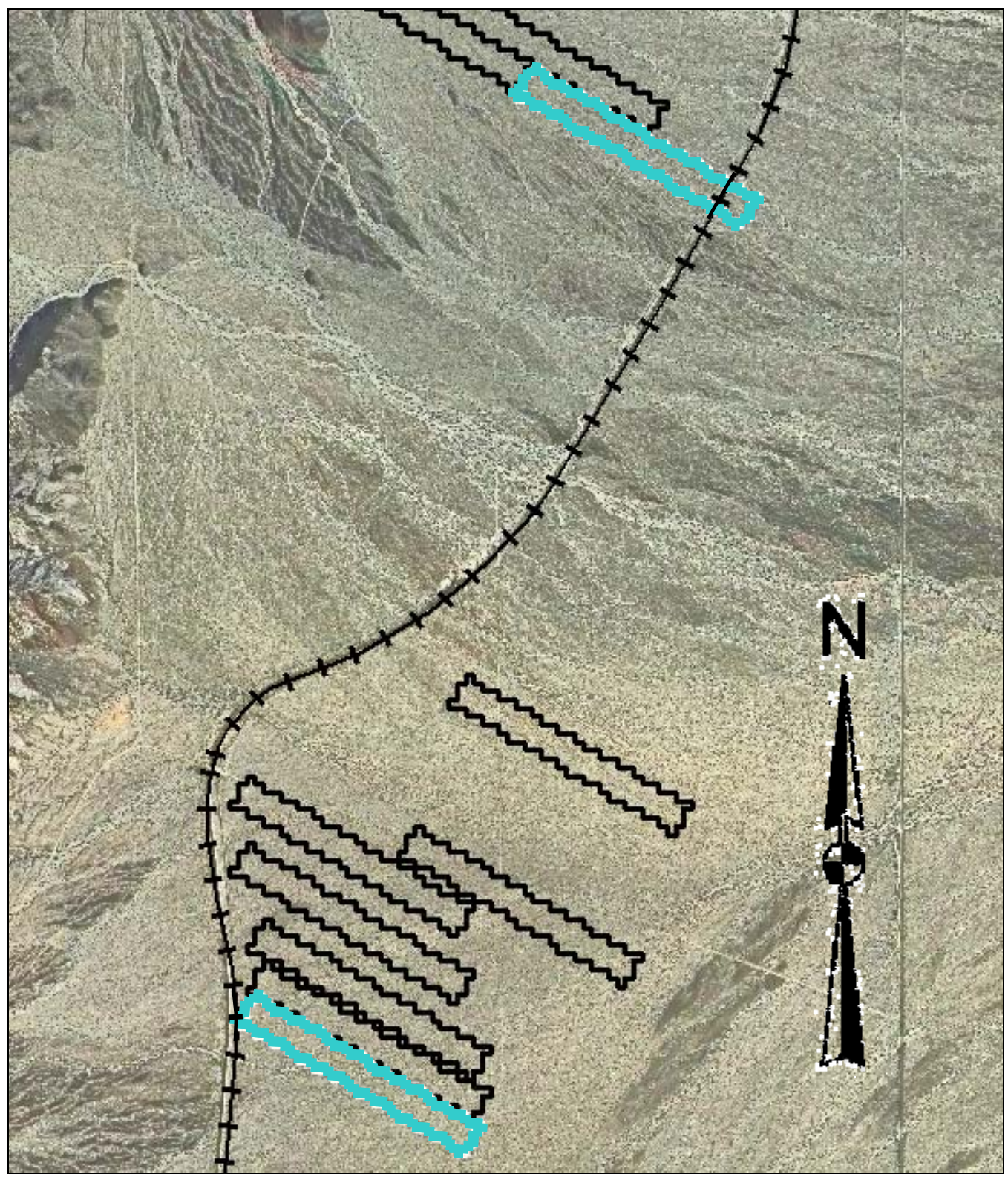

Figure 16. Railroad and OLS intersections in southern California. OLSs intersecting the railroad line are outlined in light blue, and those not intersecting are outlined in black. The OLSs are $930 \mathrm{~m}$ long and $90 \mathrm{~m}$ wide.

Figure 17 illustrates several OLSs successfully avoiding intersections with a railroad line, a road, and a transmission line and other features, though there is an apparent intersection of two of the OLSs with an agricultural road. 


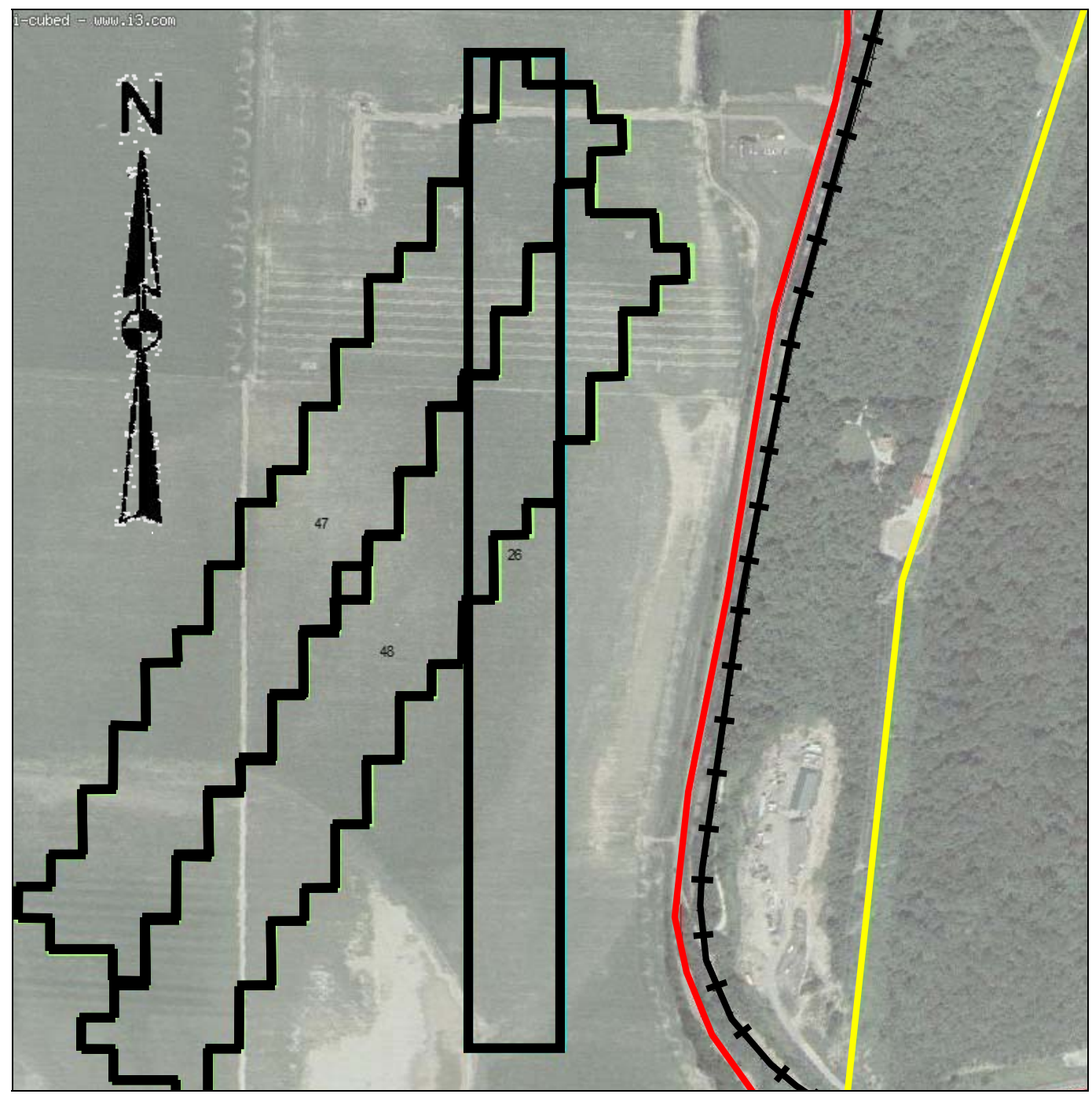

Figure 17. OLSs (outlined in black) in southern Indiana successfully avoiding trees, a highway (red), a railroad (black cross-hatched line), and a transmission line (yellow). However, two OLSs cross an apparent agricultural road at their northern ends. The OLSs are $930 \mathrm{~m}$ long and $90 \mathrm{~m}$ wide.

\section{Transmission Lines}

Two sources were investigated for electrical transmission line vector coverage: USGS and Global Energy (GE). The USGS electrical transmission line coverage was a subset of their Pipe and Transmission line database (USGS 1998). As with the other themes, a visual inspection was conducted within numerous grid cells in rural and urban environments for ground placement fidelity versus that depicted in the DOQ and Landsat images. A second comparison assessed the detail or extent of transmission line networks represented. The electrical transmission line vector product chosen as the result of these comparisons was the GE product, which was 
more complete than the other products and was used successfully in Indiana and New Mexico (Table 5).

Table 5. Transmission line intersections by OLS location and heading.

\begin{tabular}{|c|c|c|c|}
\hline $\begin{array}{l}\text { Study area/ } \\
\text { Landsat image }\end{array}$ & $\begin{array}{c}\text { Runway } \\
\text { heading } \\
\text { (degrees) }\end{array}$ & $\begin{array}{l}\text { Runways predicted by } \\
\text { OLS-MS software } \\
\text { (number and percent) }\end{array}$ & $\begin{array}{l}\text { Runways intersected by } \\
\text { electrical transmission lines } \\
\text { (number and percent) }\end{array}$ \\
\hline \multirow{7}{*}{$\begin{array}{l}\text { Southern Indiana } \\
\text { Landsat } 5 \\
\text { Path 20, Row } 22 \\
12 \text { November } 2005\end{array}$} & 0 & $36(26 \%)$ & $0(0 \%)$ \\
\hline & 30 & $17(12 \%)$ & $0(0 \%)$ \\
\hline & 60 & $2014 \%)$ & $1(1 \%)$ \\
\hline & 90 & 45 (32\%) & $4(3 \%)$ \\
\hline & 120 & $9(6 \%)$ & $0(0 \%)$ \\
\hline & 150 & $12(9 \%)$ & $0(0 \%)$ \\
\hline & Total & $139(100 \%)$ & $5(4 \%)$ \\
\hline \multirow{7}{*}{$\begin{array}{l}\text { Southern California } \\
\text { Landsat } 5 \\
\text { Path } 39, \text { Row } 37 \\
1 \text { November } 2005\end{array}$} & 0 & 3,807 (20\%) & $266(1 \%)$ \\
\hline & 30 & 2,751 (15\%) & 207 (1\%) \\
\hline & 60 & 2,781 (15\%) & $214(1 \%)$ \\
\hline & 90 & $4,282(23 \%)$ & $240(1 \%)$ \\
\hline & 120 & 2,566 (14\%) & $141(1 \%)$ \\
\hline & 150 & $2,423(13 \%)$ & $158(1 \%)$ \\
\hline & Total & $18,610(100 \%)$ & $1,226(7 \%)$ \\
\hline \multirow{7}{*}{$\begin{array}{l}\text { Southern New Mexico } \\
\text { Landsat } 5 \\
\text { Path 33, Row } 37 \\
22 \text { October } 2005\end{array}$} & 0 & $208(21 \%)$ & $2(0 \%)$ \\
\hline & 30 & $114(12 \%)$ & $0(0 \%)$ \\
\hline & 60 & $136(14 \%)$ & $1(0 \%)$ \\
\hline & 90 & 251 (25\%) & $4(0 \%)$ \\
\hline & 120 & 137 (14\%) & $1(0 \%)$ \\
\hline & 150 & 139 (14\%) & $1(0 \%)$ \\
\hline & Total & 985 (100\%) & $9(1 \%)$ \\
\hline
\end{tabular}

The GE transmission line database for southern California was found, after additional inspection, to be less accurate and have less coverage than had originally been determined, sufficiently so to cause uncertainty in the results. However, it was the best transmission line database available to us. The inspection showed unreliability in depicting what was on the ground and unreliability with regard to object location. Some digitized transmission lines could not be reliably verified in the DOQ. However, some of these cases could be underground lines. In other cases, highvoltage aerial transmission lines appearing on the DOQ were not digitized (Fig. 18). Because some lines represented in the vector data are in question, an analysis was conducted with visual verification. The GE vector file is accurate to 2005 (GE 2007). Dates of the DOQs range from J une 1996 
through August 2004. Therefore, new lines could have been added after the most recent DOQs were imaged. Because of these inconsistencies, transmission lines analyzed for their intersection with OLSs in California should be considered with the caveats described. The transmission line databases in New Mexico and Indiana, however, were accurate.

A maximum of $7 \%$ of OLSs were intercepted by transmission lines in all three study areas, and that was in southern California, where confidence in the transmission line database was low. Only $4 \%$ of OLSs were intercepted by transmission lines in Indiana, and only $2 \%$ in New Mexico. There is no directional preference; all OLS headings have similar interception rates.

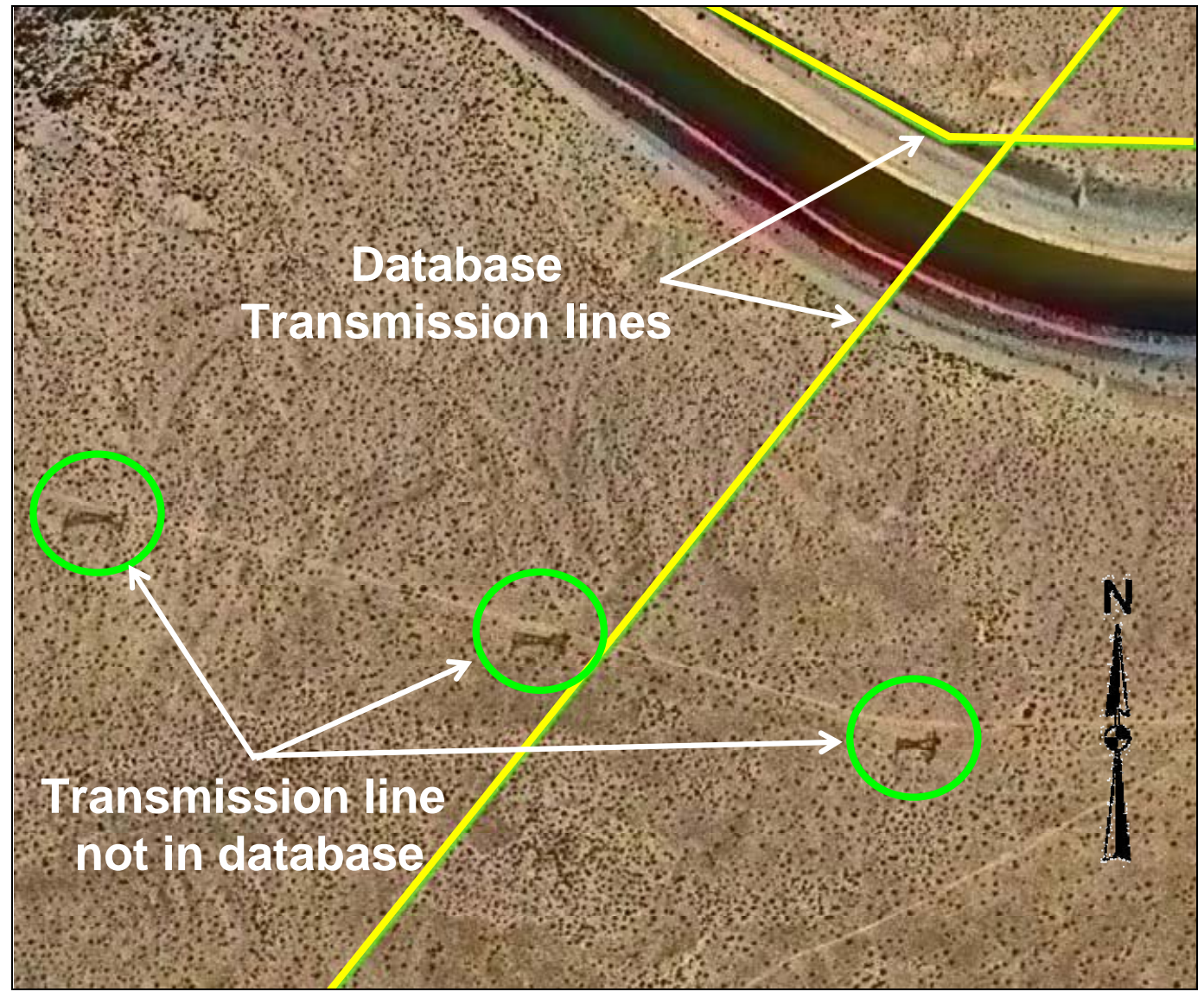

Figure 18. Area of southern California showing both undigitized transmission lines (note towers circled in green) and transmission lines digitized with no ground visual verification (yellow lines). In the latter case lines could be underground, or they could be single-pole lines and therefore are not visible in the DOQ.

Figure 19 shows a larger-scale view of Figure 18 with OLSs superimposed. Two of the blue OLSs and the two black OLSs intercept, and one crosses a tower of, the undigitized transmission line, but because the transmission 
line was not digitized, they could not recorded as interceptions. However, the blue OLSs do intercept the southwest- northeast-oriented line (yellow) discussed in Figure 18 and thus were recorded as intersecting.

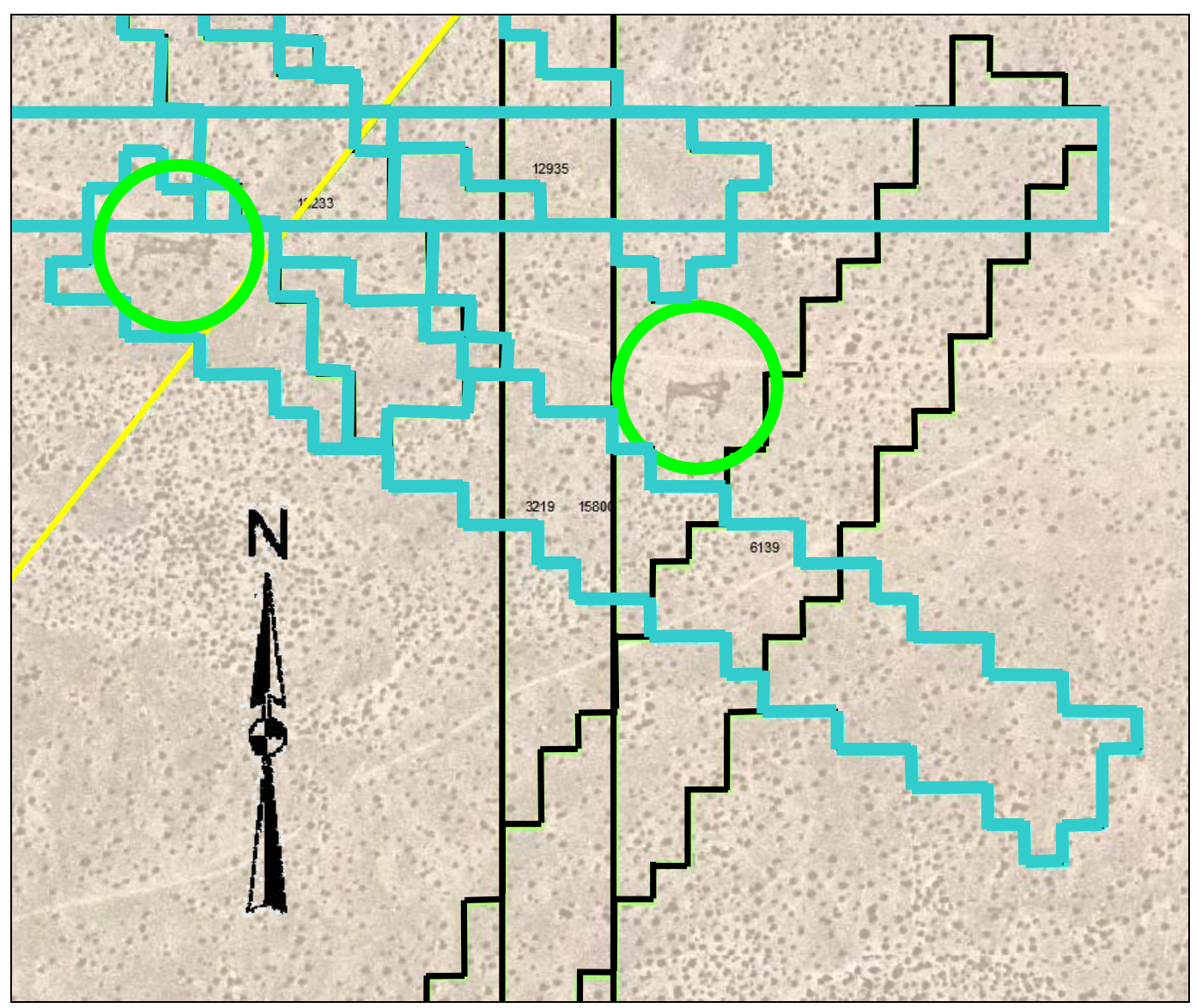

Figure 19. Interception of OLSs with digitized transmission line (yellow line) and undigitized transmission line (towers circled in green) within in subset of Figure 18. The OLSs are $930 \mathrm{~m}$ long and $90 \mathrm{~m}$ wide.

Figures 20 and 21 show the interception of north- south-oriented OLSs with GE transmission lines in southern California. In Figure 20 some OLSs intercept both roads and transmission lines. In most cases, the OLStransmission line interception is not marginal — even slight georeferencing errors would still allow interceptions. 


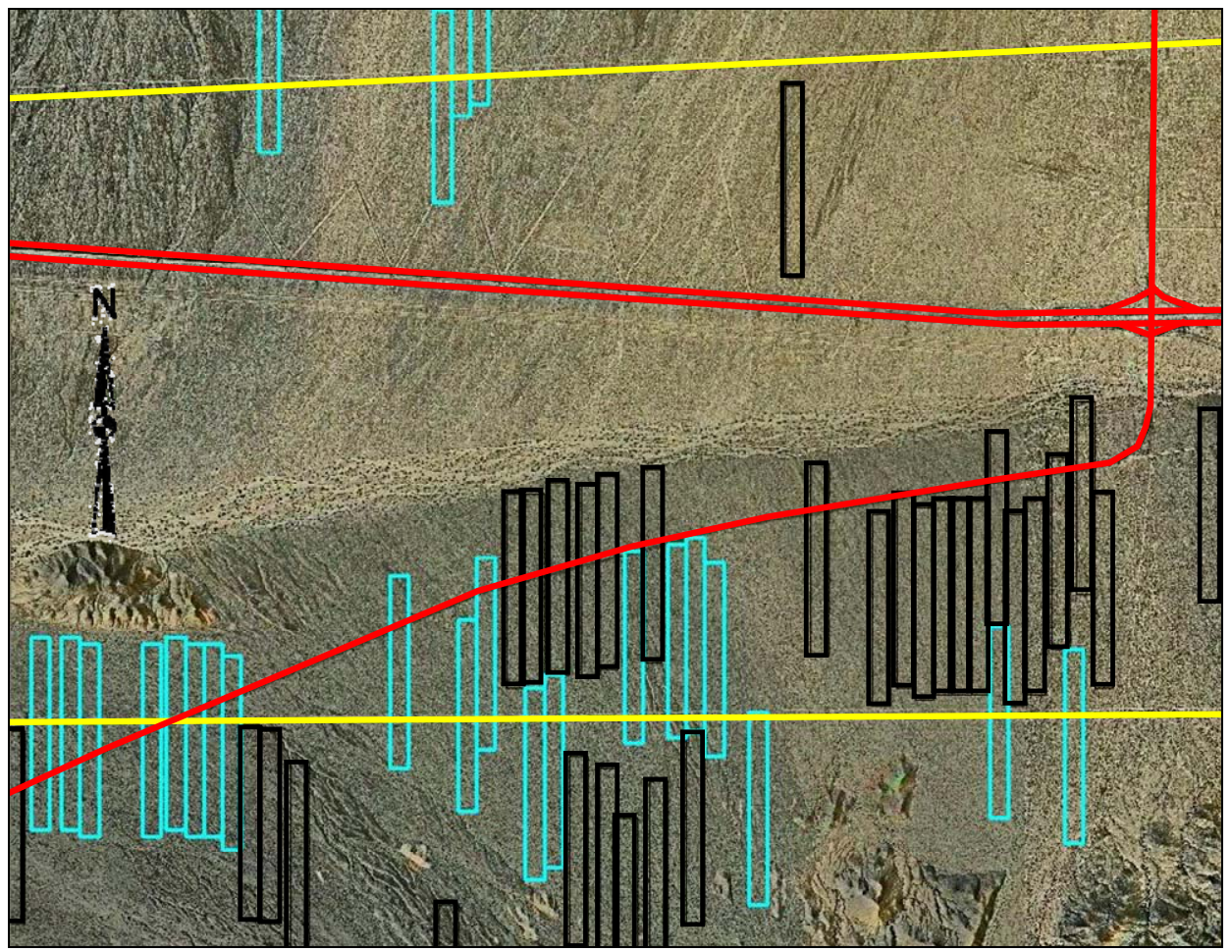

Figure 20. Intersection of transmission lines (yellow lines) with OLS runway polygons (light blue) in southern California. OLSs not intersected by transmission lines are black. Note that some OLSs intersect roads (red lines) and transmission lines. The OLSs are $930 \mathrm{~m}$ long and $90 \mathrm{~m}$ wide.

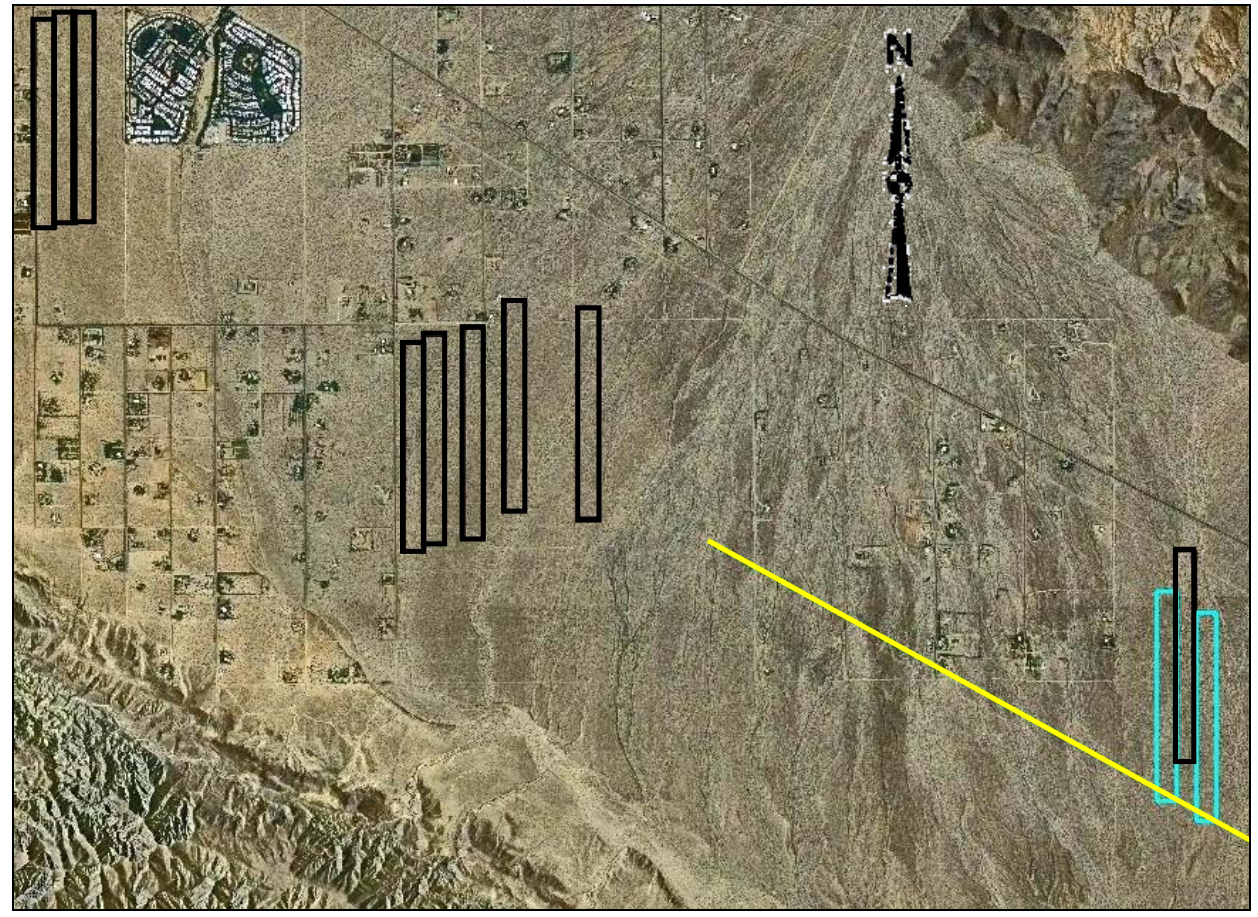

Figure 21. Intersection of transmission line (yellow line) with OLSs (light blue) in southern California. OLSs not intersected by transmission lines are black. Note how the OLSs also effectively avoid structures. The OLSs are $930 \mathrm{~m}$ long and $90 \mathrm{~m}$ wide. 
Figures 21 and 22 illustrate the effects of incomplete vector-based database coverage. Figure 21 shows the intersection of OLSs and the GE-based transmission line database. The transmission line oriented from southeast to northwest ends at approximately the center of the image, and OLSs to the west are not intercepted. However, when transmission lines from the USGS vector database are added, eight additional OLSs are intercepted (Fig. 22).

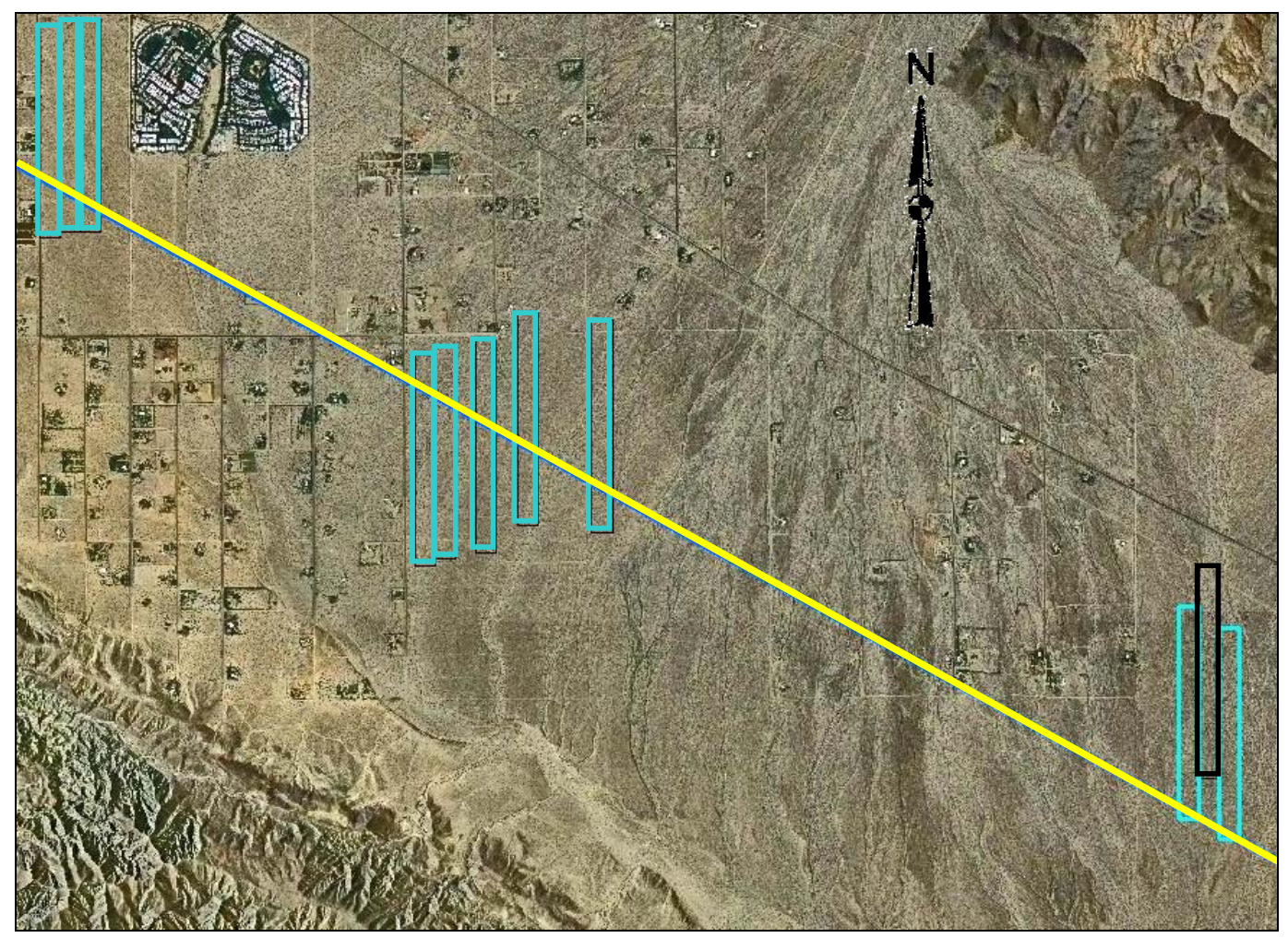

Figure 22. USGS and GE transmission lines (yellow line) together, which extend the transmission line to intersect eight additional OLSs (intersected OLS are light blue) in southern California, illustrating the effect of incomplete databases on analyses. The OLSs are $930 \mathrm{~m}$ long and $90 \mathrm{~m}$ wide. 


\section{Multiple Obstruction Interception}

Most interceptions of OLSs by roads, waterways, railroads, and transmission lines were by only one type of obstruction, as determined by the GIS intersection process. Only two OLSs in southern Indiana were intercepted by multiple obstructions, and those were both waterways and transmission lines together (Table 6). In southern California, 4.3\% of all OLSs were intercepted by multiple obstructions (Table 6). In New Mexico, 8.3\% of all OLS had multiple interceptions. The largest number in each of the three areas was roads and waterways, with decreasing numbers with waterways and transmission lines, and roads and transmission lines. In 56 cases in California, only in 6 cases in New Mexico, and in no cases in Indiana did three types of obstructions intercept OLSs: roads, waterways, and transmission lines. Some of these interceptions could be due to problems with the GE transmission line database accuracy in southern California. In no location did any OLS intercept all four obstruction themes.

Table 6. Multiple OLS and obstruction theme interceptions by location.

\begin{tabular}{|l|c|c|c|c|c|c|}
\hline \multirow{2}{*}{} & \multicolumn{2}{|c|}{ Indiana } & \multicolumn{2}{c|}{ California } & \multicolumn{2}{c|}{ New Mexico } \\
\cline { 2 - 7 } & Number & Percent & Number & Percent & Number & Percent \\
\hline Roads (R) & 12 & 8.6 & 2,251 & 12.1 & 245 & 24.9 \\
\hline Water (W) & 8 & 5.8 & 2,850 & 15.3 & 272 & 27.6 \\
\hline Railroads (RR) & 0 & 0 & 6 & 0 & 0 & 0 \\
\hline Transmission (T) & 5 & 3.6 & 1,226 & 6.6 & 9 & 0.9 \\
\hline $\begin{array}{l}\text { Total single } \\
\text { interceptions }\end{array}$ & 25 & 18 & 6,333 & 34 & 526 & 53 \\
\hline R + W & 0 & 0 & 443 & 2.4 & 73 & 7.4 \\
\hline R + RR & 0 & 0 & 3 & 0 & 0 & 0 \\
\hline R+ T & 0 & 0 & 135 & 0.7 & 2 & 0.2 \\
\hline W + RR & 0 & 0 & 1 & 0 & 0 & 0 \\
\hline W + T & 2 & 1.4 & 168 & 0.9 & 1 & 0.1 \\
\hline RR + T & 0 & 0 & 0 & 0 & 0 & 0 \\
\hline R + W + RR & 0 & 0 & 1 & 0 & 0 & 0 \\
\hline R + W + T & 0 & 0 & 56 & 0.3 & 6 & 0.6 \\
\hline R + RR+ T & 0 & 0 & 0 & 0 & 0 & 0 \\
\hline R + W + RR+ T & 0 & 0 & 0 & 0 & 0 & 0 \\
\hline $\begin{array}{l}\text { Total multiple } \\
\text { interceptions }\end{array}$ & 2 & 1 & 807 & 4 & 82 & 8 \\
\hline Total OLSs & 139 & & 18,610 & & 985 & \\
\hline
\end{tabular}


Figure 20 shows multiple OLSs being intercepted by roads and transmission lines in southern California. Figure 23 shows stream and road interceptions of a cluster of OLSs in southern California.

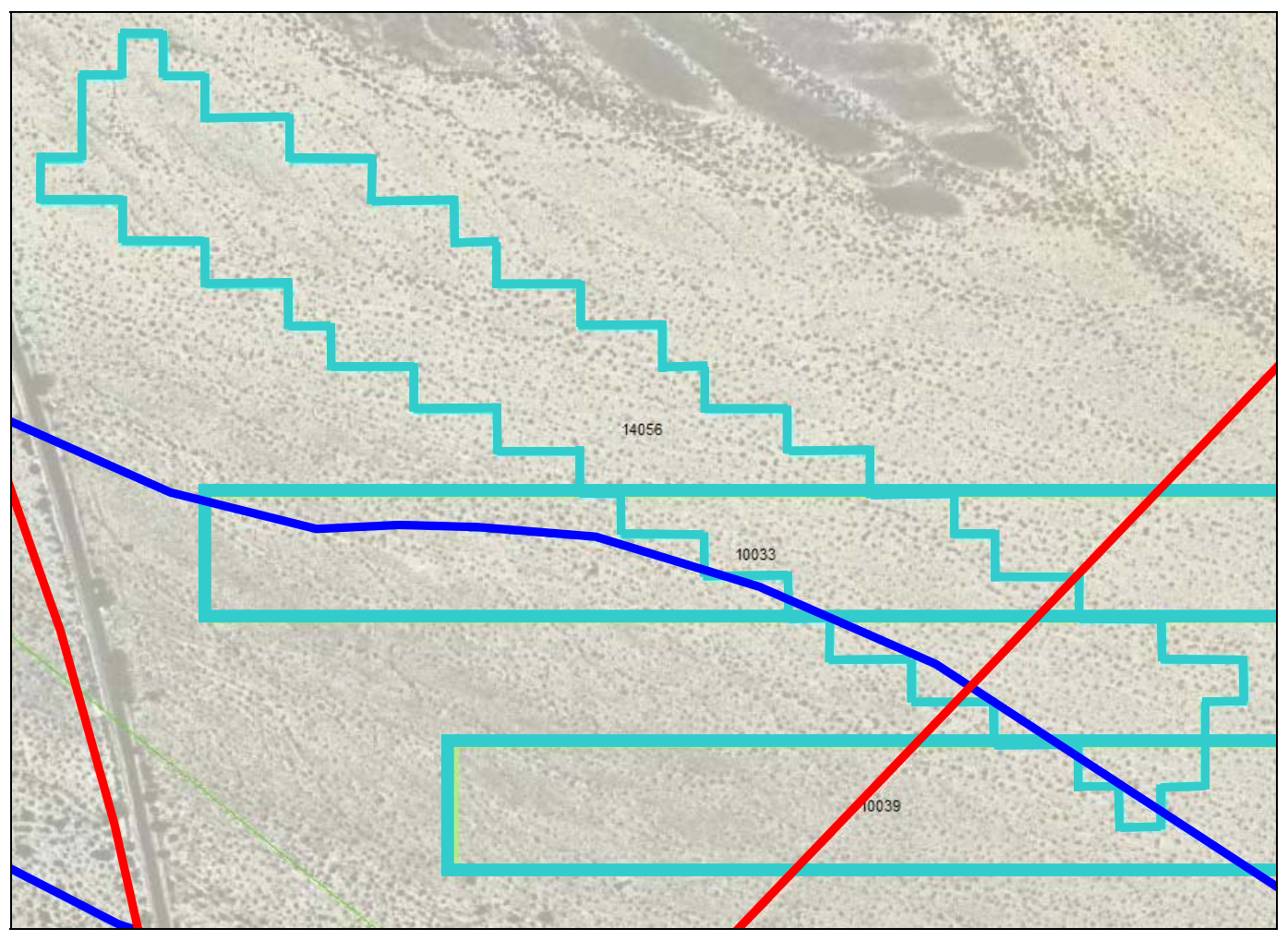

Figure 23. Multiple OLSs (light blue outlines) intercepting a stream (dark blue) and a road (red) in southern California. The OLSs are $930 \mathrm{~m}$ long and $90 \mathrm{~m}$ wide.

Figure 24 shows a road and stream crossing of an OLS in southern New Mexico. All apparent roads on the DOQ are not digitized, for an apparent road parallels the digitized road. The OLS follows the streambed in its southern half. Features in arid regions may have little contrast, especially if the vegetation is dried and has little chlorophyll. The OLS-MS software rejects areas with a green vegetation spectral signature, but not dried, brown vegetation. In addition, as a result of the relatively large Landsat pixel dimensions (30 m), areas that are not uniform may appear to be so. And, unlike humid locations where transmission lines often leave a swath cut through forest land, arid regions show little evidence of transmission line routings except for occasional access roads paralleling the tower line. 


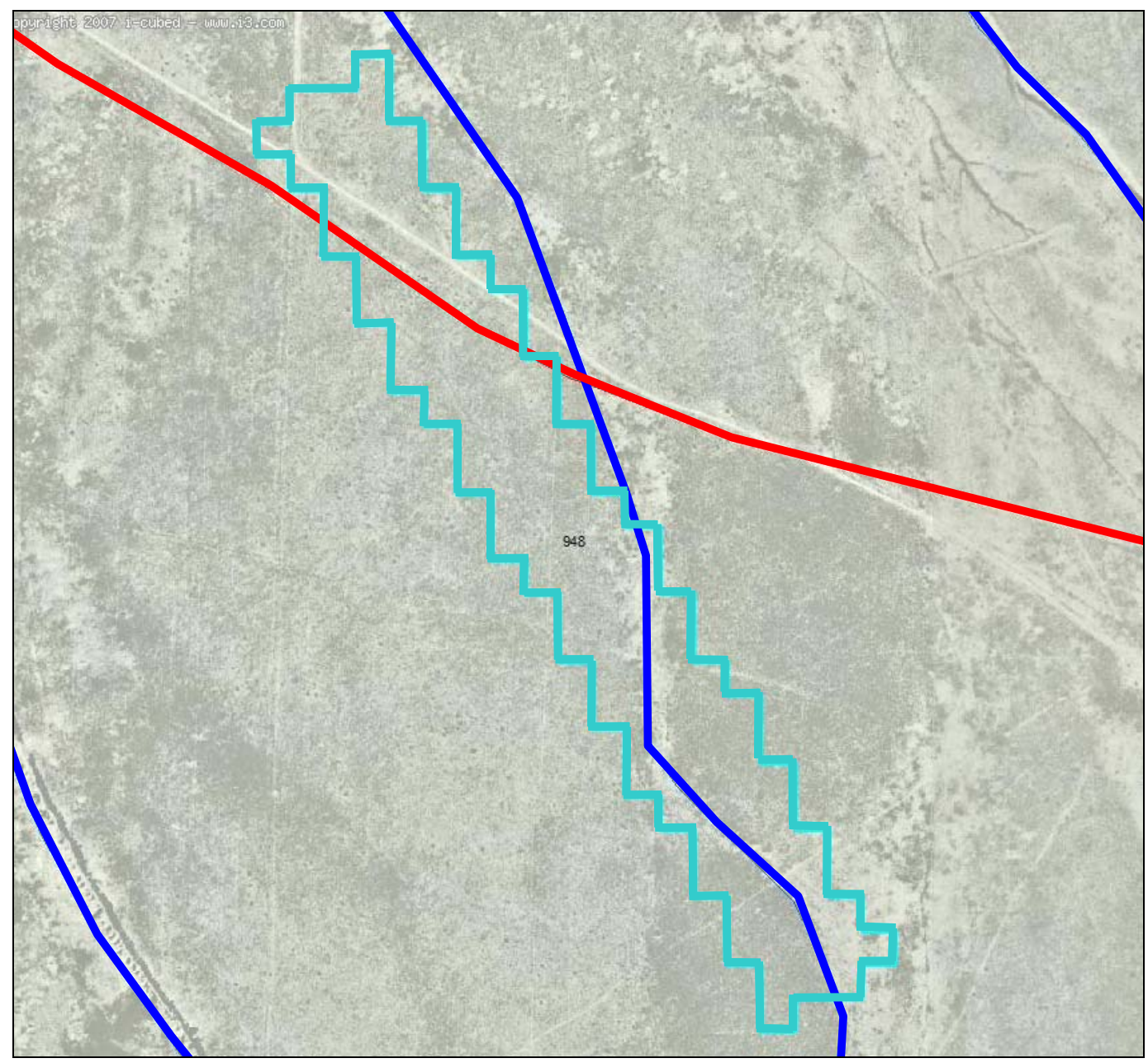

Figure 24. OLS (light blue) crossing a road (red) and a stream (dark blue) in southern New Mexico. Note that digitized streams are generally in the correct locations. The digitized road appears to be a secondary road, compared to the more prominent feature paralleling it across the OLS, which could be a pipeline or other linear disturbance if not a road. The OLSs are $930 \mathrm{~m}$ long and $90 \mathrm{~m}$ wide. 


\section{Visual Analysis}

Not all potential OLS obstructions were captured in GIS databases because of the limited number of themes that we reviewed. As a result, we also performed a visual validation of selected OLSs in each Landsat scene. Visual verification allowed us to assess the accuracy of the GIS process and to determine how significantly obstructions intercepted OLSs. For example, did obstructions graze the edges of OLSs, or did they intercept the main body of the OLSs and bisect them? In addition, it allowed an assessment of subtle features (i.e., ditches and farm roads) that may not be digitized for GIS use but still could cause problems for OLS users.

The visual analysis was conducted by overlaying OLSs and DOQs and registering them to an accuracy of about one Landsat pixel: about $30 \mathrm{~m}$ along pixel sides or $42 \mathrm{~m}$ diagonally. Also critical to the success of the process is the difference in dates between the DOQs and the Landsat images used to locate the OLSs. DOQs taken before the Landsat image are likely to include major cultural features such as roads and transmission lines that are on the Landsat image. Other than changes in position, streams should be present even if the DOQ post-dates the Landsat image.

The season in which DOQ images were acquired can also be an issue. The Landsat images used in this study were taken after leaf fall in the autumn. DOQs taken during other seasons may cause misinterpretation due to vegetation cover but also due to surface water. In addition, as indicated earlier, since DOQs are mosaics and cloud areas are eliminated, many DOQ dates can occur in one Landsat image area.

The Landsat images used in this study were all taken in October and November 2005. DOQs were taken from the Best Of The US (BOTUS) database created by I-Cubed. Each Landsat image had 59 (New Mexico) to 104 (California) DOQ images. In Indiana the DOQ images date from March 1998 through September 2004. Southern California DOQs date from J une 1996 through August 2004, and New Mexico DOQs date from J une 1996 through March 2003. All predate the Landsat images. Therefore, the databases and Landsat images should have most if not all the surface features covered by the DOQs. Our visual interpretations were sensitive to these problems. 
The following methodology was used to visually inspect OLSs. The Indiana Landsat image that we analyzed had only 139 predicted OLSs, so each OLS was visually inspected. However, the California Landsat image had 18,610 OLS, and the New Mexico Landsat image had 985. The large numbers of OLSs in California and New Mexico did not allow visual examination of each OLS. One percent of OLSs were randomly sampled in California (186), and 20\% percent were sampled in New Mexico (197). Each was assigned a number by the OLS-MS software. A random number generator in Microsoft Excel was used to select the specific OLS to inspect in each area. The GIS facilitated the process by automatically locating each OLS selected for inspection when the OLS number was entered.

Several elements of images were inspected visually. Initially, digitized obstructions were assessed for false positives and false negatives. For example, a database vector road crossing an OLS without a visual road confirmation is a false positive. However, a visual road crossing without a database vector road crossing is a false negative. Visual confirmation of a crossing is a true positive (Table 7). False positives and false negatives can be caused by vector file digitizing errors, georegistration inaccuracies, and differences in DOQ and Landsat dates and seasons.

Indiana, California, and New Mexico images were also checked for features that may not appear in the vector files used in the GIS intersection process. For example, images were checked for the presence of fences, agricultural roads, property lines that may be indicated by a physical feature, surface drainage patterns that may suggest low areas, subsurface drainage patterns that, as a result, also have surface features that may hinder aviation use, shelterbelts, and buildings.

The subjectivity of the process required careful attention to consistency. Every image was analyzed by two individuals (authors Scott and Tracy) working together and resolving differences of opinion before noting the presence or absence of features. 
Table 7. Visual feature verification.

\begin{tabular}{|c|c|c|c|c|}
\hline \multirow{2}{*}{\multicolumn{2}{|c|}{ Number of OLSs sampled }} & Indiana & California & New Mexico \\
\hline & & 139 & 186 & 197 \\
\hline \multicolumn{2}{|l|}{ Fence } & 50 & 0 & 0 \\
\hline \multicolumn{2}{|l|}{ Property Line } & 49 & 0 & 0 \\
\hline \multicolumn{2}{|l|}{ Unpaved Road } & 48 & 15 & 107 \\
\hline \multicolumn{2}{|c|}{ Agricultural Shelterbelt } & 14 & 0 & 0 \\
\hline \multicolumn{2}{|c|}{ Surface Drainage Pattern } & 51 & 115 & 110 \\
\hline \multicolumn{2}{|c|}{ SubSurface Drainage Pattern } & 11 & 0 & 0 \\
\hline \multicolumn{2}{|c|}{ Water Diversion Structure } & 0 & 3 & 0 \\
\hline \multicolumn{2}{|c|}{ Agricultural Building } & 2 & 0 & 1 \\
\hline \multicolumn{2}{|c|}{ Undefined Vegetation Clumps } & 0 & 147 & 12 \\
\hline \multicolumn{2}{|c|}{ Vegetation Limiting OLS Use } & 0 & 9 & 2 \\
\hline \multicolumn{2}{|c|}{ Lava Flow Limiting OLS } & 0 & 0 & 31 \\
\hline \multirow[t]{3}{*}{ Roads } & False Negative* & 50 & 1 & 0 \\
\hline & False Positive† & 3 & 5 & 1 \\
\hline & True Positive** & 9 & 14 & 44 \\
\hline \multirow[t]{3}{*}{ Streams } & False Negative & 10 & 1 & 0 \\
\hline & False Positive & 3 & 20 & 13 \\
\hline & True Positive & 5 & 12 & 39 \\
\hline \multirow[t]{3}{*}{ Water Body } & False Negative & 3 & 0 & 0 \\
\hline & False Positive & 0 & 0 & 0 \\
\hline & True Positive & 0 & 0 & 0 \\
\hline \multirow[t]{3}{*}{ Railroads } & False Negative & 0 & 0 & 0 \\
\hline & False Positive & 0 & 0 & 0 \\
\hline & True Positive & 0 & 0 & 0 \\
\hline \multirow{3}{*}{$\begin{array}{l}\text { Transmission } \\
\text { Lines }\end{array}$} & False Negative & 0 & 1 & 0 \\
\hline & False Positive & 0 & 10 & 1 \\
\hline & True Positive & 5 & 2 & 0 \\
\hline
\end{tabular}

* False negative: visual without vector confirmation.

†False positive: vector without visual confirmation.

** True positive: vector with visual confirmation.

\section{Southern Indiana}

Interpretation of features on DOQs in agricultural areas is difficult because of the often small size of features such as fences, ditches, and agricultural roads and because there is often some change in the appearance of features with season and over time. However, because of the unavailability of DOQs in multiple seasons for these locations, results must be interpreted based on what is available. 
The southern Indiana landscape is dominated by agricultural land use. As a result, fields are the most significant feature, and OLSs are typically located in these fields. Fields are often separated by fences and one-lane unsurfaced agricultural roads that may or may not be raised above the surrounding fields or drainage ditches. Fields are also separated by "property lines," features that are often difficult to distinguish as a distinct physical feature but are certainly visible. Shelterbelts also form the boundaries of fields.

Table 7 indicates that approximately $36 \%$ of the southern Indiana OLSs were crossed by fences, property lines, or agricultural roads. Occasionally the OLS was also crossed by a shelterbelt. These are most effectively shown by example.

Figure 25 shows an Indiana OLS crossed by a semi-permanent agricultural road. The connectivity of the feature with other roads and apparent driveways, its similar visible signature to other roads, and large trees along the right-of-way suggests that it is a permanent road that was not digitized.

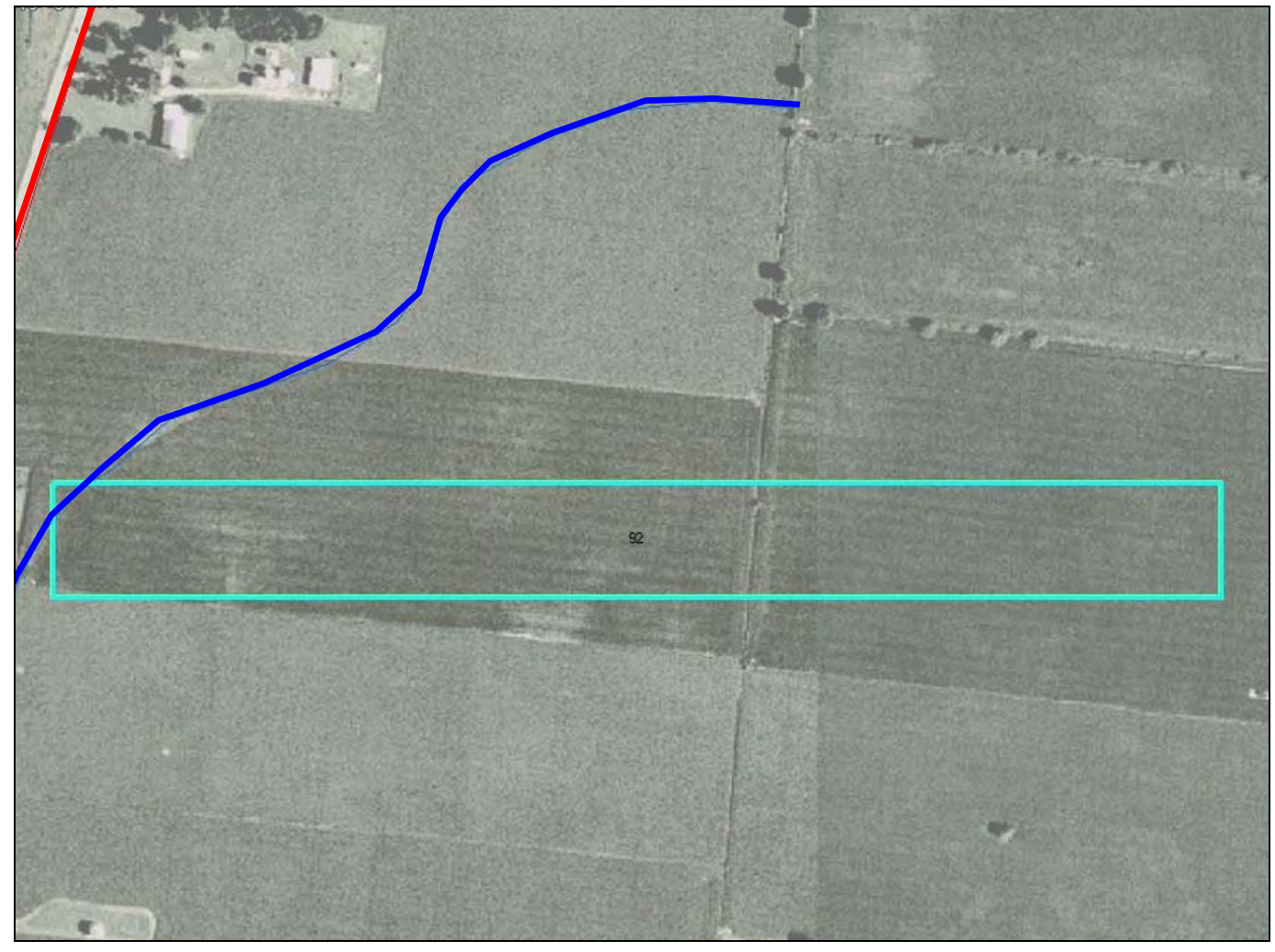

Figure 25. OLS in Indiana crossed by an undigitized agricultural road. The OLS is 930-m long and $90-\mathrm{m}$ wide. 
Figure 26 shows seven OLSs that cross a north- south feature that turns abruptly westward at it southern end. It may be visually classified as a fence row, a property line, or a road. It could also possibly be a drainage ditch. It is not clear whether it is a hazard to aviation, but it would require on-the-ground inspection, or checking with a low-flying unmanned aerial system (UAS), prior to use of the OLS for landing larger aircraft.

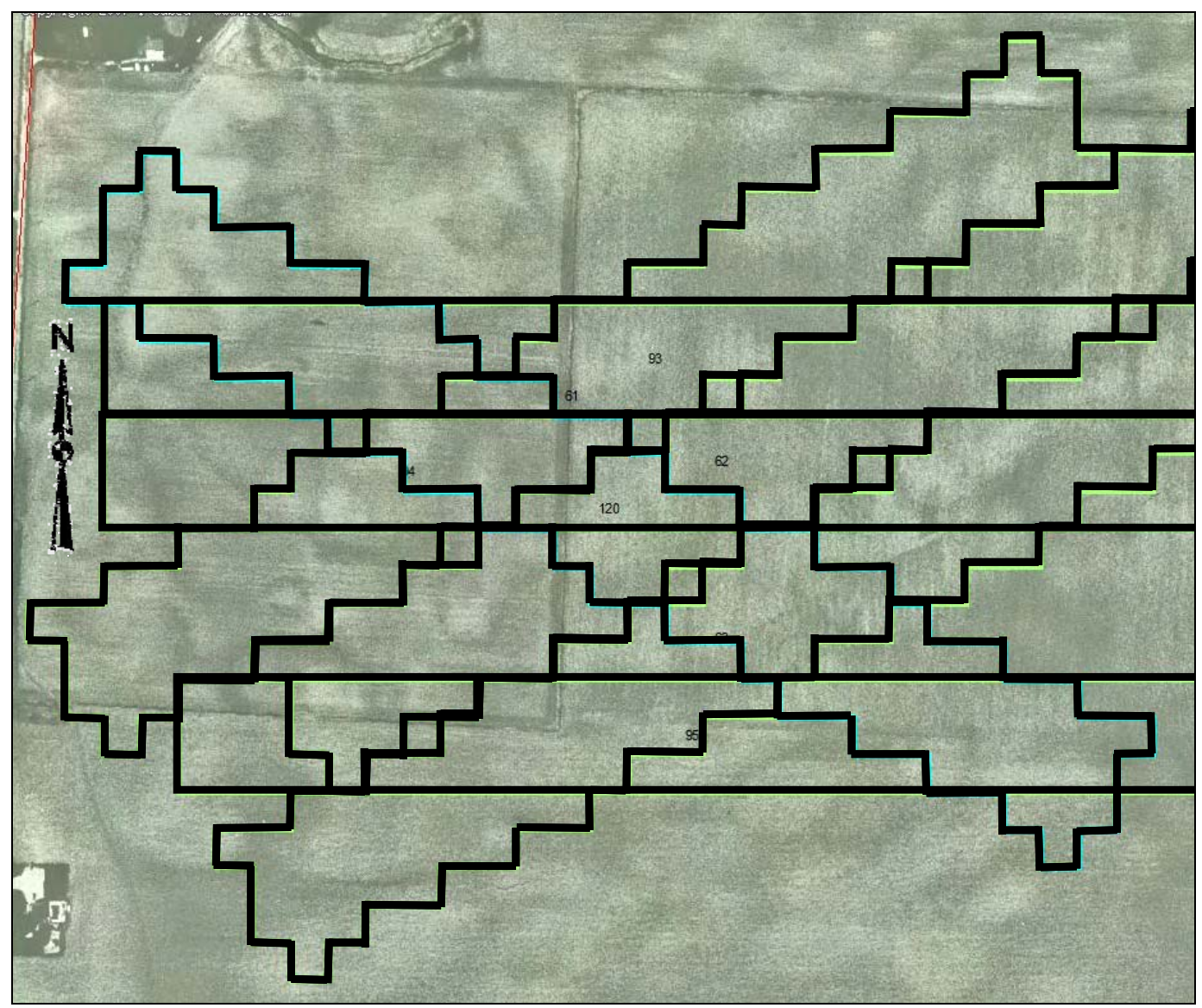

Figure 26. Seven OLSs in southern Indiana. Each OLS is being crossed all, or in part, by a north-south feature that was not digitized in the vector files. The OLSs are $930 \mathrm{~m}$ long and $90 \mathrm{~m}$ wide.

Figure 27 shows a north- south-oriented shelterbelt crossing an OLS. It is not a digitized feature, but it is apparently a semi-permanent feature because trees and bushes appear to be growing along it. Since the Landsat image for this area was taken one to nine years after the DOQ, the shelterbelt may have been removed prior to the November 2005 Landsat image. However, since the Landsat image was taken in November and is located in Indiana, the vegetation in the shelterbelt is most likely deciduous, so the shelterbelt may have been less evident in the Landsat image. This suggests that OLS-MS analyses of imagery taken after leaf-fall in areas dominated 
by deciduous vegetation may miss this kind of feature, especially with their narrow, subpixel thickness (pixel size is clearly evident along the stepped OLS border).

Surface drainage patterns are also possibly evident in Figure 27 in the northern end of the OLS. However, rather than a contemporary drainage problem, this could also be a soil feature resulting from relict glacial drainage patterns from the end of the Illinoian glaciation period approximately 150,000 years ago. Figure 28 also shows a similar feature at the northern end of the OLS.

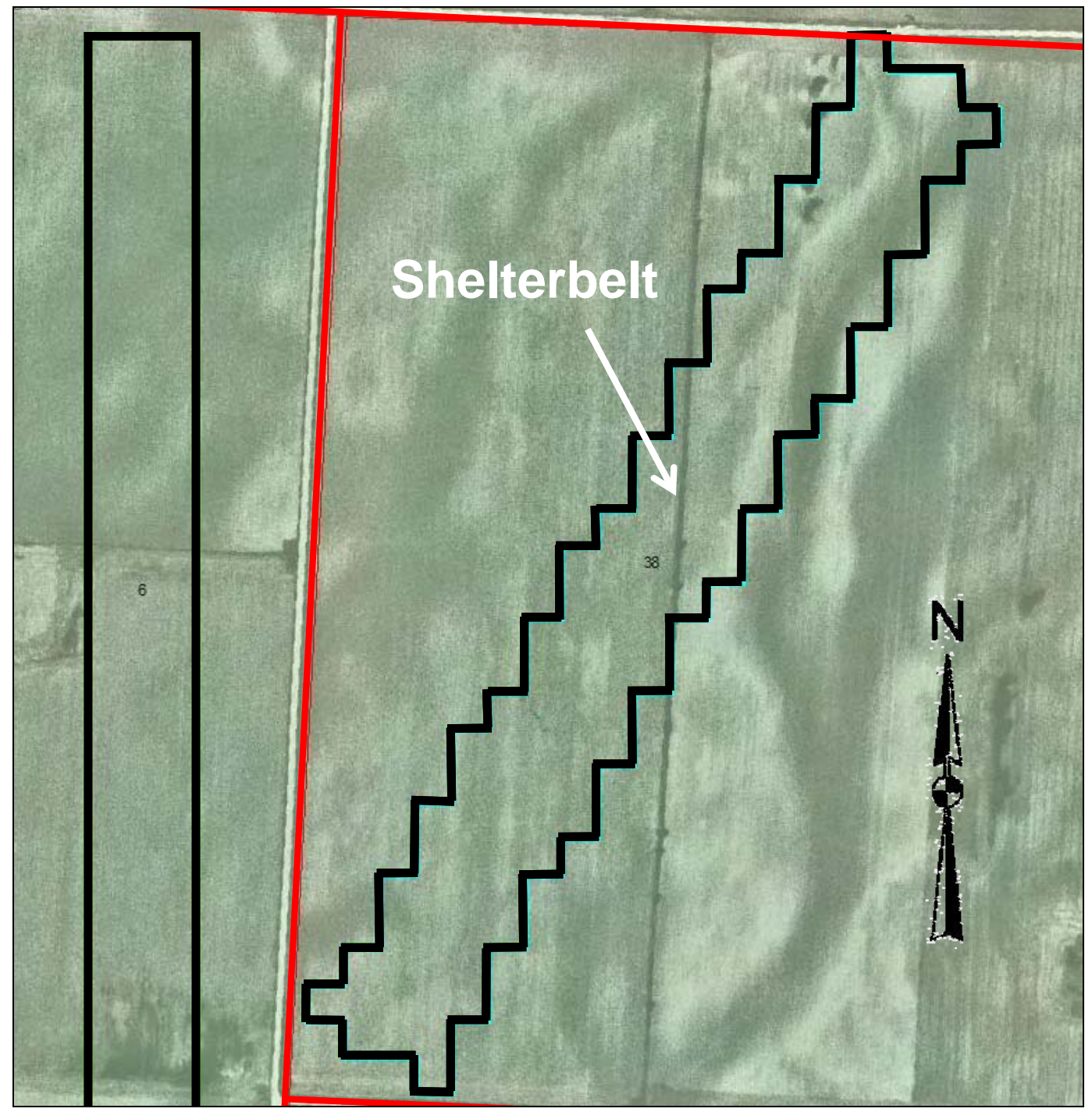

Figure 27. Apparent north-south-oriented shelterbelt crossing a black-outlined northeastsouthwest-oriented OLS. The OLSs are $930 \mathrm{~m}$ long and $90 \mathrm{~m}$ wide. 


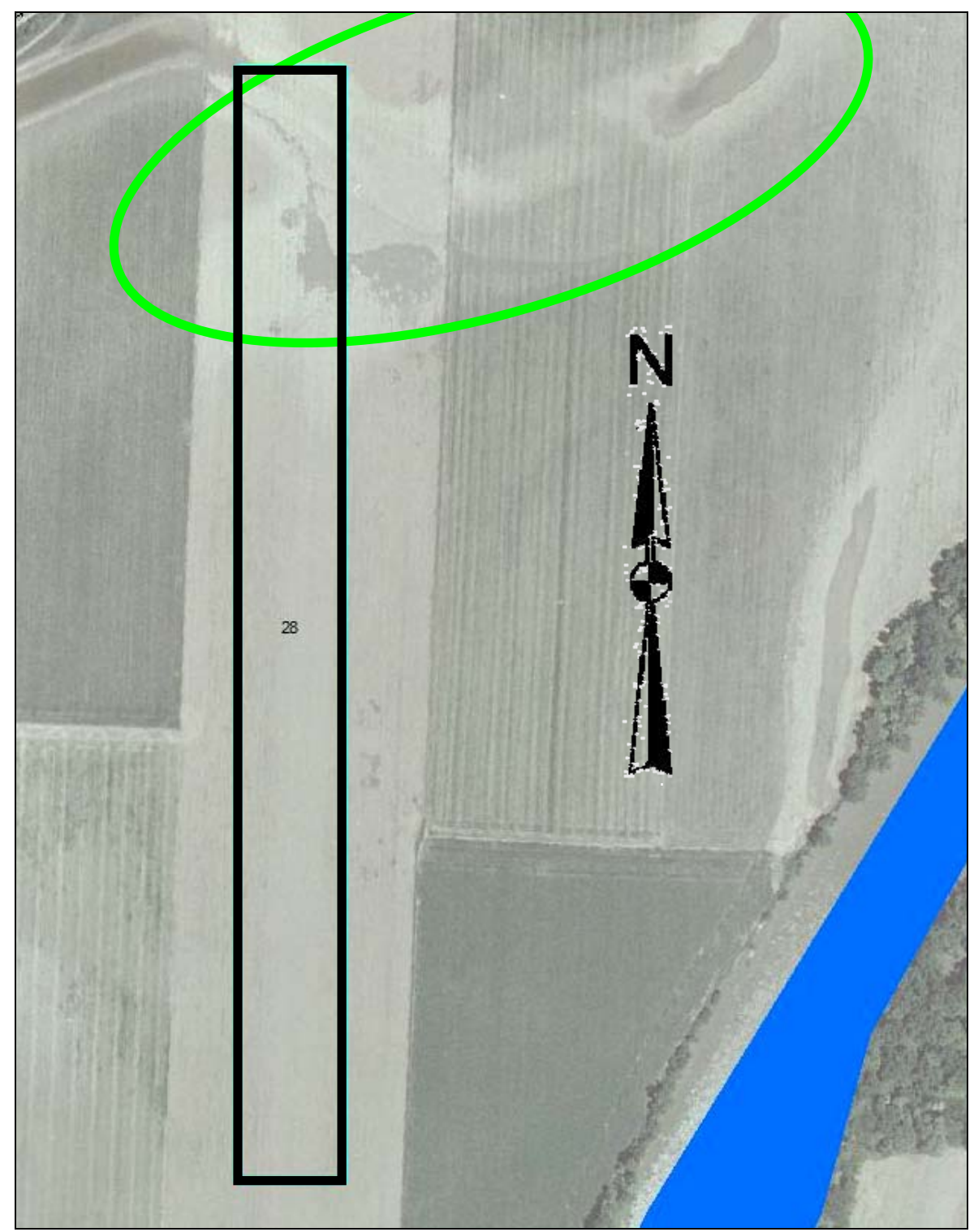

Figure 28. Possible relict surface drainage feature at the north end of an OLS. The OLS is $930 \mathrm{~m}$ long and $90 \mathrm{~m}$ wide. The blue area is a river.

Apparent subsurface drainage patterns are visible at the surface as a chevron pattern pointing southward through the center of the OLS in Figure 29. Though these features, if interpreted correctly, may not significantly hinder aircraft operations, they represent possible wet locations, and they may be expressed as a localized low area in the OLS. Similar areas were observed at the North Vernon Airport study site by Barna et al. (2008) as low-relief drainage areas. 


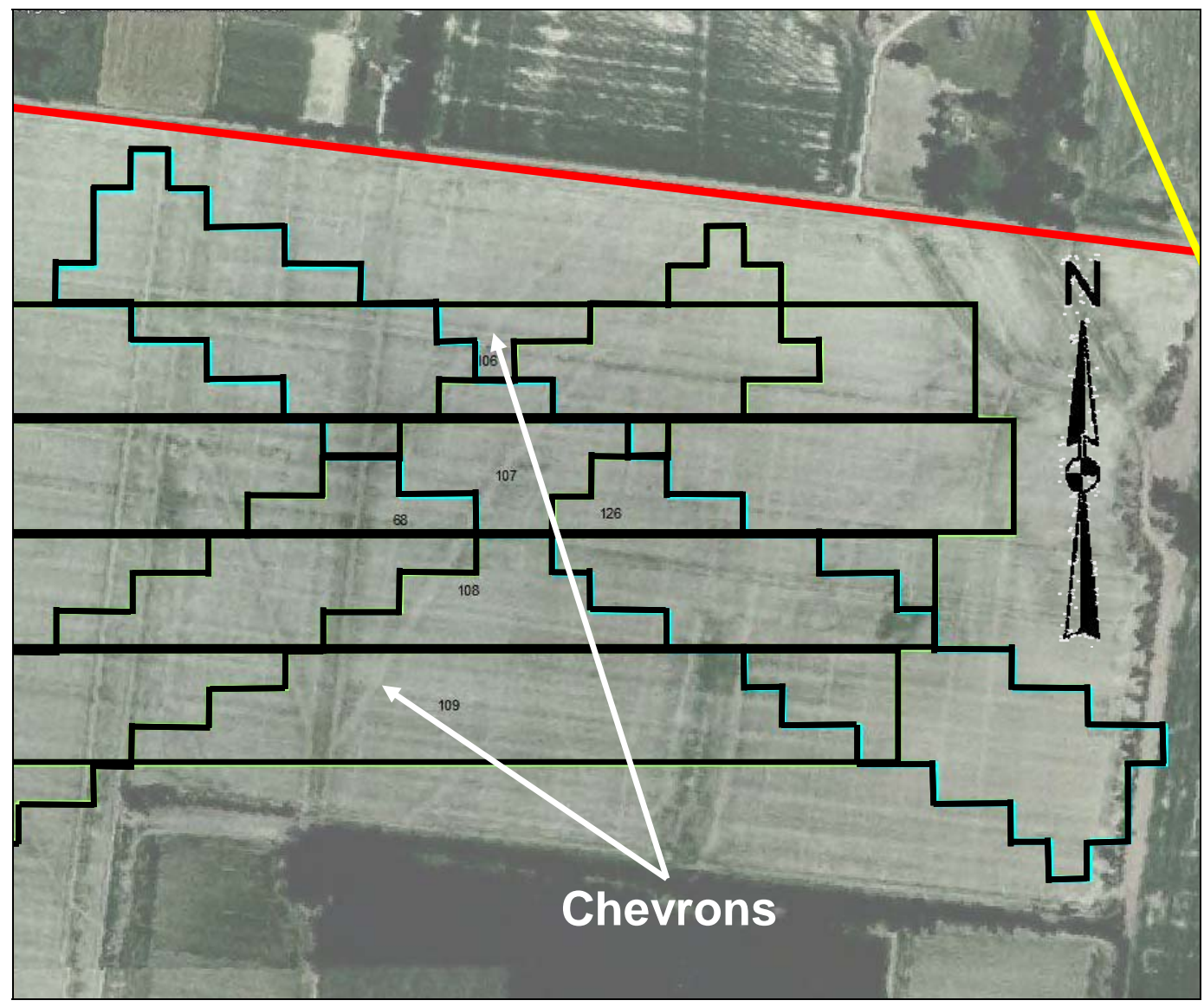

Figure 29. Chevron-shaped apparent subsurface drainage features crossing OLSs. The OLSs are $930 \mathrm{~m}$ long and $90 \mathrm{~m}$ wide. The red line is a road, and the yellow line is a transmission line.

Overall, the majority of false negatives were roads that can be largely classified as agricultural roads. The GIS vector databases do not include these, and they are apparently the greatest hazard in southern Indiana that may be missed by the GIS intersection process.

\section{Southern California}

Southern California is an arid environment with few trees but large amounts of shrub-type vegetation. In addition, since most of the area is not agricultural, and again because of the aridity, "unofficial" roads and dirt tracks remain as desert features for many years after only a few passages of vehicles. Since there is little private land and hindrance from trees, overland travel is common, causing many trails and tracks to be formed. 
One feature common to most OLSs in southern California, in addition to tracks in the desert, are clumps of vegetation such as from mesquite bushes. It is unknown from the DOQs whether these clumps are sufficiently large or woody to hinder aviation ground operations, but they are common.

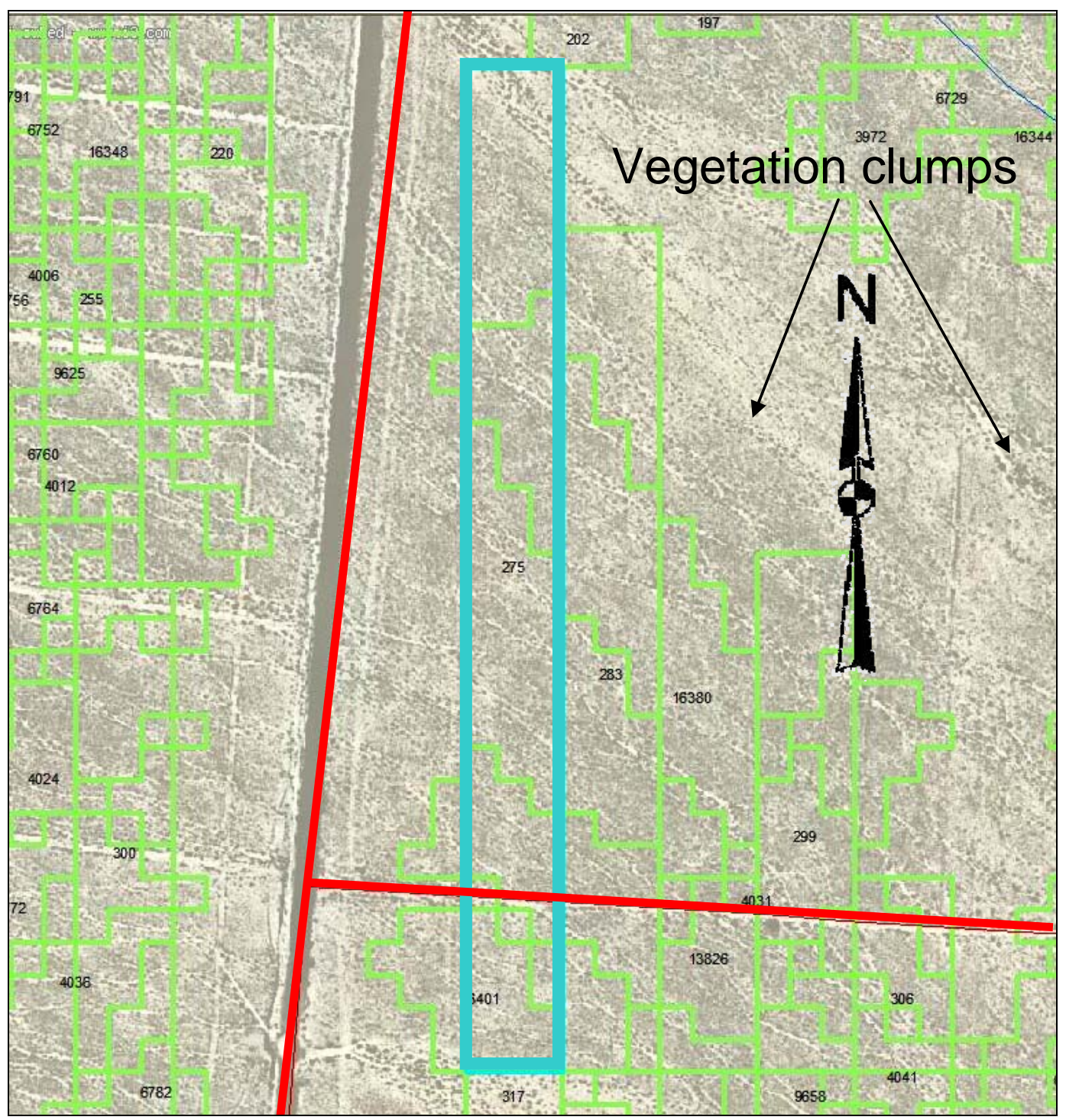

Figure 30. OLS (outlined in light blue) crossed by an unpaved road (red line) near its southern end. The dark areas are vegetation clumps, and the large numbers of light green lines signify the borders of large numbers of adjacent OLSs. The OLSs are $930 \mathrm{~m}$ long and $90 \mathrm{~m}$ wide.

Figure 30 shows a north- south OLS being crossed by a digitized unpaved road. Note the vegetation clumps on the OLS, and the unpaved tracks or roads crossing many OLSs on the west side of the north-south primary road, which is itself avoided by the OLS. 
The north- south-oriented OLS highlighted in black in Figure 31 avoids a multiple lane highway to its north. However, it is crossed by an east- westoriented transmission line that is not verifiable on the DOQ. Either the line does not exist, or it may be an underground line or a single-pole line that is too small to see on the DOQ. The vegetation is clumped and spaced evenly so that it may appear as a uniform signature on the Landsat imagery, providing the suggestion that the surface has no obstructions. Small, evenly spaced obstructions uniformly distributed over the OLS can disappear in the large Landsat pixels, as we observed on Ft. Bliss early in the OLS program (Affleck et al. 2008a).

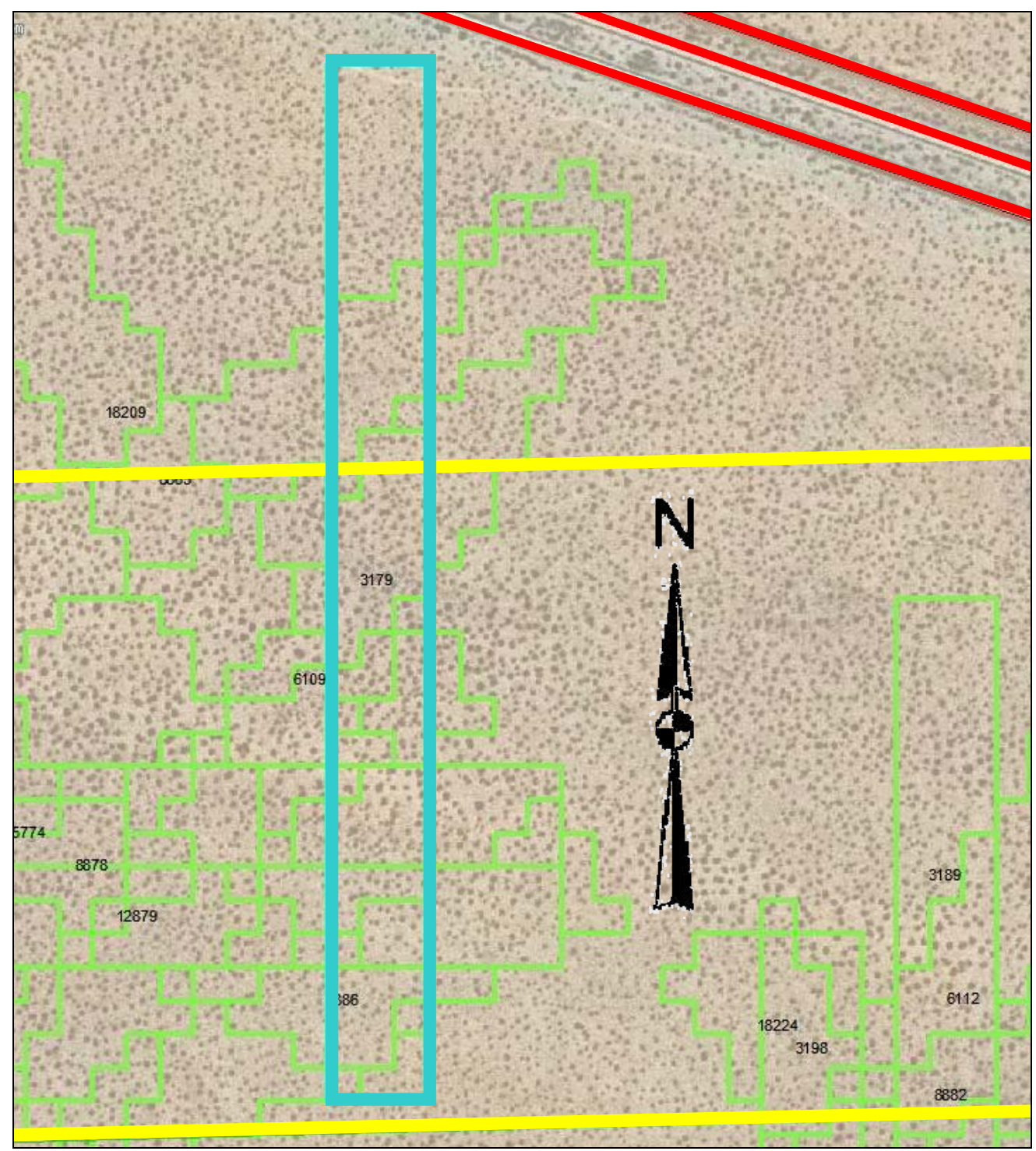

Figure 31. OLS, outlined in light blue, avoiding a multiple lane highway but crossed by an unconfirmed transmission line. Note the dark vegetation clumps and the large numbers of faint green lines signifying the borders of large numbers of adjacent OLSs. The OLSs are $930 \mathrm{~m}$ long and $90 \mathrm{~m}$ wide. 
Figure 32 shows a pair of OLSs. The easternmost OLS crosses apparent dunes that are several hundred feet long and could present a hazard to aircraft movement. Figure 33 shows another OLS cluster crossed by a road and water vectors. The road cannot be visually confirmed, so it may be a minor feature. The streams appear to characterize the drainage pattern of the area, but only the northernmost drainage feature appears significant, and it is largely avoided by the OLS.

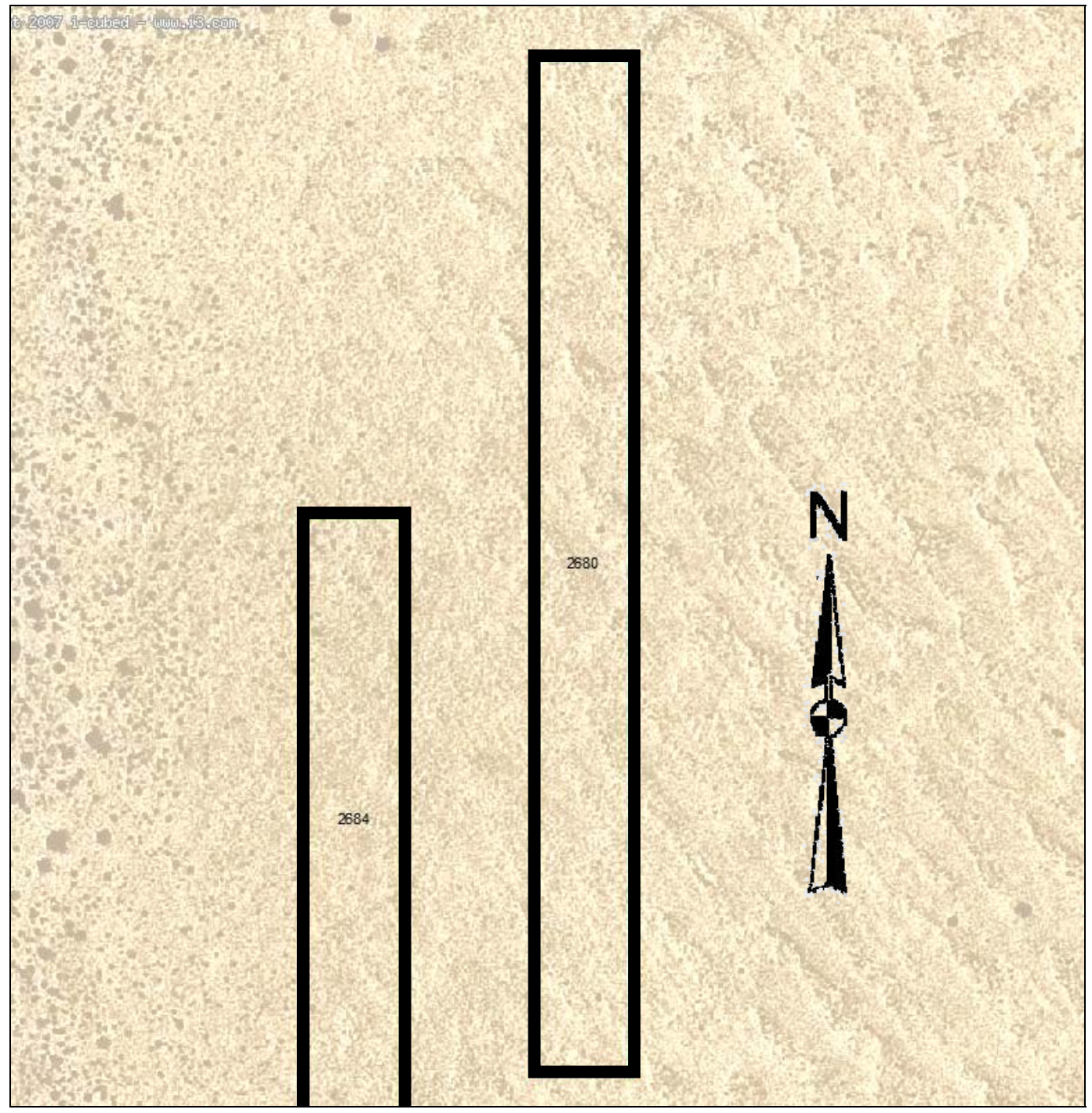

Figure 32. OLS (easternmost) crossing a dune field that could have sufficient soft sand and relief to hamper aircraft ground operations. The OLSs are $930 \mathrm{~m}$ long and $90 \mathrm{~m}$ wide. 


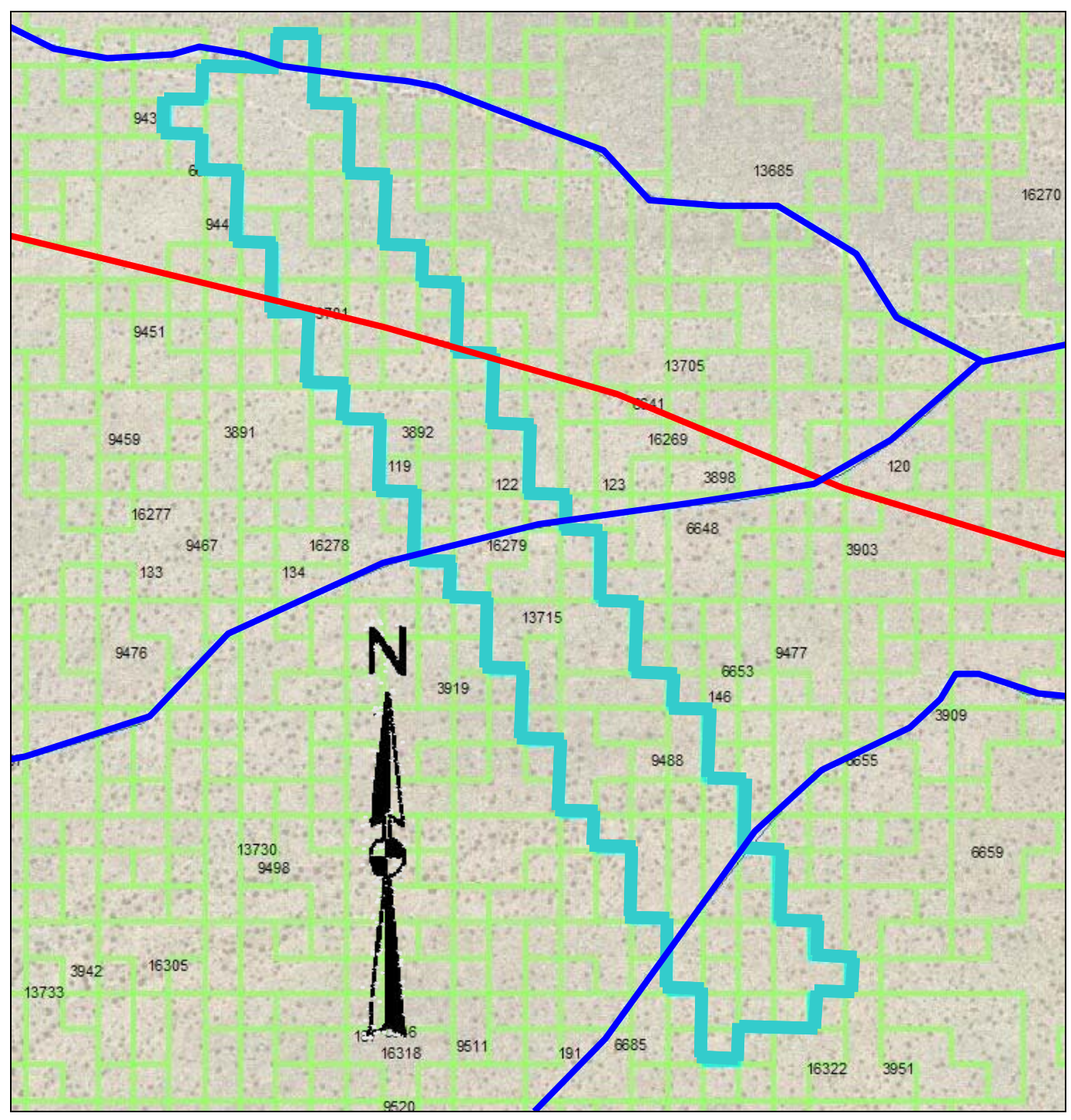

Figure 33. OLS, outlined in light blue, crossed by a road (red) and drainage features (dark blue). The light green pattern represents the outlines of many crossing OLSs in the area. The OLSs are $930 \mathrm{~m}$ long and $90 \mathrm{~m}$ wide.

Figure 34 shows an OLS cluster that avoids a dark feature, perhaps a lava field, to the northeast and streams to the southwest. However, the area is streaked with drainage features that would require on-the-ground inspection to determine their impact on OLS surface quality. 


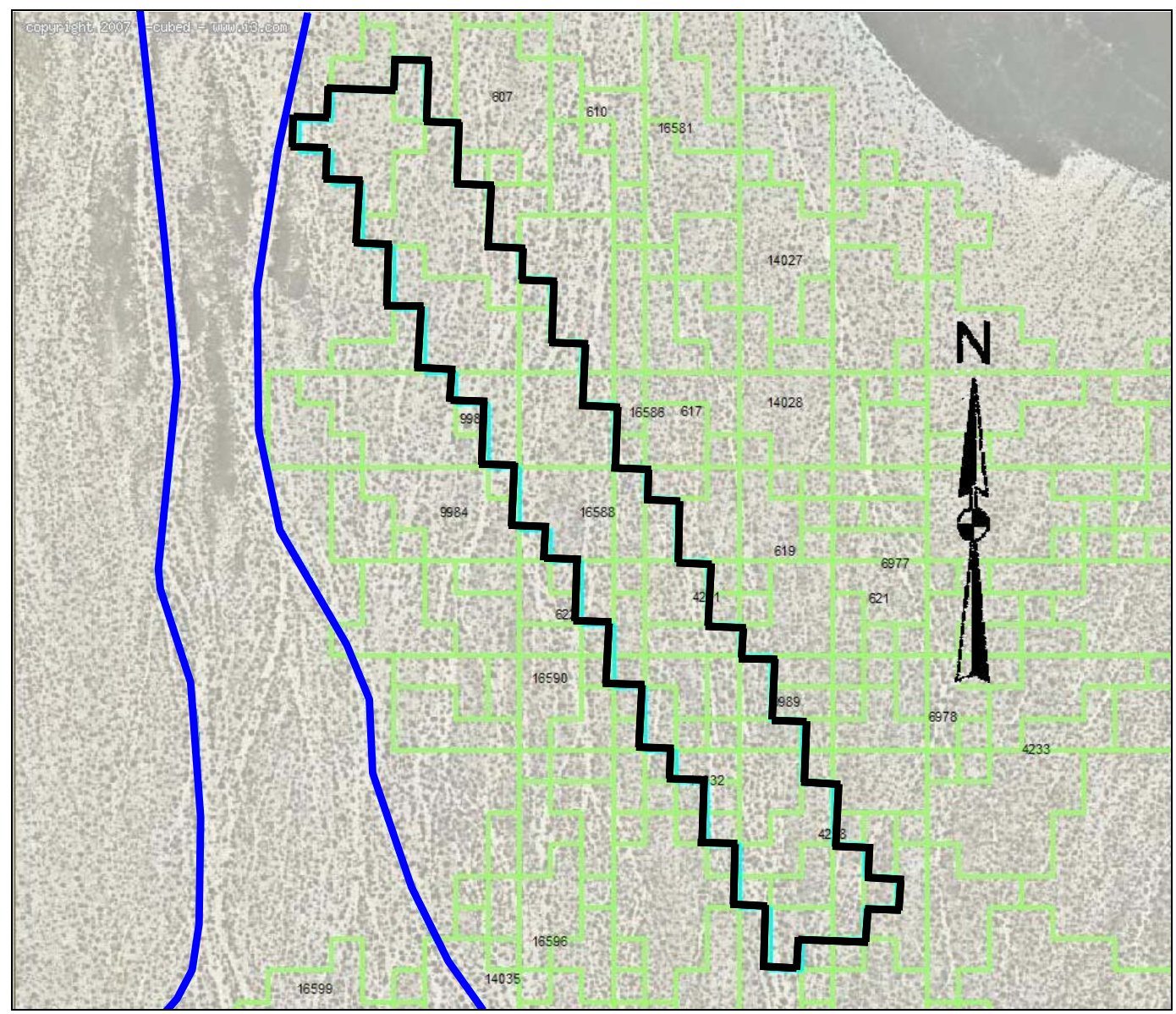

Figure 34. OLS, outlined in black, avoiding streams to the west and a lava field to the northeast, as do the surrounding light green OLSs. The OLSs are $930 \mathrm{~m}$ long and $90 \mathrm{~m}$ wide.

Figure 35 avoids a road to the northwest but crosses a less prominent, but digitized, road to the southeast. There is disagreement between the location of the road in the southeast and the digitized vector. Note how the surrounding OLS cluster avoids the prominent northwest road and the apparent drainage feature to the southwest. Figure 36 shows a nearly ideal OLS, except perhaps for vegetation; the OLS appears to be smooth, free of significant obstructions, and parallel to the road allowing access to the airfield. 


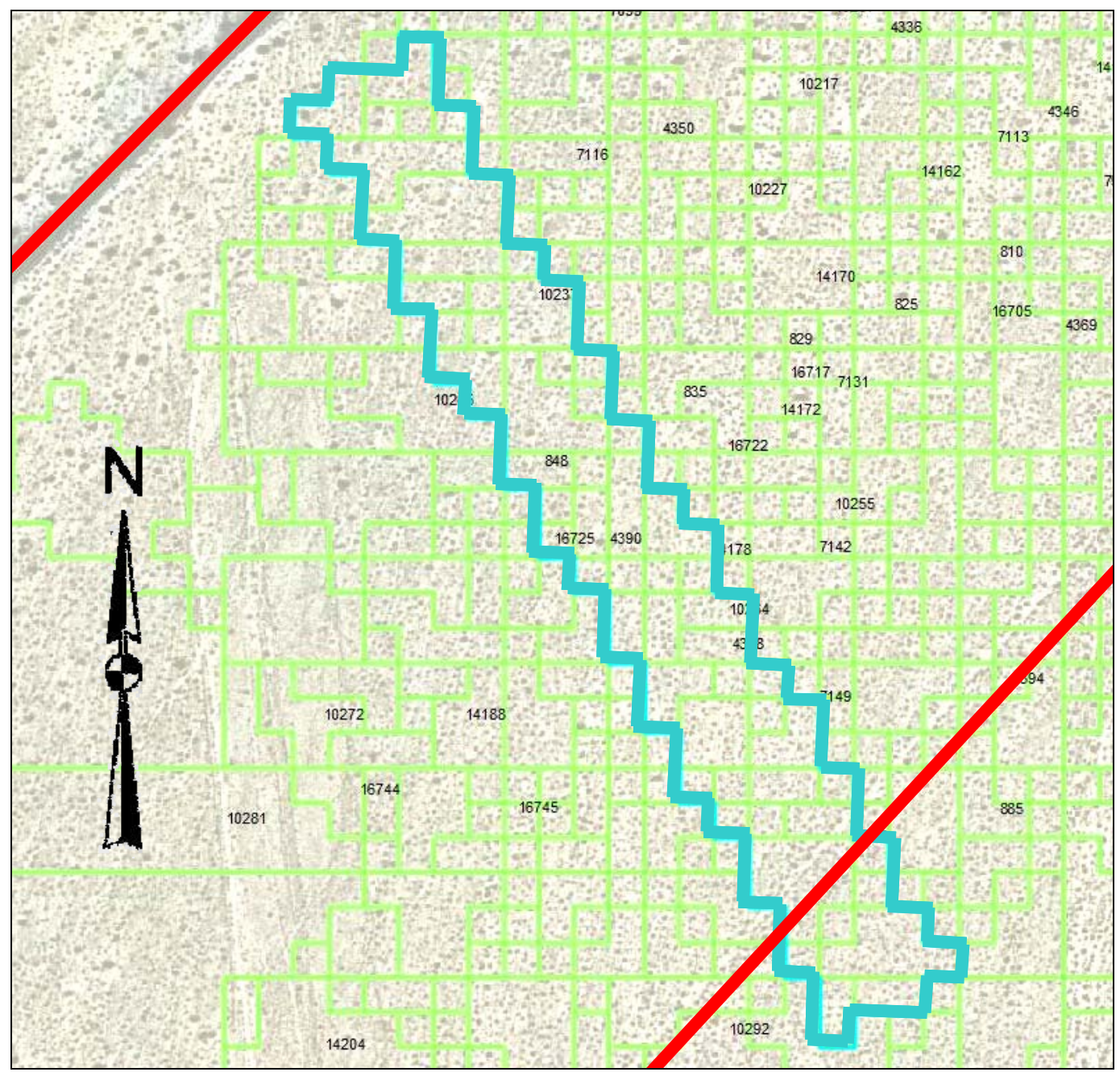

Figure 35. Northwest-southeast-oriented OLS (outlined in light blue) avoiding road (red line) to the northwest but crossing a road (red line) to southeast. The complex of light green lines signifies many crossing OLSs in the area.The OLSs are $930 \mathrm{~m}$ long and $90 \mathrm{~m}$ wide. 


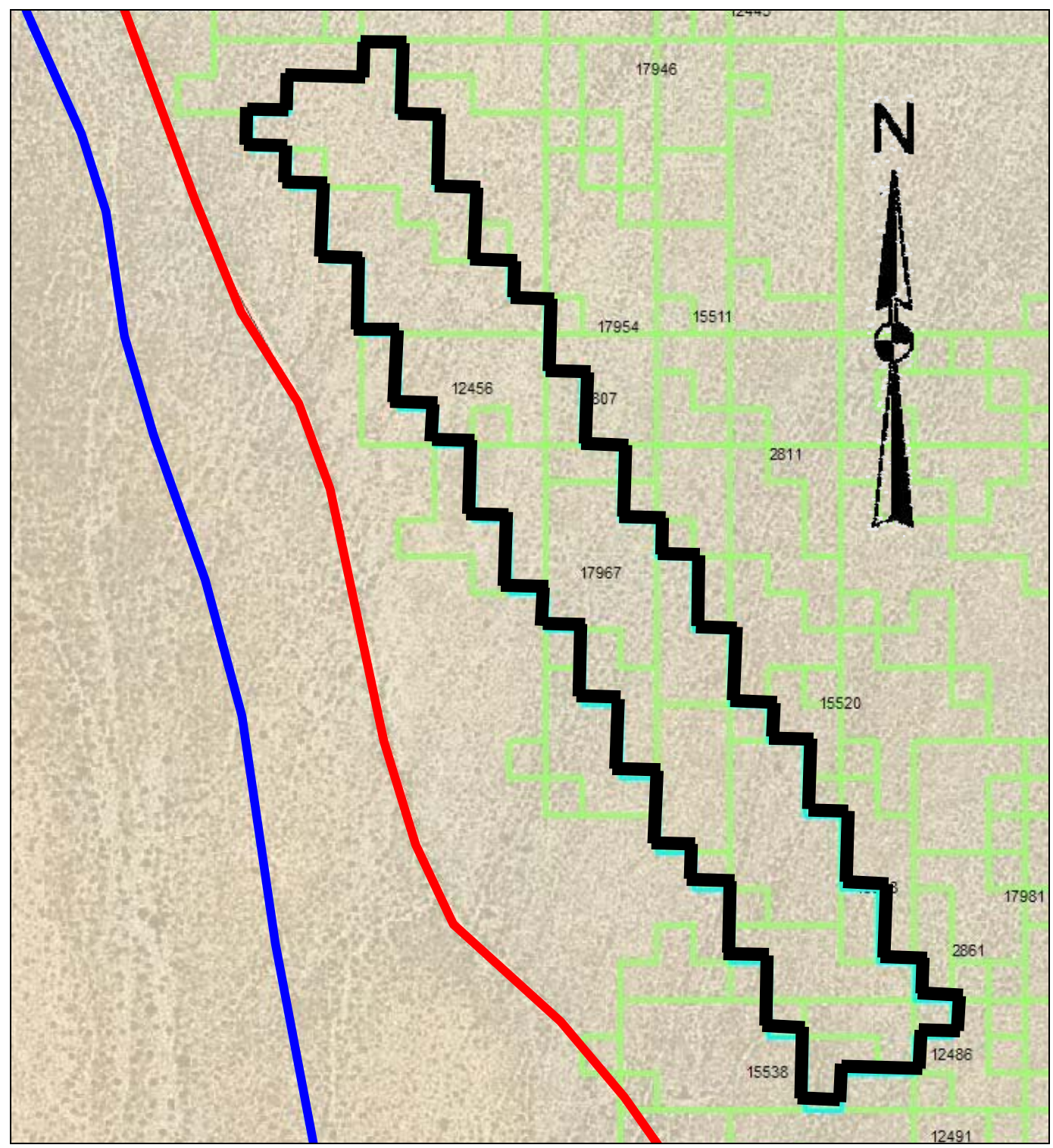

Figure 36. OLS, outlined in black, located alongside and avoiding a road (red) and a stream (blue). The light green outlines signify the locations of many OLSs in the vicinity. The OLSs are $930 \mathrm{~m}$ long and $90 \mathrm{~m}$ wide.

\section{Southern New Mexico}

Southern New Mexico is also arid and similar to southern California. Because of this, the intersections of features with OLSs are also similar.

Desert drainage features are often fine, braided structures (Fig. 37). In this case, the OLS outlined in black avoids the digitized water body but crosses relatively prominent washes that, at times, could be moist and perhaps less firm than surrounding areas. They could also be incised into the desert floor. 


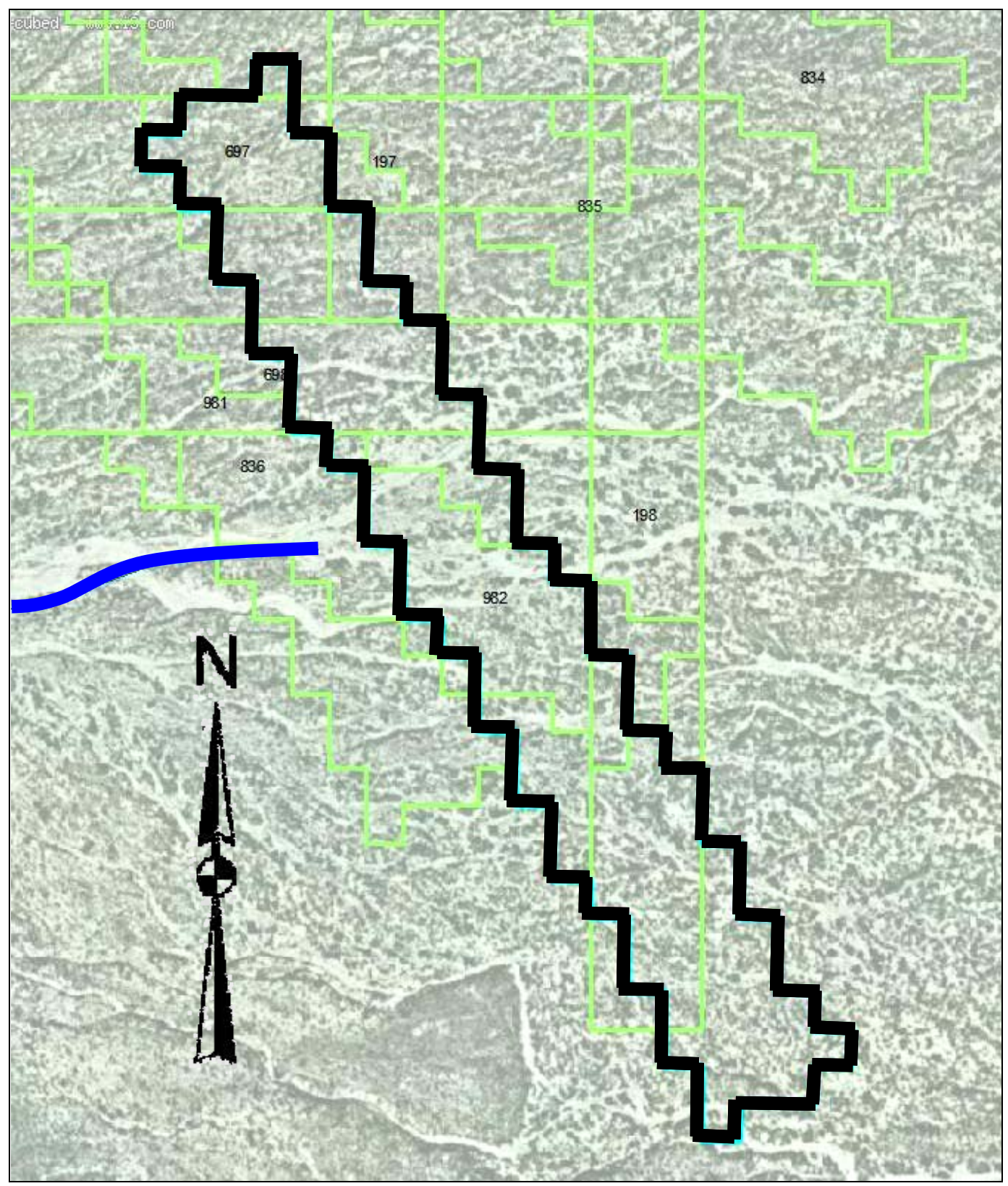

Figure 37. OLS (outlined in black) crossing drainage features. The blue line is a digitized stream, and the light green pattern outlines the edges of other OLSs in the area. The OLSs are $930 \mathrm{~m}$ long and $90 \mathrm{~m}$ wide.

Figure 38 shows an OLS that is well located parallel to and between two streams. It is likely higher, and thus drier, than the streams since it is located in an interfluve. A cluster of OLSs to the northeast do cross a road, which, if not incised as some unpaved roads are, would cause few ground operation difficulties. 


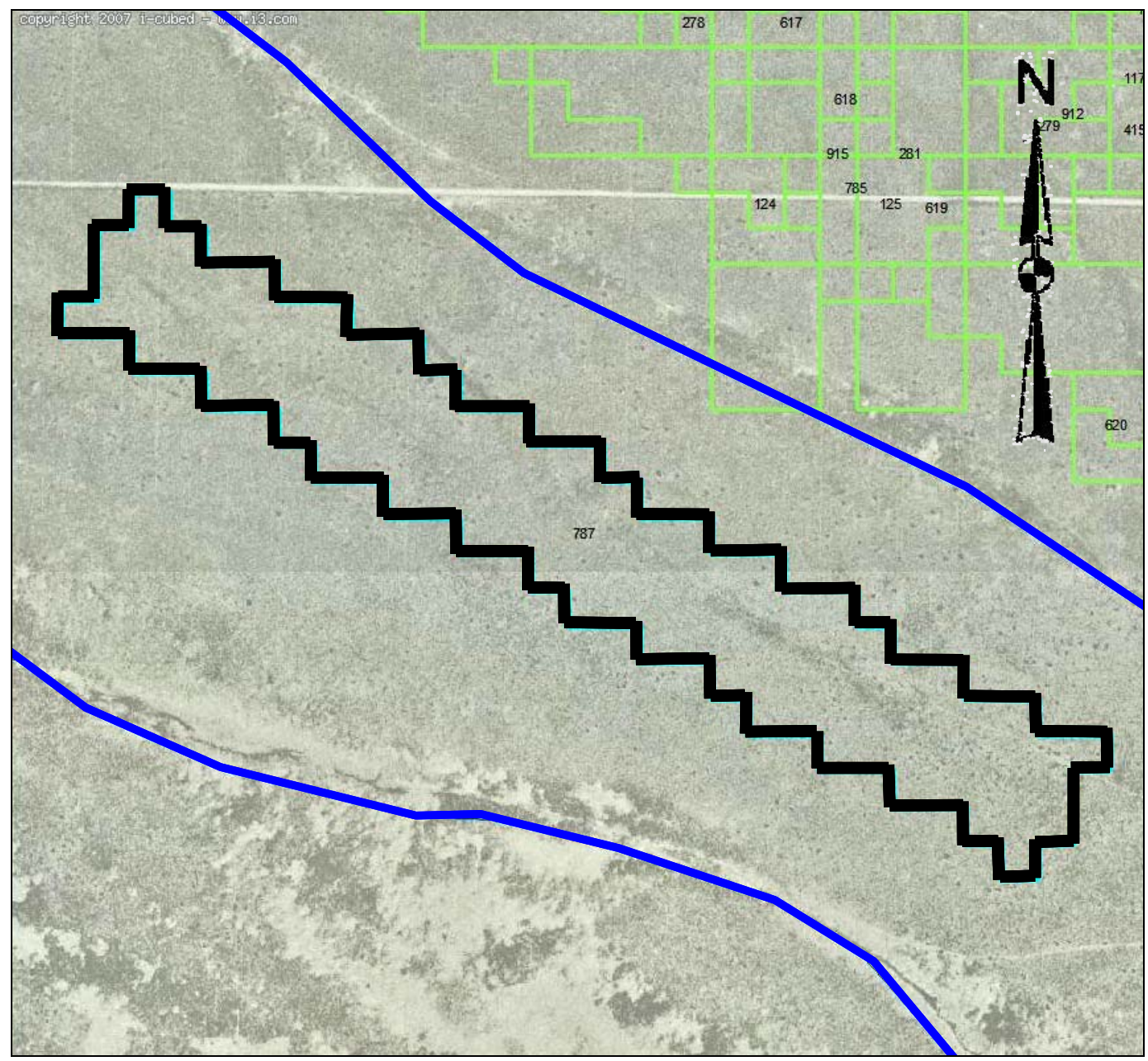

Figure 38. OLS, outlined in black, well located between waterways (blue lines). The OLS cluster to the northeast, denoted by many light green lines, crosses an undigitized road. The OLSs are $930 \mathrm{~m}$ long and $90 \mathrm{~m}$ wide.

Figure 39 shows an OLS crossed by digitized roads. However, the roads' appearance on the DOQ suggests that they are minor in nature and may not hamper operations. The OLS has been successfully positioned to avoid more prominent features, including buildings, roads, and a railroad. The digitized roads are offset from the roads on the DOQ image by at least 30 $\mathrm{m}$ in some areas. 


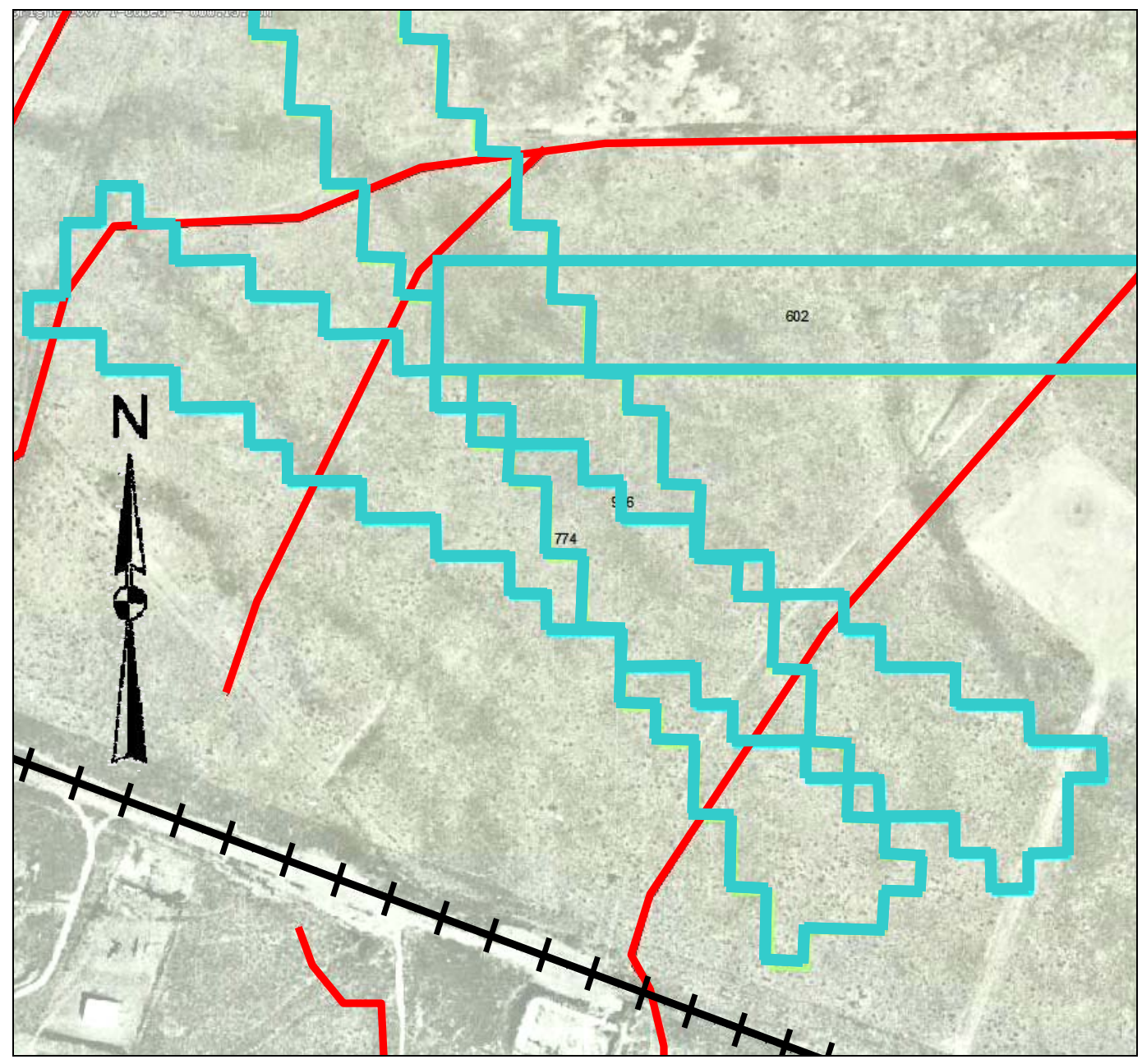

Figure 39. Three OLSs (light blue lines) crossed by minor roads (red lines). The OLSs do avoid the railroad line (black cross-hatched line). All OLSs are $915 \mathrm{~m}$ long.

In general, drainageways in arid regions can be visible and still not impose significantly on the smoothness of the terrain. However, in the case shown in Figure 40, OLSs cross a more prominent drainage feature with suggested incipient meandering and, it appears, some incision sufficient to cause significant operational problems. Shadows suggest that meanders could be at least $0.5 \mathrm{~m}$ deep. The OLSs do, however, avoid the stream located most extremely to the southwest, which may be somewhat better developed.

Figure 41 demonstrates a northeast- southwest-oriented OLS that is reasonably well located except for a stream crossing its southern corner. The east- west-oriented OLS is crossed by several roads. The roads appear to be either poorly digitized (being possibly offset in position by hundreds of meters), or they represent less prominent roads than others on the image that are not digitized. The streams, though positioned with some accuracy, are heavily generalized. 


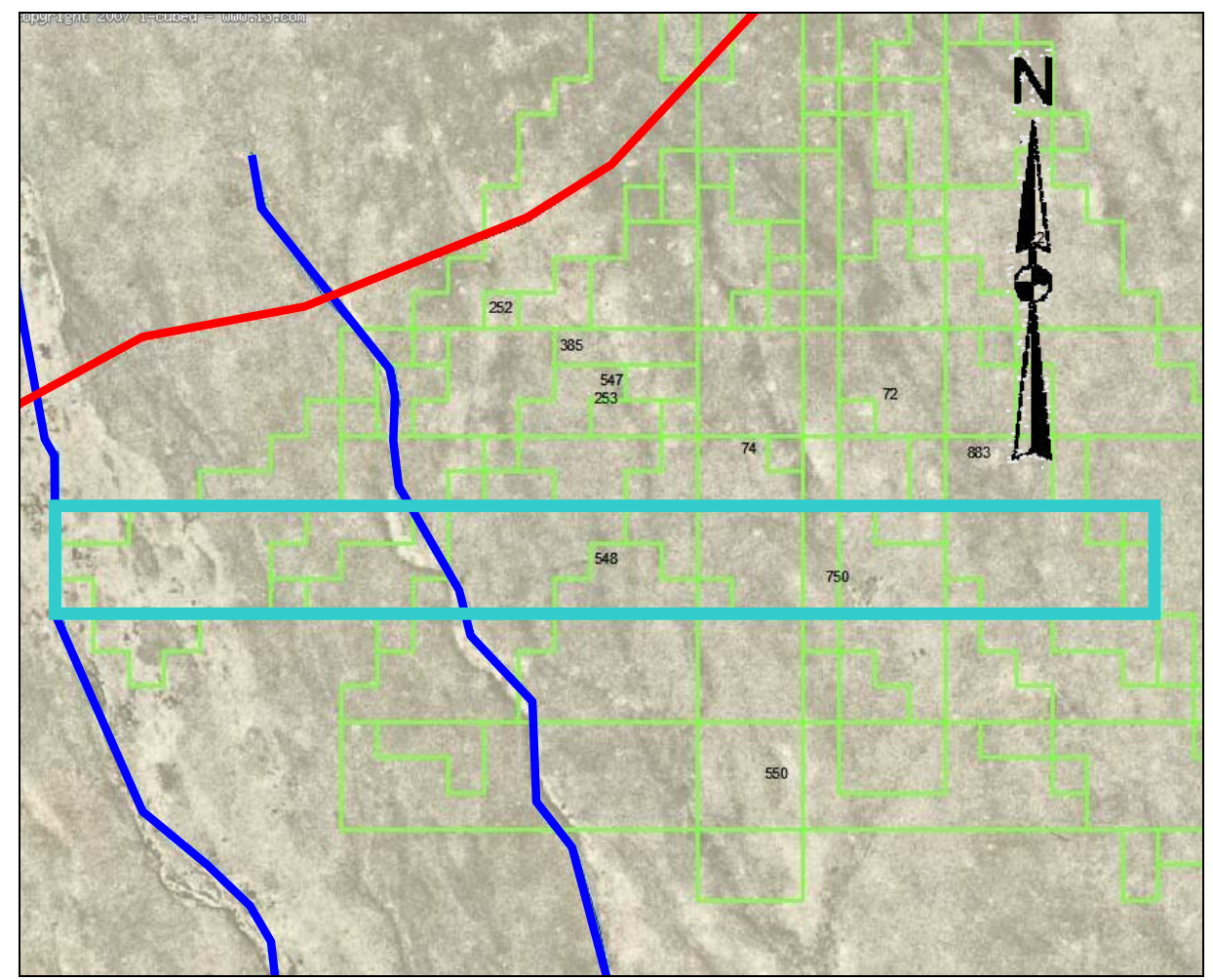

Figure 40. OLS, outlined in light blue, crossing prominent waterways, colored dark blue. Other OLSs in the area, outlined in light green, also cross the easternmost stream, and some cross the road (red line). The OLSs are $930 \mathrm{~m}$ long and $90 \mathrm{~m}$ wide.

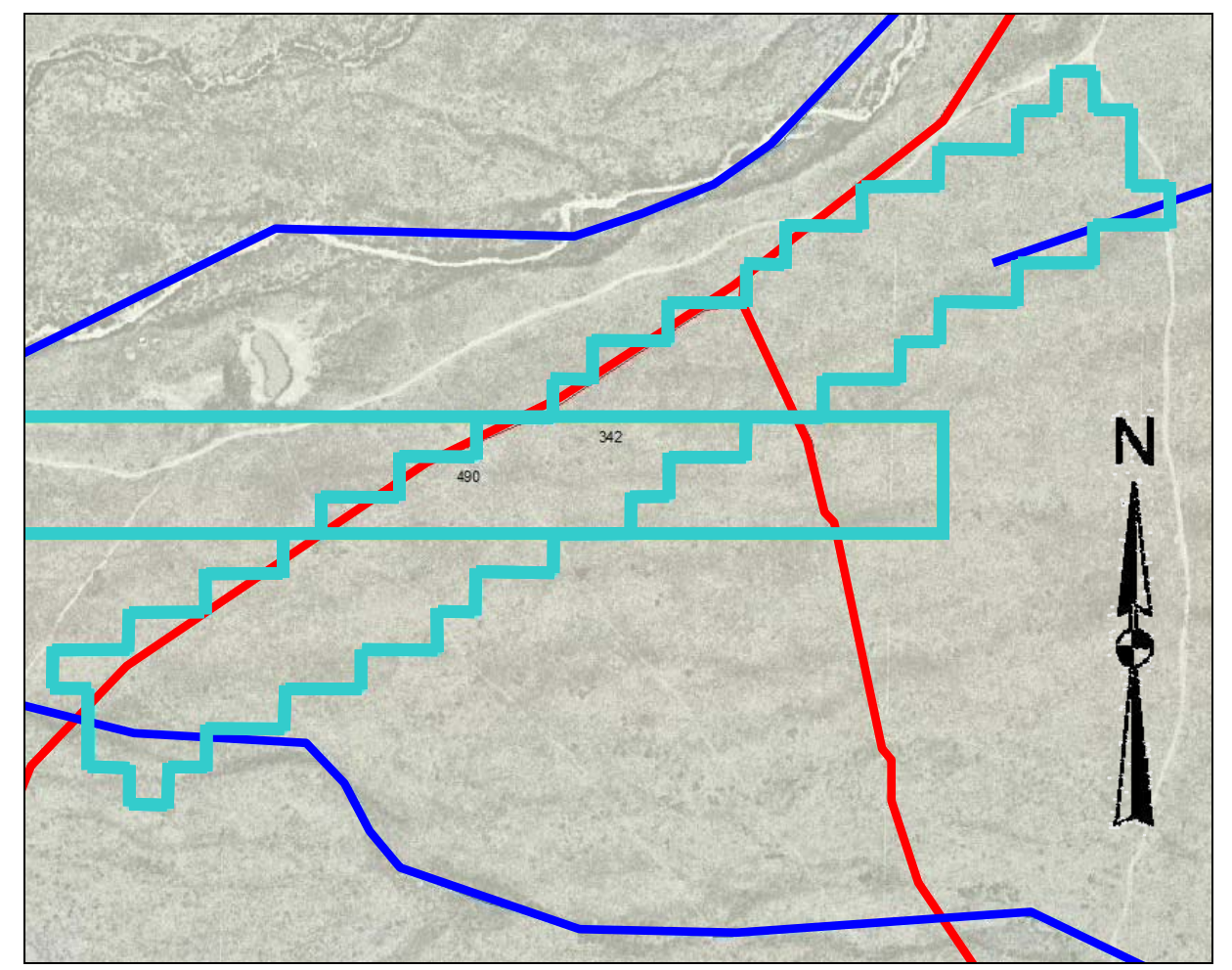

Figure 41. Two OLSs, outlined in light blue, crossing examples of possibly poorly digitized roads (red) and streams (blue). The OLSs are $930 \mathrm{~m}$ long and $90 \mathrm{~m}$ wide. 
Figure 42 shows a north- south-oriented OLS crossing multiple roads and entering a golf course. The northern end of the OLS crosses three fairways but apparently no roughs or sand traps.

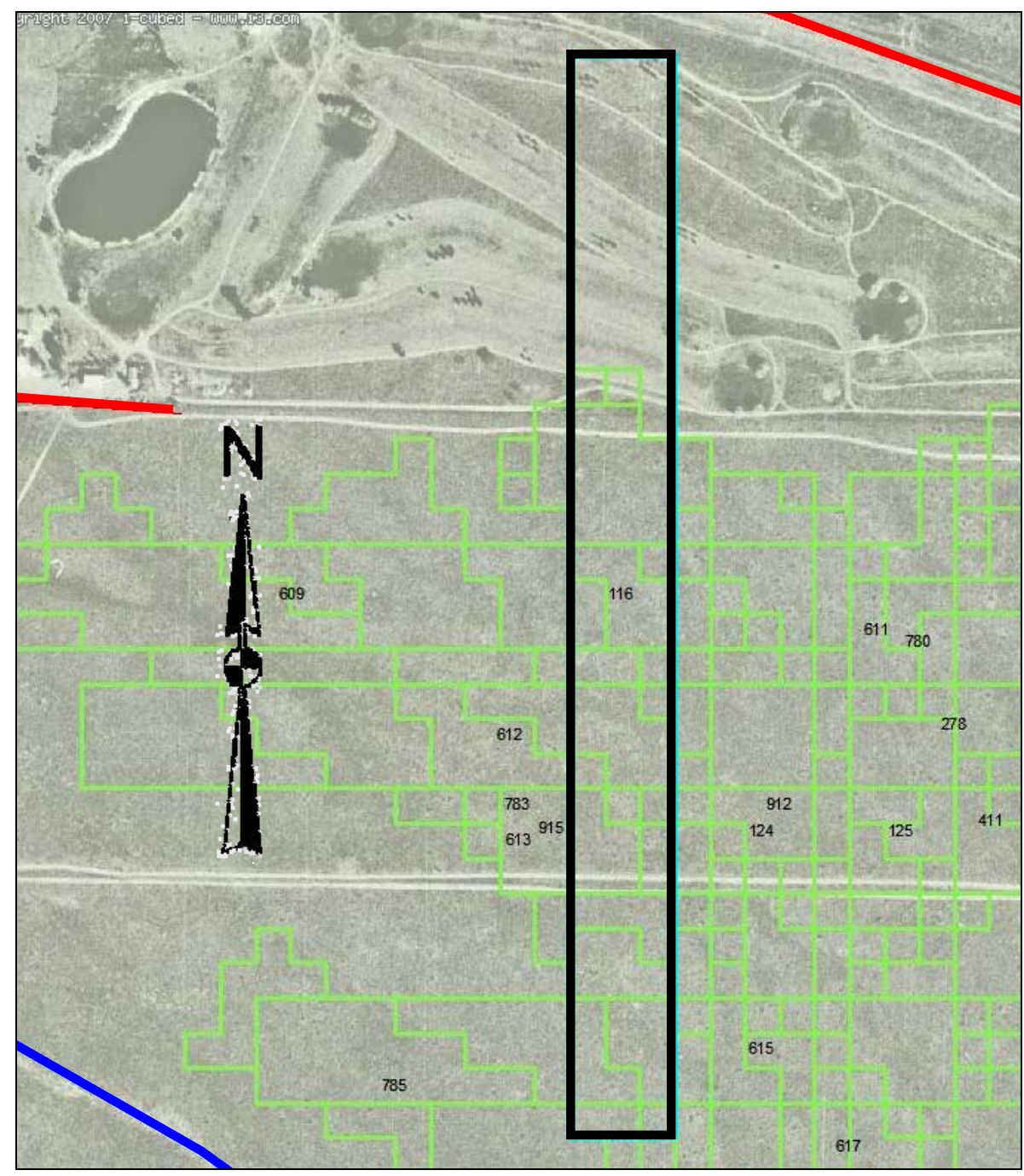

Figure 42. OLS, outlined in black, crossing into a golf course at its northern end. The OLS avoids digitized roads and a stream but crosses undigitized roads and fairways. Other OLSs, symbolized with light green outlines, do not enter the golf course. The OLSs are 930-m long and 90-m wide.

The OLS-MS software also located 31 of the visually inspected OLSs on the Carrizozo Malpais Lava Flow, a surface of broken lava with large cracks and relief of several meters (Fig. 43). Though appearing uniform at the resolution of Landsat, the surface is unsuitable for aircraft ground operations (Fig. 44). This is an obstacle that a vector database would not have located, though a digital surface geologic map may have provided an indication of conditions. 


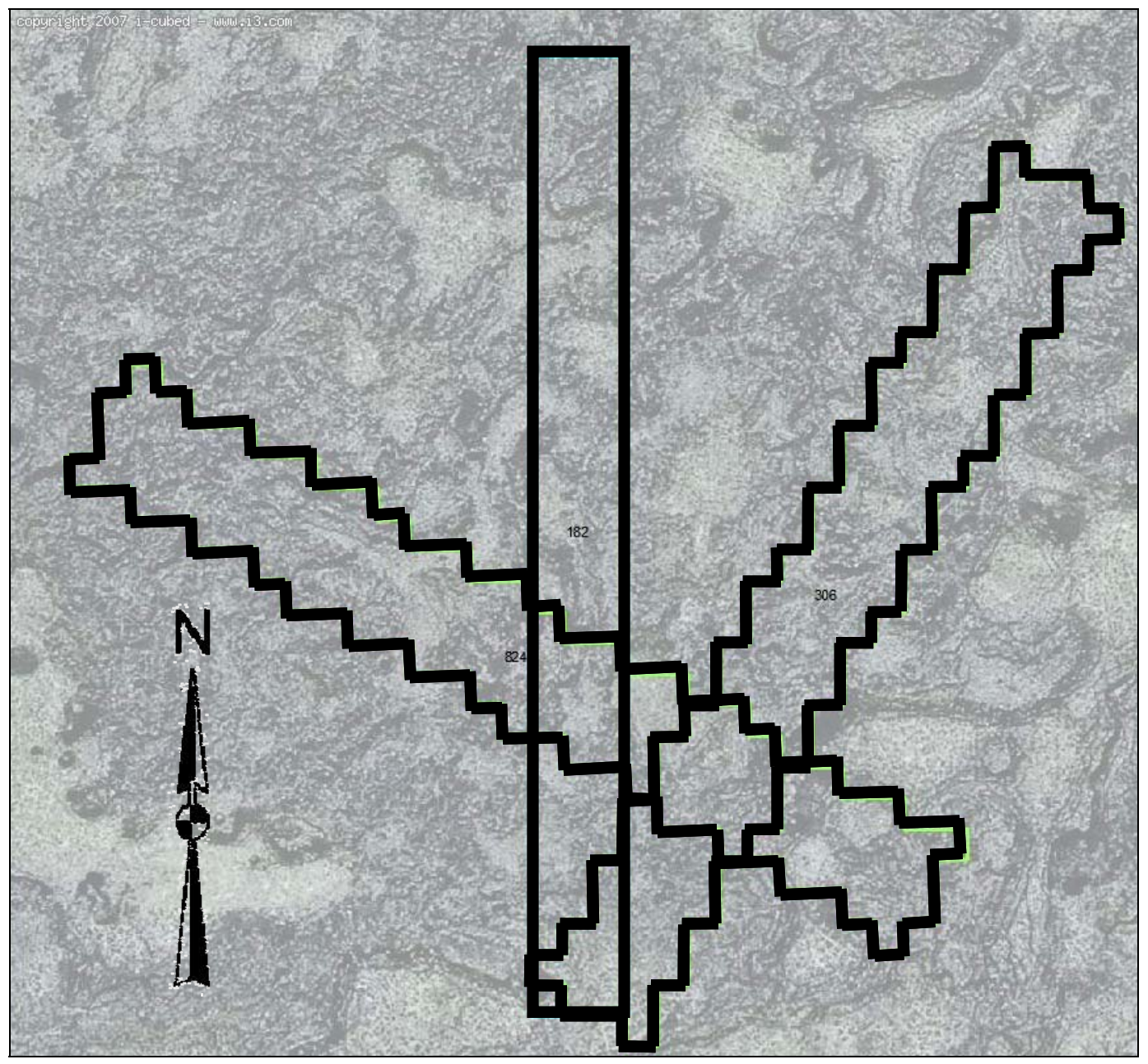

Figure 43. OLSs, outlined in black, crossing the Carrizozo Malpais Lava Flow. The OLSs are $930 \mathrm{~m}$ long and $90 \mathrm{~m}$ wide.

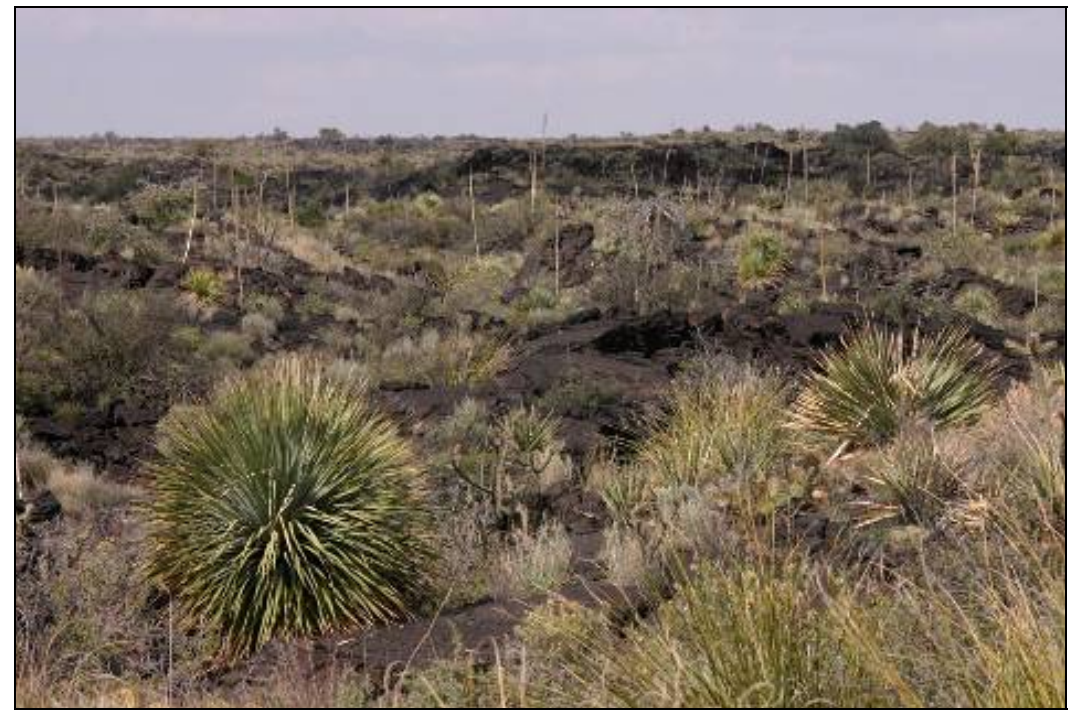

Figure 44. Surface of the Carrizozo Malpais Lava Flow, which is unsuitable for aircraft ground operations. 


\section{Discussion}

The results of this study show that the Boeing OLS-MS software can attain 85\% and higher accuracy with regard to selecting OLSs that avoid features available in GIS vector databases. However, in southern New Mexico, 25\% of OLSs were crossed by digitized roads, and $28 \%$ were crossed by digitized waterways. Though digitizing accuracy and Landsat image, vector database, and DOQ georeferencing accuracy are all issues, careful attention to image and database georeferencing standards, and checking of georeferencing quality, can minimize these problems. Our New Mexico Landsat image, though georeferenced by the USGS at precision accuracy, was accurately georeferenced only along a north- south axis near the middle of the image. Locations east and west of the image center were in positional error by as much as several hundred meters, well outside of the acceptable precision error standard. This required us to regeorectify the image through a "rubber-sheeting" process. Our work has demonstrated that georectification can sufficiently move pixels and change signatures such that OLSs change their position, and the total numbers of OLSs located on the Landsat image can change significantly from those located before the image is accurately georeferenced. Nevertheless, even though we carefully rubber-sheeted the New Mexico Landsat image, this area had the highest number of road and waterway intersections. This could be due to the Landsat image georeferencing error, even though it was carefully checked at nine or more locations over the image area to be within onepixel accuracy. It could also be due to vector file digitizing inaccuracies or to OLS-MS software difficulties in avoiding obstructions in this environment.

The obstacle vector data varied considerably in digitizing accuracy, completeness, and level of detail. Streams and roads were often out of position, often paralleling their position on DOQs. Highways and railroads were simplified with regard to numbers of lanes or tracks, and intersections were often simplified. Completeness and consistency of the databases can have a large effect. We demonstrated the effect of incomplete databases in finding intersections of transmission lines and OLSs in southern California. In addition, we demonstrated through the visual analysis that databases that do not include low-trafficked roads, such as local farm roads, may cause road-compromised OLSs to be missed. 
One reason for incomplete databases may be the dates when the vector datasets were last updated. If datasets are old and not updated, or if they are created from old, incomplete, low-resolution imagery or incorrectly georeferenced images, the data will be incorrect. Our largest difficulty in this regard was with the GE transmission line dataset for southern California. In this area, transmission lines were digitized that had no confirmation with ground features on DOQs. In addition, transmission line digitizing appeared to be incomplete. Catching these problems required checking against DOQs. However, even DOQs can be a source of error because their dates can be nearly 10 years different than the date of the Landsat image and all within the same areas as one Landsat image. In addition, for features subject to seasonal effects such as streams and agricultural land, the season of the DOQ or dataset creation can lead to misinterpretation. Even periodic changes in features, such as the rise and fall of reservoir levels, can cause problems; for example, a Landsat image taken when the Caballo Reservoir in southern New Mexico was low and soil was visible at the bottom of the reservoir, so an OLS was located in the bottom of the reservoir. A GIS-based polygonal water-area database caught the situation and indicated that the reservoir is periodically filled with water. This was confirmed by the DOQs. Although the bottom of the reservoir may make an acceptable OLS if sufficiently firm, temporal consistency when comparing OLS, DOQ, and vector obstacle data will decrease the uncertainty in locating OLSs safely. Although this OLS was not plotted by OLS-MS after the image was georectified to higher accuracy, the potential exists for this type of occurrence on any image.

Finally, the relatively coarse resolution of the Landsat imagery compared to the size of obstructions could be a significant reason for missed obstructions. Figure 45 illustrates the effect of DOQ and Landsat image resolution differences in making narrow linear features visible against the background. The narrow transmission line and stream provide insufficient information to make them visible as linear landscape features. The OLS-MS software may miss obstructions for this reason. It is likely that the availability of higher-resolution multi-spectral imagery would have allowed the detection of obstructions mapped in this study with greater reliability. If this is true, investments in higher-resolution multi-spectral imagery is more likely to yield improvements in OLS accuracy than will software improvements.

Attention to image and dataset accuracy, spatial-temporal consistency, and higher resolution imagery assures a more accurate analysis. We 
believe that the analyses presented here provide accuracy that is consistent with the state-of-the-art of GIS analysis for readily available and/ or free data sources.
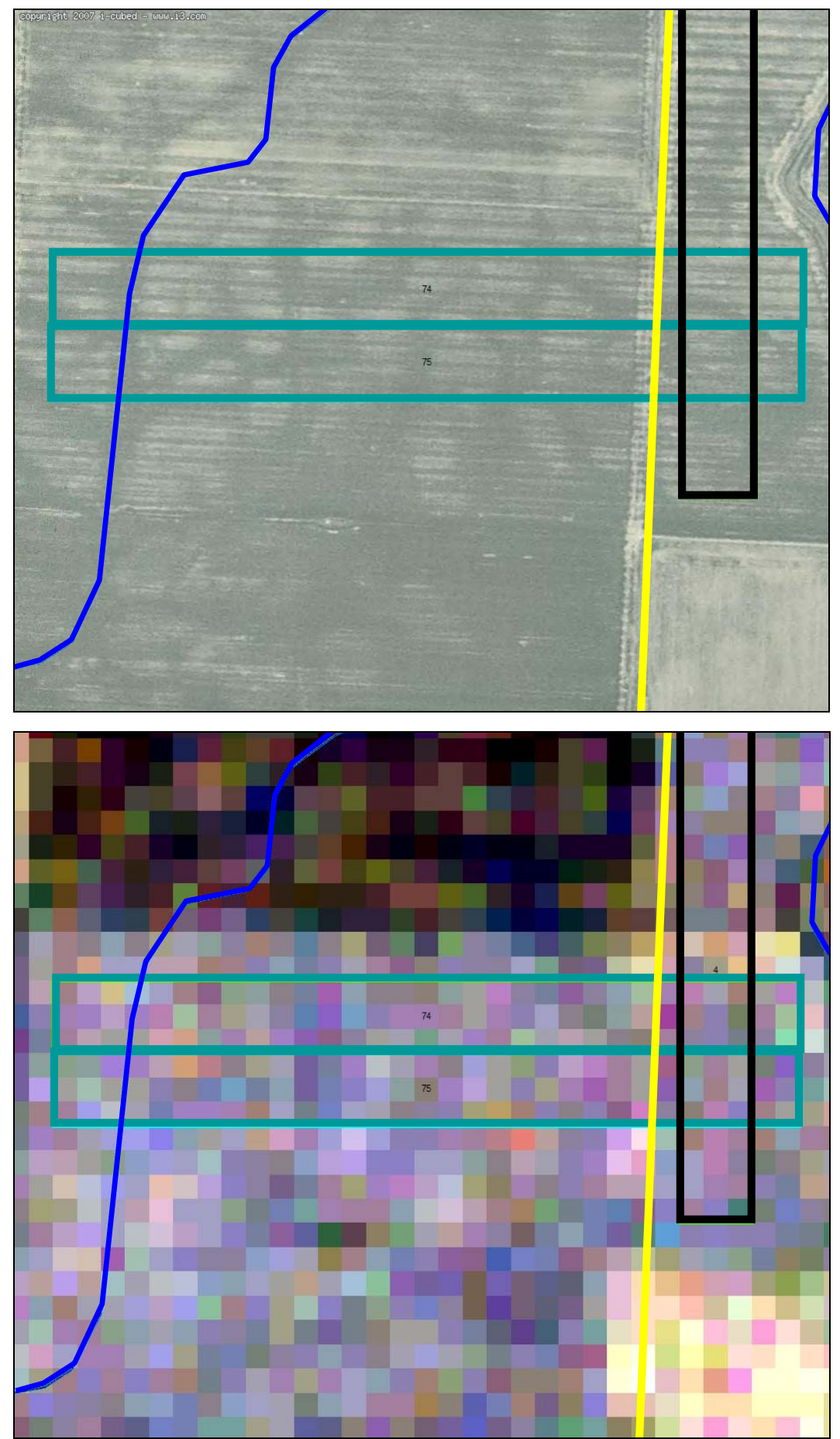

Figure 45. OLSs in southern Indiana (upper image; blue outline) crossed by a transmission line and stream represented by GIS databases with a DOQ background. The lower image shows the same features against the Landsat image processed to map the OLSs. 


\section{Conclusions}

Methods are necessary to make research and operationally required validation of predicted OLS quality faster, cheaper, and less dangerous. Validation of OLS quality is a key process for assuring safety in the operational environment and accuracy in the research environment.

Our initial intent for this study was to evaluate the accuracy of the OLSMS software with regard to its ability to avoid obstructions that may be in geographic datasets. This would allow a statistical analysis of the software accuracy in a variety of environments with a variety of features. Statistical analysis of OLS-MS accuracy in this regard has not been heretofore possible because of the inability to visit and inspect large numbers of OLSs. This could practically be accomplished only using light aircraft or helicopters to avoid trespassing on private land, a time-consuming and expensive endeavor. We believe that within the uncertainty of GIS datasets and georeferencing (the latter of which is an issue throughout the automated OLS evaluation process), we have obtained accurate results. The results presented indicate statistically the ability of the OLS-MS software to avoid major obstructions for the three locations assessed and the Landsat images that were used. The visual analysis, though more subjective, also provides an additional indication of the OLS-MS software's ability to avoid features that are less significant features but nevertheless could put missions at risk.

The tools presented for providing a statistical analysis of software capability in research and development environments could also be used in the operational environment to reduce uncertainty in OLS safety. The techniques could be executed after the OLS-MS software is executed to further reduce the number of unacceptable OLSs. Such a tool may be somewhat compromised in some OCONUS locations due to the quality or availability of datasets. However, homeland security and emergency management applications in CONUS could surely benefit from the capabilities presented here.

Operationally, Air Force Combat Control Teams routinely check OLS quality using remotely sensed and traditional mapped information, processed using image analysis software such as FalconView. Teams are then placed 
on the ground at selected OLSs to reassess site geometry such as flatness, smoothness, and freedom from obstructions and to make soil strength measurements not obtainable from imagery. Operationally, current methods of seeking OLS and evaluating their capability are labor intensive, slow, and potentially dangerous to personnel if operating in hostile areas.

Operationally, GISs may provide a capability of satisfying some of the shortcomings of current procedures and replacing some of the field tasks beyond the capabilities demonstrated in this study. For example, a GIS can evaluate the flatness and levelness of OLSs using a DTED, the variability of soil types from inferred soil types, the spatial variability of soil moisture, the soil strength, and the vegetation cover on a pixel-by-pixel basis along the length of an OLS. In a research and development environment, a GIS can also evaluate the seasonal quality of OLSs chosen by the OLS-MS software, evaluate the effect of software attribute choices on OLS quality, and evaluate the quality of OLSs chosen in geographic areas that may be different, for example, with regard to climate.

Challenges will continue to be the georeferencing accuracy of imagery, maps, and digitized vector data representing roads, hydrography, and other linear features, and the completeness of the digitized information. The unavailability of concurrently dated imagery, maps, and vector data also present a challenge with regard to the validity of conclusions drawn from one source versus another.

This feasibility study has proven the initial concepts for a limited number of potential obstruction types in three geographically diverse areas. The analyses demonstrate the capability of GIS tools to be used to prudently assess OLS quality beyond that possible with Landsat imagery alone. 


\section{References}

Affleck, R.T., C.C. Ryerson, L. Barna, and K. Claffey. 2008a. Opportune Landing Site (OLS) Program: Suitability measurement and analysis for Fort Bliss OLS. ERDC/CRREL Technical Report. Hanover, NH: U.S. Army Engineer Research and Development Center, Cold Regions Research and Engineering Laboratory.

. 2008b. Opportune Landing Site (OLS) Program: Suitability measurement and analysis for El Centro NAF OLS. ERDC/ CRREL Technical Report. Hanover, NH: U.S. Army Engineer Research and Development Center, Cold Regions Research and Engineering Laboratory.

Almassy, R., and P. Blake. 2007. Opportune Landing Site Multispectral (OLS-MS) software operation description. Version 10. Huntington Beach, CA: The Boeing Company.

Barna, L.A., R. Affleck, and C.C. Ryerson. 2008. Opportune Landing Site (OLS) Program: southeastern Indiana field data collection and assessment. ERDC/CRREL Technical Report. Hanover, NH: U.S. Army Engineer Research and Development Center, Cold Regions Research and Engineering Laboratory.

Global Energy. 2007. HSIP_GOLD. Electric Transmission Lines. Boulder, CO: Global Energy.

Ryerson, C., and J . McDowell. 2007. Anywhere-anytime: Enhancing battlespace vertical mobility. AIAA 2007-1103, American Institute of Aeronautics and Astronautics 45th Aerospace Sciences Meeting and Exhibit, 8-11J anuary, Reno.

Schwarz, C.R., and E.B. Wade. 1990. The North American datum of 1983: Project methodology and execution. J ournal of Geodesy 64(1): 28-62.

Tele Atlas. 2005. OneMap. Lebanon, NH: Tele Atlas North America, Inc.

Tele Atlas. 2007. TANA ArcSDE® User Manual. Lebanon, NH: Tele Atlas North America, Inc.

USGS. 1999. National Mapping Program Technical Instructions, Part 2, Specifications.

USGS. Standards for Digital Line Graphs. Department of the Interior, U.S. Geological Survey, National Mapping Division.

Vincent, R.K., and D.L. J ennings. 2004. A four-state evaluation of the Boeing Landing Suitability Index (BLSI) for automatically mapping candidate aircraft operating sites in natural terrain from LANDSAT TM data. J ournal of Terramechanics 41: 151-162. 


\section{Appendix A. Acronyms}

AFRL/RB: $\quad$ Air Force Research Laboratory Air Vehicles Directorate

BOTUS: $\quad$ Best of the U.S.

CBR: $\quad$ California bearing ratio

CCT: $\quad$ Combat control teams

COTS: $\quad$ Commercial off the shelf

CRG: $\quad$ Contingency response groups

CRREL: $\quad$ Cold Regions Research and Engineering Laboratory

DCP: $\quad$ Dynamic cone penetrometer

DEM: $\quad$ Digital elevation model

DLG: $\quad$ Digital line graph

DOQ: $\quad$ Digital orthophotoquadrangles

DOQQ: $\quad$ Digital orthophotographic quarter-quadrangles

DTED: $\quad$ Digital terrain elevation data

ENVI: Environment for visualizing images

ERDC: $\quad$ Engineer Research and Development Center

ESRI: $\quad$ Environmental Research Institute

GAAT: $\quad$ Global Airfield Assessment Teams

GCP: $\quad$ Ground control points

GE: $\quad$ Global Energy

GIS: $\quad$ Geographic information system

GPS: $\quad$ Global positioning system

MGRS: $\quad$ Military Grid Reference System

NAPP: $\quad$ National Aerial Photography Program

NMAS: $\quad$ National Map Accuracy Standards

OLS: $\quad$ Opportune landing site

OLS-OLS: $\quad$ Multi-Spectral (OLS-MS) 
RED HORSE: Rapid Engineer Deployable Heavy Operational Repair Squadron Engineers

RS/GIS: Remote Sensing/Geographic Information Center, CRREL

STT: $\quad$ Special Tactics Teams

TANA: $\quad$ Tele Atlas North America

TCSB: $\quad$ Terrain and Cryospheric Sciences Branch, CRREL

TRANSCOM: U.S. Transportation Command

UAS: Unmanned aerial system

USACE: $\quad$ U.S. Army Corps of Engineers

USGS: $\quad$ U.S. Geological Survey

UTM: $\quad$ Universal transverse mercator

VGIS: $\quad$ Virtual geographic information system

WGS: $\quad$ World Geodetic System 


\section{Appendix B. Landsat Image Characteristics for Products Used}

\begin{tabular}{|c|c|c|c|c|}
\hline $\begin{array}{l}\text { Geographic } \\
\text { Location }\end{array}$ & New Mexico & California & Indiana & Comments \\
\hline \begin{tabular}{|l|} 
USGS satellite \\
designator
\end{tabular} & Landsat 5 & Landsat 5 & Landsat 5 & \\
\hline Imagery date & 220CT05 & 01N0V05 & 12NOV05 & \\
\hline \begin{tabular}{|l|} 
Orbit-related \\
row/path used
\end{tabular} & $33 / 37$ & $38 / 37$ & $20 / 33$ & $\begin{array}{l}\text { Row relates to latitude of coverage for an image, with } \\
\text { lower numbers towards North Pole. Path relates to } \\
\text { longitude of image coverage, with path \#1 over } \\
\text { Greenwich, England. }\end{array}$ \\
\hline \begin{tabular}{|l|} 
Release \\
agency
\end{tabular} & USGS & USGS & USGS & \\
\hline Source & USGS & USGS & Ohio View & $\begin{array}{l}\text { Ohio View is part of America View, a university consortium } \\
\text { that makes remote sensing data available for public use. } \\
\text { More information at http://americaview.usgs.gov. }\end{array}$ \\
\hline $\begin{array}{l}\text { Image Format } \\
\text { Designator }\end{array}$ & GeoTIFF & GeoTIFF & GeoTIFF & $\begin{array}{l}\text { Landsat imagery that is radiometrically and geometrically } \\
\text { corrected (Level } 1 \mathrm{G} \text { processing) is output in one of four } \\
\text { standard formats; GeoTIFF, FAST-L7A, HDF, or NDF. See } \\
\text { http://landsat.usgs.gov/resources/files/LS-DFCB- } \\
\text { 04_L1_DFCB.pdf. }\end{array}$ \\
\hline Datum & WGS-84 & WGS-84 & WGS-84 & \\
\hline Map projection & UTM & UTM & UTM & \\
\hline UTM zone & 13 & 11 & 17 & $\begin{array}{l}\text { Image zone assignments can vary slightly from season to } \\
\text { season due to orbital path alignment within sensor's } \\
\text { swath. }\end{array}$ \\
\hline $\begin{array}{l}\text { Level of geo- } \\
\text { referencing }\end{array}$ & Precision & Precision & Precision & $\begin{array}{l}\text { Landsat geo-referencing has three levels: Systematic is } \\
\text { based on satellite ephemeris and is least accurate }(10 \\
\text { pixels); Precision is based on WGS84 horizontal datum } \\
\text { and is of medium accuracy ( } 3 \text { pixels); and Terrain } \\
\text { corrected utilizes a digital elevation model (DEM) in } \\
\text { addition to WGS84 datum and is of higher accuracy ( }<3 \\
\text { pixels) }\end{array}$ \\
\hline $\begin{array}{l}\text { Resampling } \\
\text { method }\end{array}$ & $\mathrm{CC}$ & $\mathrm{CC}$ & $\mathrm{CC}$ & $\begin{array}{l}\text { Resampling refers to assigning values to pixels after they } \\
\text { are moved by rectification process. Resampling often } \\
\text { uses one of three techniques: Nearest Neighbor (NN), } \\
\text { Bilinear Interpretation (BI), and Cubic Convolution (CC), } \\
\text { among others. Descriptions for processes can be found at } \\
\text { http://geography.uoregon.edu/amarcus/geog418/ } \\
\text { Labs/Lab06_rectification.htm. }\end{array}$ \\
\hline $\begin{array}{l}\text { Mean error } \\
\text { along track } \\
\text { (m) }\end{array}$ & 0.28 & 0.39 & -0.08 & $\begin{array}{l}\text { Mean error along track is defined as statistical average } \\
\text { error for the ground control points' (GCP) horizontal } \\
\text { position after USGS georectification process in direction } \\
\text { of satellite's flight path. }\end{array}$ \\
\hline
\end{tabular}




\begin{tabular}{|c|c|c|c|c|}
\hline $\begin{array}{l}\text { Mean error } \\
\text { across track } \\
\text { (m) }\end{array}$ & 0.27 & -0.26 & -0.25 & $\begin{array}{l}\text { Mean error across track is defined as statistical average } \\
\text { error for GCP horizontal position after USGS } \\
\text { georectification process in direction perpendicular to } \\
\text { satellite's flight path. }\end{array}$ \\
\hline $\begin{array}{l}\text { Mean error } \\
\text { height }(\mathrm{m})\end{array}$ & 0.05 & -0.02 & 0.05 & $\begin{array}{l}\text { Mean error height is defined as statistical average error } \\
\text { for GCP vertical position after USGS georectification } \\
\text { process. }\end{array}$ \\
\hline $\begin{array}{l}\text { Mean error } \\
\text { combined }(\mathrm{m})\end{array}$ & 0.39 & 0.47 & 0.26 & $\begin{array}{l}\text { Mean error combined is defined as statistical average } \\
\text { error for GCP position after USGS georectification process } \\
\text { using combination of along track, across track, and } \\
\text { vertical positioning errors. }\end{array}$ \\
\hline $\begin{array}{l}\text { RMS error } \\
\text { along track } \\
(\mathrm{m})\end{array}$ & 6.12 & 6.11 & 5.33 & $\begin{array}{l}\text { Root Mean Square error is mathematically the spatial } \\
\text { equivalent to standard deviation. See http://www.geo.ed. } \\
\text { ac.uk/agidexe/term?982. RMS error along track is } \\
\text { defined as error for GCP horizontal position after USGS } \\
\text { georectification process in direction of satellite's flight } \\
\text { path. }\end{array}$ \\
\hline $\begin{array}{l}\text { RMS error } \\
\text { across track } \\
(\mathrm{m})\end{array}$ & 6.90 & 6.31 & 6.74 & $\begin{array}{l}\text { RMS error across track is defined as error for GCP } \\
\text { horizontal positioning after USGS georectification process } \\
\text { in direction perpendicular to satellite's flight path. }\end{array}$ \\
\hline $\begin{array}{l}\text { RMS error } \\
\text { height }(m)\end{array}$ & 0.67 & 0.56 & 0.79 & $\begin{array}{l}\text { RMS error height is defined as error for GCP vertical } \\
\text { position after USGS georectification process. }\end{array}$ \\
\hline \begin{tabular}{|l|} 
RMS error \\
combined $(\mathrm{m})$
\end{tabular} & 9.25 & 8.81 & 8.63 & $\begin{array}{l}\text { RMS error combined is defined as error for GCP position } \\
\text { after USGS georectification process using combination of } \\
\text { along track, across track, and vertical position errors. }\end{array}$ \\
\hline $\begin{array}{l}\text { Number of } \\
\text { control points }\end{array}$ & 27 & 28 & 35 & $\begin{array}{l}\text { Number of physical geographic features used to adjust } \\
\text { and recalculate the image coordinates during the USGS } \\
\text { georectification process. }\end{array}$ \\
\hline Pixel size $(\mathrm{m})$ & 30 & 30 & 30 & $\begin{array}{l}\text { Landsat image pixel size varies depending on } \\
\text { characteristics for satellite, orbit, sensor, and processing } \\
\text { algorithms in use. See http://landsat.usgs.gov/ } \\
\text { project_facts/history/index.php. }\end{array}$ \\
\hline $\begin{array}{l}\text { Product } \\
\text { orientation }\end{array}$ & Map North & Map North & Map North & $\begin{array}{l}\text { Product orientation has two options. Map version has the } \\
\text { image data geographically rotated to a North up } \\
\text { orientation, while Sat version has a nominal system (path) } \\
\text { orientation for image data. }\end{array}$ \\
\hline
\end{tabular}




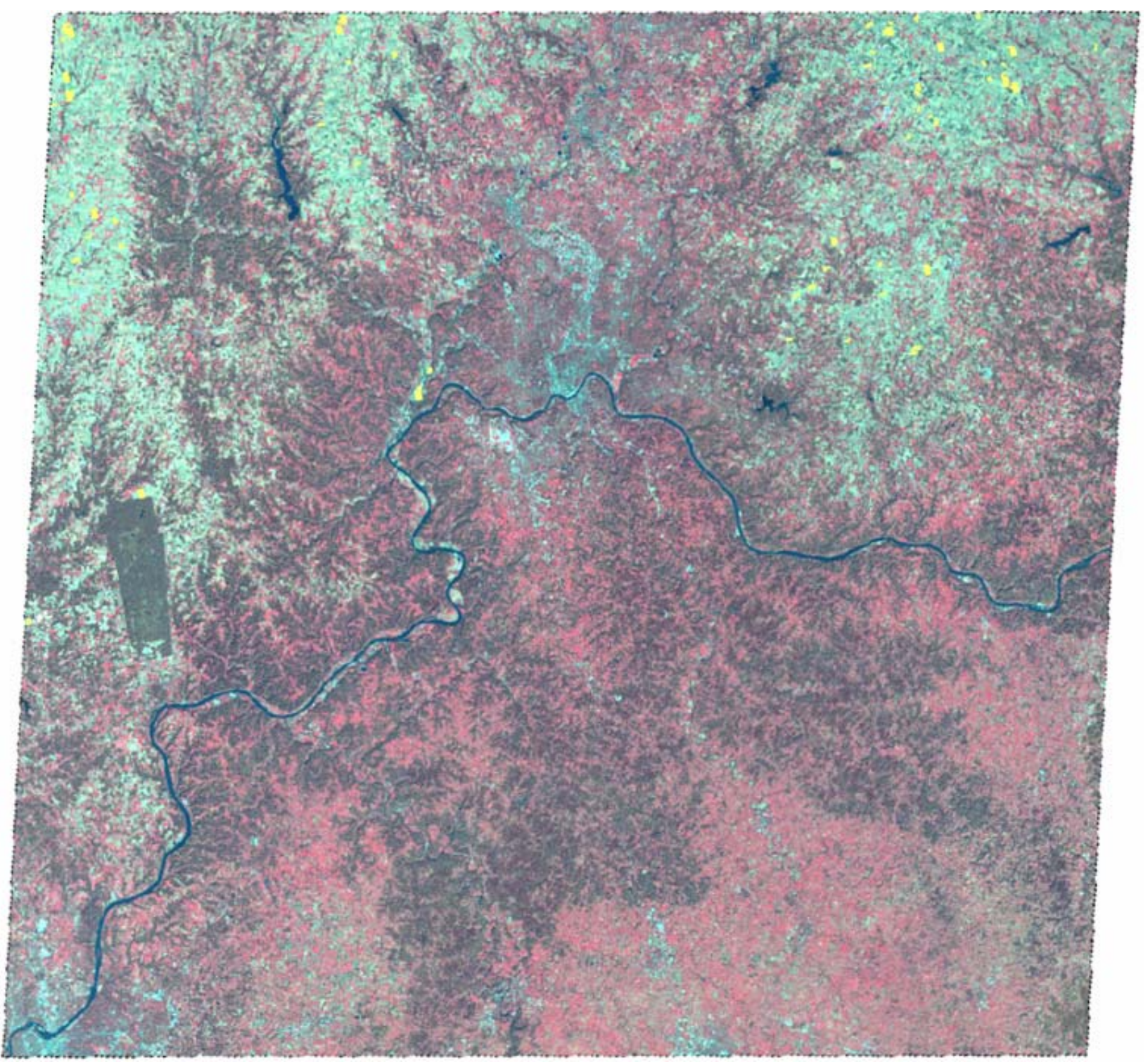

Figure B1. Southern Indiana Landsat 5 image Path 20, Row 33, 12 November 2005, with 139 915-m-long by 61-m-wide OLSs plotted in yellow. 


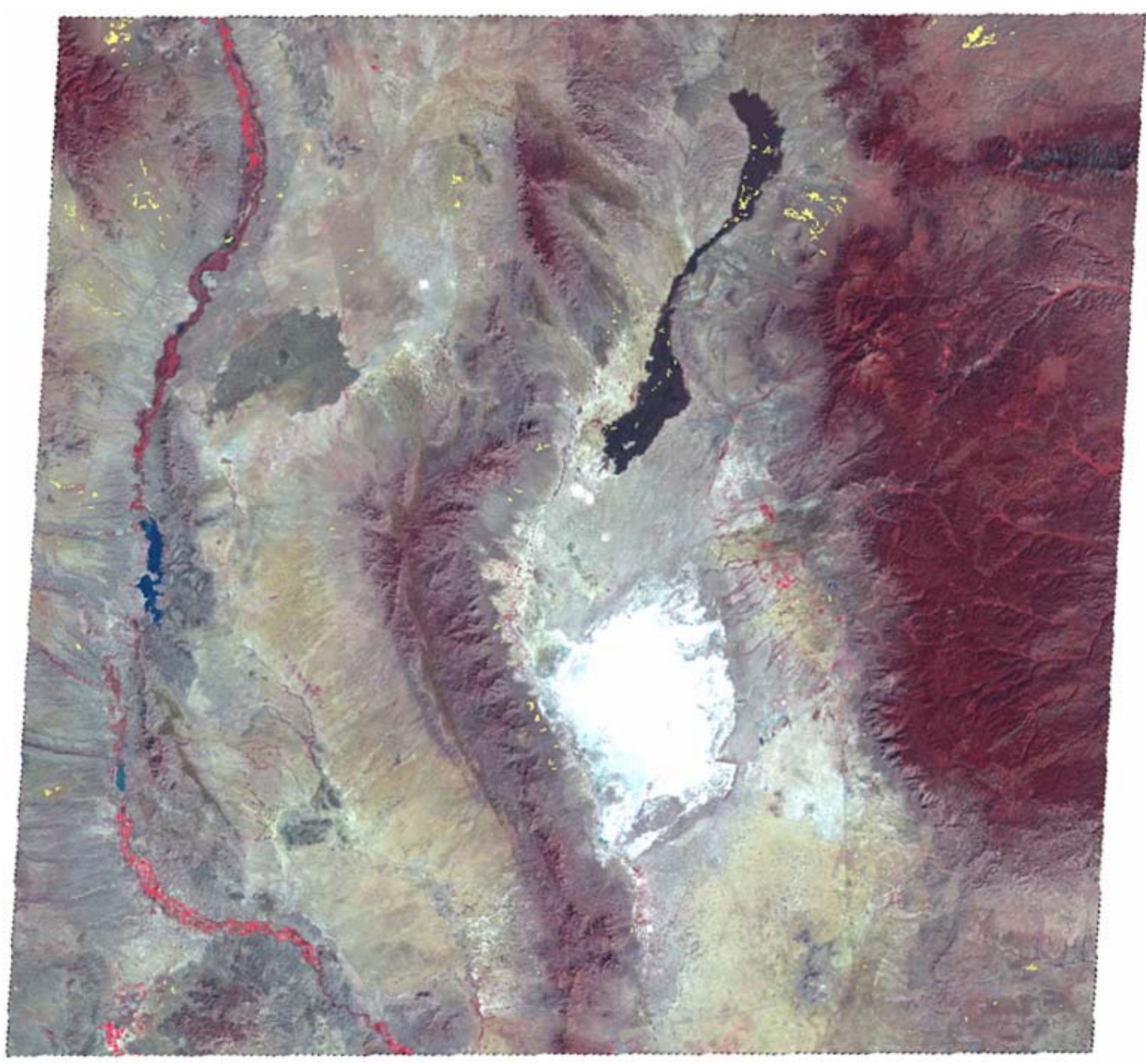

Figure B2. Southern New Mexico Landsat 5 image Path 33, Row 37, 22 October 2005, with 985 915-m-long by 61 -m-wide OLSs plotted in yellow. 


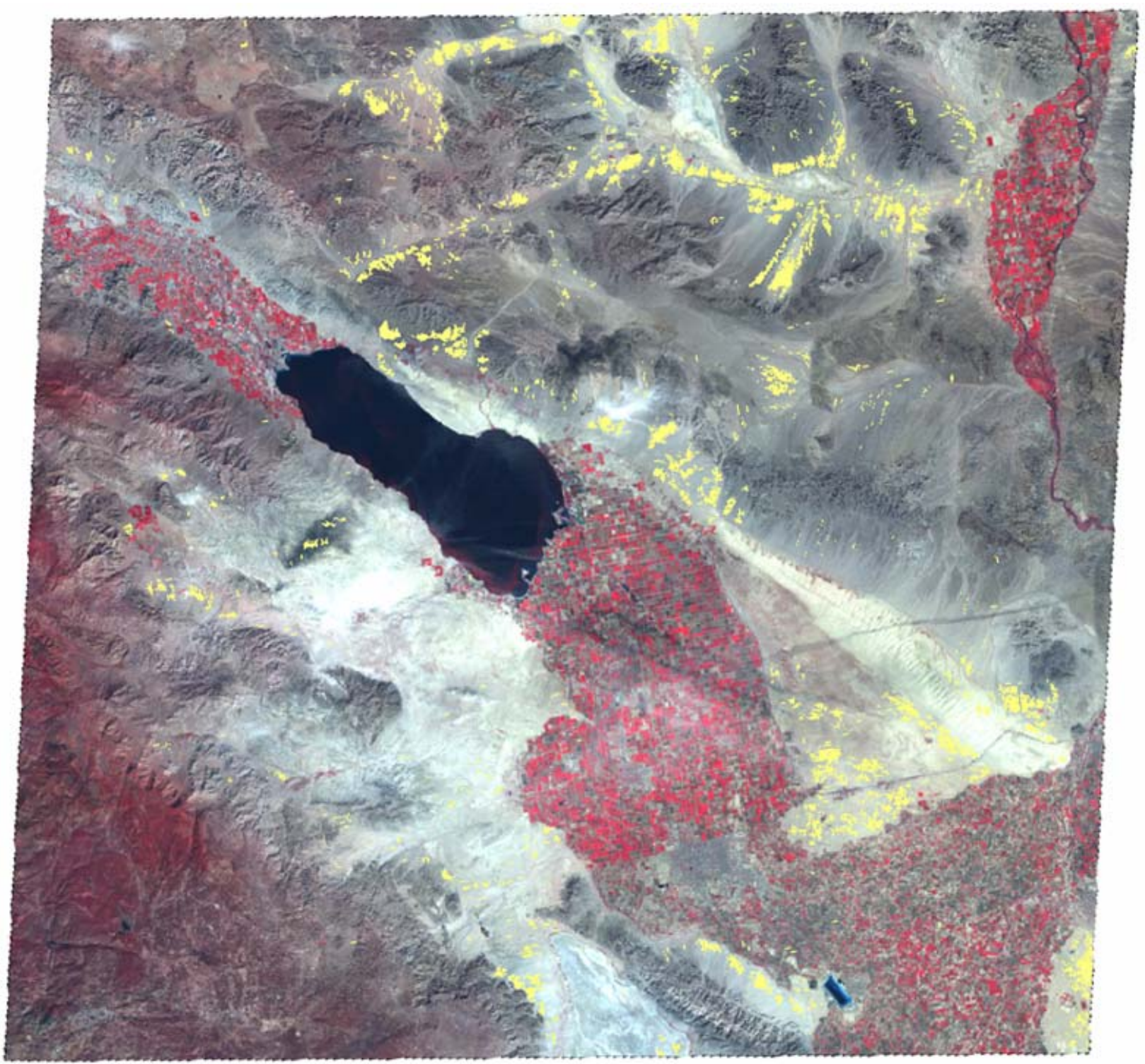

Figure B3. Southern California Landsat 5 image Path 39, Row 37, 1 November 2005, with 18,610 915-m-long by 61 -m-wide OLSs plotted in yellow. 


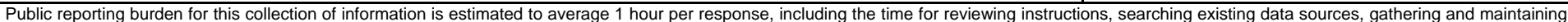

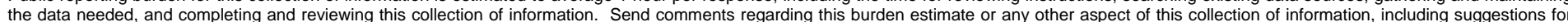

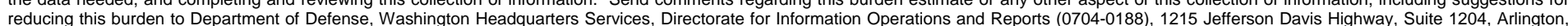

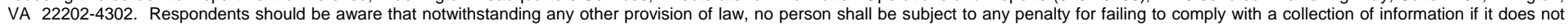
display a currently valid OMB control number. PLEASE DO NOT RETURN YOUR FORM TO THE ABOVE ADDRESS.

\begin{tabular}{l|l} 
1. REPORT DATE (DD-MM-YYYY) & 2. REPORT TYPE \\
April 2008 & Technical Report
\end{tabular}

4. TITLE AND SUBTITLE

GIS-based OLS Suitability Assessment

Charles Ryerson, Forrest Scott, and Brian Tracy
6. AUTHOR(S)

3. DATES COVERED (From - To)

5a. CONTRACT NUMBER

5b. GRANT NUMBER

5c. PROGRAM ELEMENT NUMBER

5d. PROJECT NUMBER

5e. TASK NUMBER

5f. WORK UNIT NUMBER

8. PERFORMING ORGANIZATION REPORT NUMBER

ERDC/CRREL TR-08-4

U.S. Army Engineer Research and Development Center

Cold Regions Research and Engineering Laboratory

72 Lyme Road

Hanover, NH 03755-1290

9. SPONSORING I MONITORING AGENCY NAME(S) AND ADDRESS(ES)

10. SPONSOR/MONITOR'S ACRONYM(S)

U.S. Air Force Mobility Command

and

U.S. Air Force Research Laboratory Air Vehicles Directorate
11. SPONSOR/MONITOR'S REPORT NUMBER(S)

\section{DISTRIBUTION / AVAILABILITY STATEMENT}

Approved for public release; distribution is unlimited.

Available from NTIS, Springfield, Virginia 22161.

13. SUPPLEMENTARY NOTES

\section{ABSTRACT}

A goal of the Air Force Research Laboratory Opportune Landing Site (OLS) program was to locate large, smooth, flat, obstruction-free areas safe for aircraft operations. The ERDC was tasked to evaluate the quality of OLSs as located by OLS Multi-Spectral (OLS-MS) software that was developed by the Boeing Company and uses Landsat multispectral imagery. ERDC conducted extensive field work evaluating OLSs in Indiana, New Mexico, and California. However, while seeking these OLS-MS-selected field sites, many other software-selected potential OLSs were casually observed not to satisfy requirements with regard to obstructions. Our objective was to evaluate a statistically valid sample of OLSs for freedom from obstructions. We utilized OLSs located by the final version of the OLSMS software, plotted them over orthophotoquads, and assessed their intersections with obstructions within geographic information system (GIS) datasets containing natural and cultural features. A sample of OLSs was also visually evaluated to assess the accuracy of the GIS analysis process. Features in the GIS datasets often did not correspond exactly with features on the ground, a source of analysis error that may be due to digitizing uncertainty and differences in the creation dates of the images and datasets. The success of the OLS software in avoiding obstructions is presented in the results.

\section{SUBJECT TERMS}

Aircraft operations

Landsat imagery

16. SECURITY CLASSIFICATION OF:

a. REPORT

$\mathrm{U}$ b. ABSTRACT

$\mathrm{U}$
Opportune landing sites

Remote sensing

\begin{tabular}{|c|c|}
\hline 17. LIMITATION & 18. NUMBER \\
OF ABSTRACT & OF PAGES \\
\cline { 3 - 3 }$U$ & \\
& \\
\hline
\end{tabular}

19a. NAME OF RESPONSIBLE PERSON

19b. TELEPHONE NUMBER (include area code) 